\title{
Treatment with Mesenchymal-Derived Extracellular Vesicles Reduces Injury-Related Pathology in Pyramidal Neurons of Monkey Perilesional Ventral Premotor Cortex
}

\author{
${ }^{\circ}$ Maria Medalla, ${ }^{1,3 *}$ Wayne Chang, ${ }^{1 *}$ Samantha M. Calderazzo,,${ }^{1}$ Veronica Go, ${ }^{2}$ Alexandra Tsolias, ${ }^{1}$ \\ Joseph W. Goodliffe, ${ }^{1}$ Dhruba Pathak, ${ }^{1}$ Diego De Alba, ${ }^{1}$ Monica Pessina, ${ }^{1}$ Douglas L. Rosene, ${ }^{1,3}$ \\ Benjamin Buller, ${ }^{4 \dagger}$ and Tara L. Moore ${ }^{1,3 \dagger}$ \\ ${ }^{1}$ Department of Anatomy and Neurobiology, ${ }^{2}$ Department of Pharmacology \& Experimental Therapeutics, Boston University School of Medicine, \\ Boston, Massachusetts, $02118,{ }^{3}$ Center for Systems Neuroscience, Boston University, Boston, Massachusetts, 02215 , and ${ }^{4}$ Department of Neurology, \\ Henry Ford Health System, Detroit, Michigan, 48202
}

Functional recovery after cortical injury, such as stroke, is associated with neural circuit reorganization, but the underlying mechanisms and efficacy of therapeutic interventions promoting neural plasticity in primates are not well understood. Bone marrow mesenchymal stem cell-derived extracellular vesicles (MSC-EVs), which mediate cell-to-cell inflammatory and trophic signaling, are thought be viable therapeutic targets. We recently showed, in aged female rhesus monkeys, that systemic administration of MSC-EVs enhances recovery of function after injury of the primary motor cortex, likely through enhancing plasticity in perilesional motor and premotor cortices. Here, using in vitro whole-cell patch-clamp recording and intracellular filling in acute slices of ventral premotor cortex (vPMC) from rhesus monkeys (Macaca mulatta) of either sex, we demonstrate that MSC-EVs reduce injury-related physiological and morphologic changes in perilesional layer 3 pyramidal neurons. At 14-16 weeks after injury, vPMC neurons from both vehicle- and EV-treated lesioned monkeys exhibited significant hyperexcitability and predominance of inhibitory synaptic currents, compared with neurons from nonlesioned control brains. However, compared with vehicle-treated monkeys, neurons from EV-treated monkeys showed lower firing rates, greater spike frequency adaptation, and excitatory:inhibitory ratio. Further, EV treatment was associated with greater apical dendritic branching complexity, spine density, and inhibition, indicative of enhanced dendritic plasticity and filtering of signals integrated at the soma. Importantly, the degree of EV-mediated reduction of injury-related pathology in vPMC was significantly correlated with measures of behavioral recovery. These data show that EV treatment dampens injury-related hyperexcitability and restores excitatory:inhibitory balance in $\mathrm{PPMC}$, thereby normalizing activity within cortical networks for motor function.

Key words: exosomes; inhibitory neurons; mesenchymal stem cell; motor cortex; neuronal excitability; stroke

Significance Statement

Neuronal plasticity can facilitate recovery of function after cortical injury, but the underlying mechanisms and efficacy of therapeutic interventions promoting this plasticity in primates are not well understood. Our recent work has shown that intravenous infusions of mesenchymal-derived extracellular vesicles (EVs) that are involved in cell-to-cell inflammatory and trophic signaling can enhance recovery of motor function after injury in monkey primary motor cortex. This study shows that this EV-mediated enhancement of recovery is associated with amelioration of injury-related hyperexcitability and restoration of excitatory-inhibitory balance in perilesional ventral premotor cortex. These findings demonstrate the efficacy of mesenchymal EVs as a therapeutic to reduce injury-related pathologic changes in the physiology and structure of premotor pyramidal neurons and support recovery of function.

Received Sep. 13, 2019; revised Mar. 11, 2020; accepted Mar. 16, 2020.

Author contributions: M.M., D.L.R., B.B., and T.L.M. designed research; M.M., W.C., S.M.C., V.G., A.T., J.W.G., D.P., D.D.A., M.P., D.L.R., and T.L.M. performed research; M.M., W.C., S.M.C., V.G., A.T., D.D.A., and M.P. analyzed data; M.M. and W.C. wrote the first draft of the paper; M.M., W.C., S.M.C., V.G., A.T., J.W.G., D.P., M.P., D.L.R., B.B., and T.L.M. edited the paper; M.M., W.C., D.L.R., and T.L.M. wrote the paper; B.B. contributed unpublished reagents/analytic tools.
This work was supported by National Institutes of Health: National Institute of Neurological Disorders and Stroke R21-NS102991 to T.L.M. and B.B.; National Institute on Aging R21 NS111174 to T.L.M. and D.L.R.; National Institute of Mental Health K99/R00MH101234 to M.M.; National Institute on Aging R01AG043640 to D.L.R.; and the National Center for Advancing Translational Sciences BU-CTSI 1UL1TR001430 to T.L.M. We thank Bethany Bowley, Silas E. Busch, Penny Schultz, Afroze Shaikh, Karen Slater, and Vincent Turnbull for technical assistance; Dr. Jennifer Luebke for experimental consultation, discussion, and sharing resources for the electrophysiological experiments; and Dr. Zheng Gang Zhang and Dr. Michael Chopp for assistance in the preparation of extracellular vesicles. 


\section{Introduction}

The pathogenesis of cortical injury, such as stroke, and how changes in neuronal circuits after injury can support recovery of function is complex and multifaceted. The acute phase of cortical injury is associated with neuronal dystrophy and inflammation that lead to alterations in membrane conductances, synaptic dysfunction, and excitotoxicity (for review, see Wang et al., 2007; Brouns and De Deyn, 2009; Carmichael, 2012; Lai et al., 2014; Anrather and Iadecola, 2016; Jayaraj et al., 2019). Subsequently, anti-inflammatory and trophic factors are upregulated (Kaushal and Schlichter, 2008) to promote neurite regrowth (Jones and Schallert, 1992; S. Li and Carmichael, 2006; Buga et al., 2008), synaptic remodeling (Stroemer et al., 1998; Benowitz and Carmichael, 2010), and compensatory changes in excitability, in an attempt to restore cortical function (for review, see Miyai et al., 2002; Jang et al., 2003; Ward, 2004; Dancause et al., 2005; S. Li and Carmichael, 2006). However, chronic excitotoxity and inflammation exacerbates neuronal damage, impairs cortical reorganization, and prevents full recovery (Kaushal and Schlichter, 2008; Carmichael, 2012; Kohman and Rhodes, 2013; Jayaraj et al., 2019). Recovery can thus be facilitated by limiting acute damage and inflammation, and promoting neuronal plasticity (Chavez et al., 2009; Lakhan et al., 2009; Lambertsen et al., 2019), but underlying mechanisms, especially in primates, are unknown.

The immune regulation of neuronal plasticity after injury is largely mediated by signaling between neurons, and central and peripheral immune cells, such as microglia and $\mathrm{T}$ cells (for review, see Y. Wu et al., 2015; Yshii et al., 2015; Colonna and Butovsky, 2017; Lannes et al., 2017; Szepesi et al., 2018; VeigaFernandes and Artis, 2018; Thurgur and Pinteaux, 2019). One potential therapeutic that is thought to modulate neuroimmune signaling is extracellular vesicles (EVs), which are endosomederived spheroids that transport nucleic acids and proteins between cells and are highly implicated in models of injury and neurodegeneration (for review, see Chivet et al., 2012; Di Trapani et al., 2016; Z. G. Zhang and Chopp, 2016; DeLeo and Ikezu, 2018; Munir et al., 2018; Reza-Zaldivar et al., 2018; Ruppert et al., 2018; Shanmuganathan et al., 2018; van Niel et al., 2018; Wilson et al., 2018; Saeedi et al., 2019; Z. G. Zhang et al., 2019). In our rhesus monkey model of cortical injury, we demonstrated the efficacy of EVs derived from bone marrow mesenchymal stem cells (MSCs) to enhance recovery of function following damage in the primary motor cortex (M1). EV-treated monkeys exhibited recovery to preinjury fine motor function by 3-5 weeks after treatment. In contrast, vehicle-treated monkeys reached a plateau, with incomplete functional recovery 812 weeks after injury (Moore et al., 2019).

In the current study, we investigated the neural basis of this EV-mediated enhancement of recovery by assessing injuryrelated biophysical and structural changes in pyramidal neurons in perilesional ventral premotor cortex (vPMC) of the monkeys from Moore et al. (2019), using in vitro whole-cell patch-clamp recording, intracellular filling, and immunohistochemistry. Specifically, we investigated layer 3 pyramidal neurons, which are thought to be involved in corticocortical pathways that

The authors declare no competing financial interests.

*M.M. and W.C. contributed equally to this work.

†T.L.M. and B.B. contributed equally to this work as co-senior authors.

Correspondence should be addressed to Maria Medalla at mmedalla@bu.edu.

https://doi.org/10.1523/JNEUROSCI.2226-19.2020

Copyright $\odot 2020$ the authors modulate movement-related activity and undergo plasticity after injury (for review, see Johansen-Berg et al., 2002; Miyai et al., 2002; Carmichael, 2003, 2006; Dancause et al., 2005; Fregni and Pascual-Leone, 2006; S. Li and Carmichael, 2006; Darling et al., 2011; Nishimura and Isa, 2012). Our previous study has shown that motor task-related upregulation of c-fos, an activity-dependent intermediate early gene marker, in vPMC neurons is correlated with recovery of function in monkeys (Orczykowski et al., 2018). We provide evidence that injury to M1 induces hyperexcitability and enhances inhibition in perilesional vPMC neurons, to presumably compensate for damage and restore function, albeit not to the degree of an intact normal network. EV treatment appears to ameliorate these injury-related changes and restore excitatory:inhibitory (E:I) network balance in vPMC to support a greater degree of functional recovery.

\section{Materials and Methods}

\section{Subjects}

Brain tissue used in this study was from 13 aged rhesus monkeys (Macaca mulatta) of either sex, ranging from 16 to 26 years old ( $\sim 48-78$ human years) (Tigges et al., 1988). Monkeys were acquired from national

primate research facilities with complete health records, and were housed individually in the Laboratory Animal Science Center at Boston University School of Medicine, which is fully accredited by the Association for Assessment and Accreditation of Laboratory Animal Care. All procedures were approved by the Boston University Institutional Animal Care and Use Committee and were conducted in accordance with the guidelines established by the National Institutes of Health's Guide for the care and use of laboratory animals.

MSC-EVs were extracted from MSCs harvested from the bone marrow of a young female adult monkey in our colony, as described previously (Moore et al., 2019). Tissue for experiments was obtained from 3 aged nonlesioned monkeys (female, age $17 \mathrm{y}$; female, age $19 \mathrm{y}$; male, age 20 y) that had no induced injury, and from 10 aged lesioned monkeys (female, ages 16-26 y old) randomly assigned to a treatment group before receiving a targeted cortical injury in the hand representation of the M1, as described in detail in our previous study (Moore et al., 2019). Five of these aged lesioned monkeys received vehicle (PBS) and five received EV treatment (see Fig. 1A). All personnel were blinded to groups for all procedures and experiments.

Electrophysiological mapping of M1 hand area, surgical lesion, and treatment administration

After preoperative testing on the Hand Dexterity Task (HDT), surgical procedures to localize and lesion the hand area of M1 were conducted under aseptic conditions, as described previously (Moore et al., 2019). Briefly, each monkey was sedated with ketamine hydrochloride $(10 \mathrm{mg} /$ $\mathrm{kg}$, i.m.) and anesthetized with sodium pentobarbital ( $15-25 \mathrm{mg} / \mathrm{kg}$, i.v.) to effect. The head was stabilized in a stereotactic apparatus and, after skin incision and reflection of the temporalis muscle, a bone flap $(\sim 40$ $\mathrm{mm}$, anterior to posterior extent; $\sim 35 \mathrm{~mm}$, medial to lateral extent) centered over the frontal and parietal lobes was removed. The dura was incised to expose the central sulcus and primary motor cortex. Electrical stimulation to evoke movements was delivered systematically across a grid of sites along the entire extent of the precentral gyrus, using a monopolar silver ball surface electrode (1 $\mathrm{mm}$ diameter). Stimulation grid sites were spaced $2 \mathrm{~mm}$ apart. Monopolar stimulus pulses of $250 \mu \mathrm{s}$ duration at amplitudes from 2.0 to $3.0 \mathrm{~mA}$ were delivered at each site once every $2 \mathrm{~s}$, first as a single pulse and then in a short train of four pulses at $100 \mathrm{~Hz}$. During each stimulation, a trained observer noted muscle movements (e.g., distinct movement or twitches of muscle) in specific areas of the digits, hand, forearm, or arm, both visually and by palpation. The intensity of the motor response in the hand and digits was graded on a scale of 1-3 (barely visible to maximal). Stimulation sites with the lowest threshold and largest motor response were marked on the calibrated photograph, creating a cortical surface map of the hand area, 


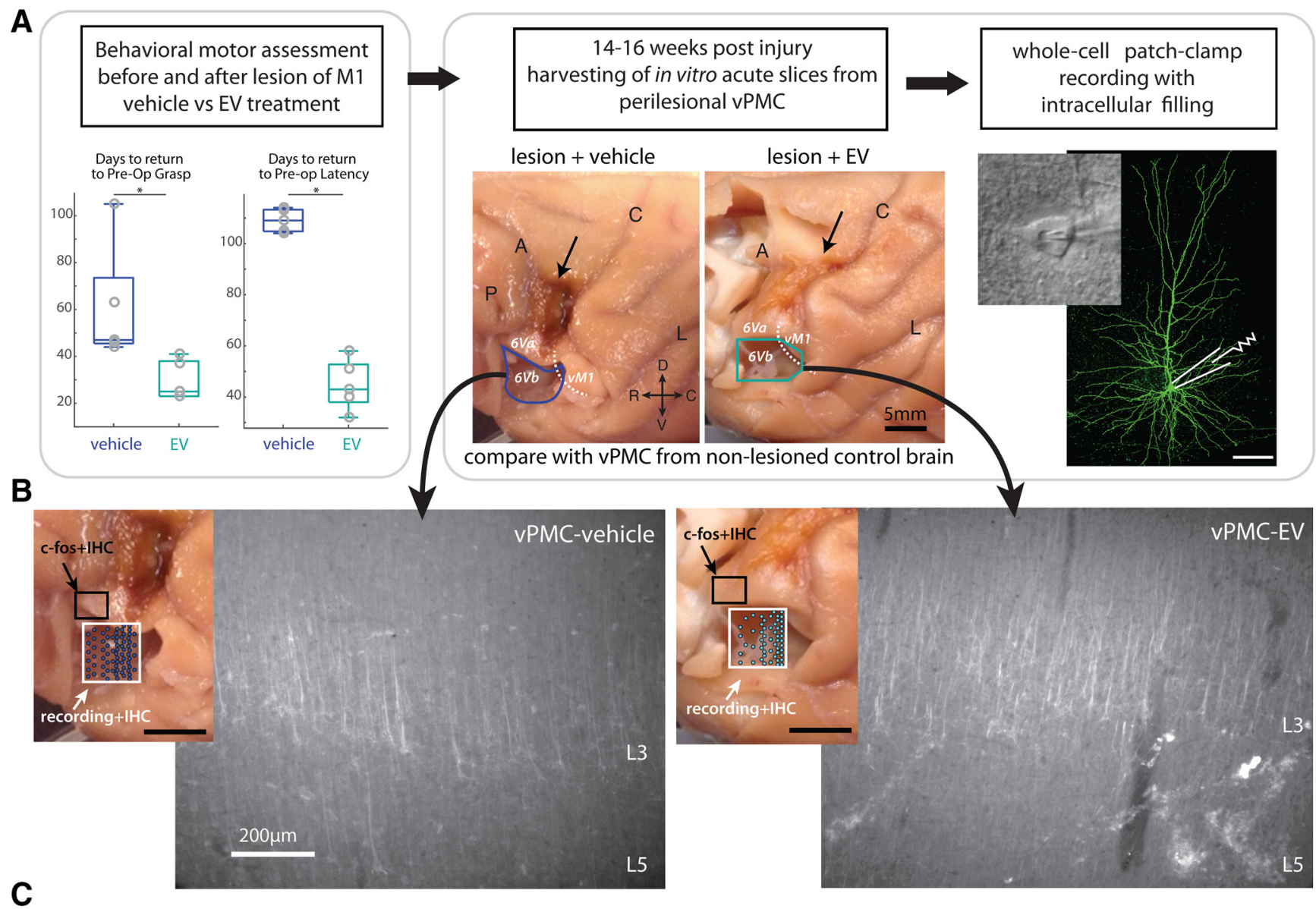

C

non-lesion

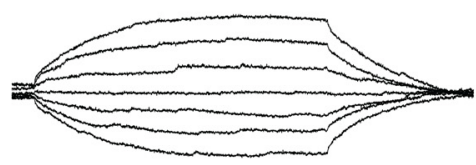

lesion +vehicle

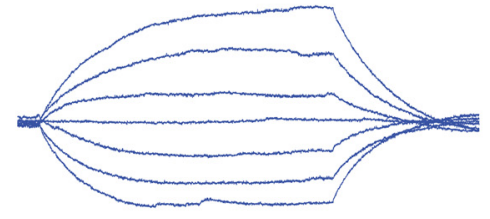

$\operatorname{Rn}(\mathrm{M} \Omega)$ lesion $+\mathrm{EV}$
D

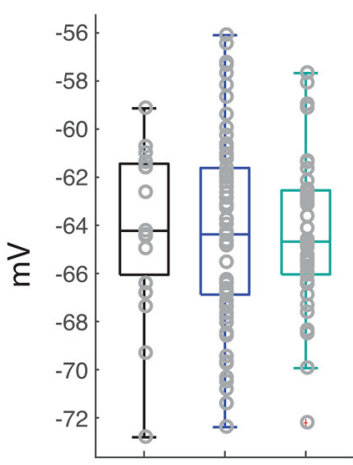

Tau (ms)

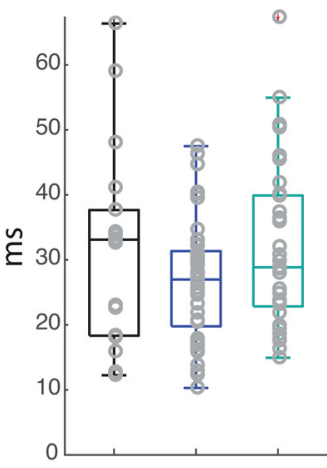

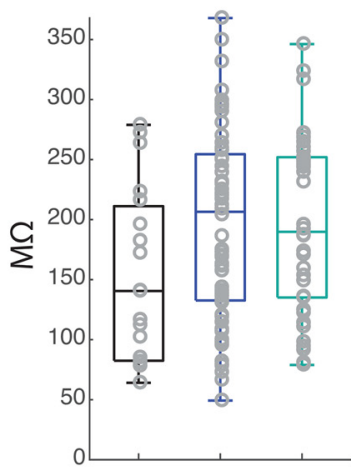

E Rnvs Tau

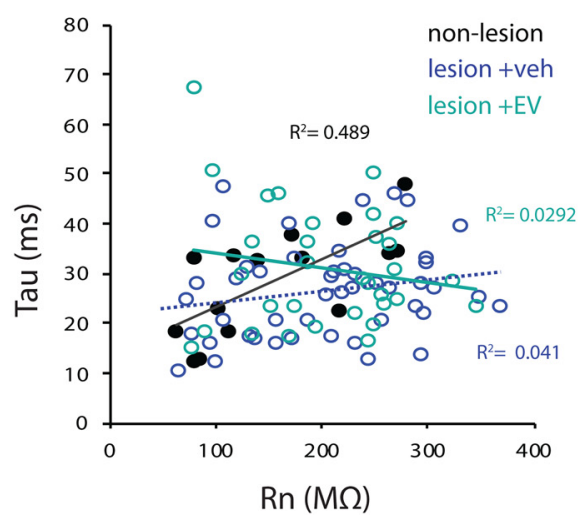

Figure 1. Experimental design and measurement of passive membrane properties of VPMC pyramidal neurons. $A$, Experimental workflow: Monkeys were first behaviorally assessed using our HDT (left panel) before and after cortical injury (arrow, middle panel), as described previously (Moore et al., 2019). The monkeys were randomly assigned to receive either vehicle or EV treatment, and then the rate and degree of behavioral recovery of preoperative grasp pattern and latency were assessed. Recovery data (adapted from Moore et al., 2019) show the number of days to recover, which was fewer (faster rate) in EV compared with vehicle-treated monkeys ( $t$ test, $p<0.01$ ). At 14-16 weeks after injury, acute slices were harvested during perfusion with Kreb's buffer from VPMC (VPMC ${ }_{\text {veh }}$ Vs VPMC EV). Location of tissue block harvested containing VPMC (area 6Vb) immediately ventral to the lesion $(\boldsymbol{A}$, arrow) and the estimated boundary between VPMC (area 6Va and 6Vb) and ventral M1 (vM1) are shown on the lateral surface of rhesus monkey brain. Whole-cell patch-clamp recording and intracellular filling of layer 3 vPMC $\mathrm{C}_{\text {eh }}(n=69$ neurons from 4 monkeys) and $\mathrm{VPMC}_{\mathrm{EV}}(n=39$ neurons from 2 monkeys) neurons were employed. Data from $\mathrm{VPMC}$ were compared with neurons harvested from vPMC of nonlesioned 
where the lesion was localized. Cortical injury was induced by making a small incision in the pia at the dorsal limit of the mapped representation, and a small glass suction pipette was then inserted under the pia to bluntly transect the small penetrating arterioles. After the lesion was made, the dura was closed, the bone flap was sutured back in place, and the muscles, fascia, and skin were closed in layers. Immediately following surgery, antibiotics and analgesics were administered, and the monkey was monitored continuously until fully awake and able to eat and drink.

EVs were extracted from MSCs harvested from the bone marrow of a young female adult monkey in our colony that is part of our other studies on anatomic pathways, as described previously (Moore et al., 2019). The MSC-EV treatment doses were prepared at Henry Ford, according to well-established protocols in rodents and porcine animal models (Xin et al., 2013), and then were shipped back to Boston University School of Medicine on ice. The EV treatment, diluted $4 \times 10^{11}$ particles $/ \mathrm{kg}$ in $10 \mathrm{ml}$ of PBS or vehicle treatment (PBS), was administered intravenously to each randomly assigned monkey (while sedated with ketamine hydrochloride $10 \mathrm{mg} / \mathrm{kg}$, i.m.), $24 \mathrm{~h}$ and again $14 \mathrm{~d}$ after cortical injury. Postoperative testing on the HDT began 2 weeks after surgery and continued for 12 weeks, as described previously (Moore et al., 2019).

\section{Perfusion and preparation of acute slices}

At $\sim 14-16$ weeks after injury, monkeys were perfused using our twostage Krebs-PFA perfusion method for harvesting live tissue and subsequent fixation (Amatrudo et al., 2012; Estrada et al., 2017). The animals were initially sedated with ketamine hydrochloride $(10 \mathrm{mg} / \mathrm{ml})$ and deeply anesthetized with sodium pentobarbital (to effect, $15 \mathrm{mg} / \mathrm{kg}$, i.v.), then perfused through the ascending aorta first with 1-4 $\mathrm{L}$ of ice-cold Krebs-Henseleit buffer (in $\mathrm{mM}$ as follows: $6.4 \mathrm{Na}_{2} \mathrm{HPO}_{4}, 1.4 \mathrm{Na}_{2} \mathrm{PO}_{4}$, $137 \mathrm{NaCl}, 2.7 \mathrm{KCl}, 5$ glucose, $\left.0.3 \mathrm{CaCl}_{2}, 1 \mathrm{MgCl}_{2}, \mathrm{pH} 7.4\right)$. Within 5 min of opening of the chest cavity (anoxia), a block of tissue $\left(1 \mathrm{~cm}^{3}\right)$, which included the caudal ventral premotor (area 6Vb (Barbas and Pandya, 1987; Morecraft et al., 2004) or area F4 (Matelli and Luppino, 1996; Rizzolatti et al., 1998)) and motor cortices, was harvested immediately below the lesion (Fig. 1A,B). We estimated the stereotactic location of the tissue block to be harvested from each monkey using gross landmarks based on the electrophysiological motor map we recorded during the lesion surgery (Moore et al., 2019). This block was transferred to oxygenated $\left(95 \% \mathrm{O}_{2}, 5 \% \mathrm{CO}_{2}\right)$ ice-cold Ringer's solution (in $\mathrm{mM}$ as follows: $26 \mathrm{NaHCO}_{3}, 124 \mathrm{NaCl}, 2 \mathrm{KCl}, 3 \mathrm{KH}_{2} \mathrm{PO}_{4}, 10$ glucose, $1.3 \mathrm{MgCl}_{2}$, $\mathrm{pH}$ 7.4), and sectioned into $300 \mu \mathrm{m}$ coronal acute slices with a vibrating microtome. To ensure that each block contained mainly vPMC, $\sim 2-3$ $\mathrm{mm}$ from the caudal end of each block containing M1 was trimmed off and flash-frozen for biochemical analyses. The block was then mounted caudal side down on the vibratome stage to cut coronal slices through vPMC. Slices for recording were immediately placed into room temperature Ringer's solution and equilibrated for $1 \mathrm{~h}$. To keep track of the rostrocaudal level (distance from the central sulcus) of the slices, every fifth $300 \mu \mathrm{m}$ coronal slice was immediately fixed in $4 \%$ PFA for verification of cytoarchitectonic boundaries. Once fresh tissue harvesting was concluded, perfusate was switched to freshly depolymerized 4\% PFA in 0.1

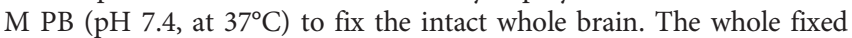
brain sample was blocked in situ in the coronal plane and then removed

aged-matched control brains (vPMC nonlesioned; $n=22$ neurons from 2 monkeys) from a cohort of monkeys in a separate study. $\boldsymbol{B}$, Lateral surface of brain maps (left insets) shows the sampling location and 2D plots of recorded cells (white box), and sampling location of tissue analyzed for $c$-fos labeling experiments (black box; $n=5 \mathrm{EV}$-treated, $n=5$ vehicletreated monkeys). Representative epifluorescence images (right panels) show coronal vPMC slices from which recordings were obtained, which were labeled with SMI- $32^{+}$after fixation to verify cytoarchitecture. Note the strong band of SMI32 ${ }^{+}$label in layer $3(\mathrm{~L} 3)$ and 5 (L5). The absence of large SMI32 ${ }^{+}$Betz cells in L5 is consistent with the cytoarchitecture of VPMC. C, Representative traces of voltage responses to a series of $200 \mathrm{~ms}$ current pulses. D, Boxand-whisker and vertical scatter plots of $V_{r}$, tau $u_{m}$ and $R_{n}$. E, Within-group linear relationships of membrane tau versus $R_{n}$. from the skull, cryoprotected in a series of glycerol solutions, and flashfrozen in $-70^{\circ} \mathrm{C}$ isopentane (Rosene et al., 1986). The brain was cut on a freezing microtome in the coronal plane at 30 or $60 \mu \mathrm{m}$. Sections were stored in cryoprotectant ( $15 \%$ glycerol, in $0.1 \mathrm{M} \mathrm{PB}, \mathrm{pH} 7.4$ ) at $-80^{\circ} \mathrm{C}$ until use (Estrada et al., 2017).

\section{Whole-cell patch-clamp recording and assessment of electrophysiological} properties

After a $1 \mathrm{~h}$ equilibration period, living acute slices were placed into submersion-type recording chambers (Harvard Apparatus), mounted on the stages of Nikon EDC infrared-differential interference contrast microscopes. All physiological experiments were conducted at room temperature, in oxygenated Ringer's solution (superfused at $2-2.5 \mathrm{ml} /$ $\mathrm{min}$ ), which improves the viability and duration of recordings from monkey acute slices. Standard tight-seal, whole-cell patch-clamp recordings with simultaneous biocytin filling were obtained from layer 3 pyramidal cells as described previously (Chang et al., 2005; Amatrudo et al., 2012; Medalla and Luebke, 2015; Medalla et al., 2017). Patch electrodes fabricated on a horizontal Flaming and Brown micropipette puller (Model P-87, Sutter Instruments) were filled with potassium methanesulfonate-based internal solution (in $\mathrm{mM}$ as follows: $122 \mathrm{KCH}_{3} \mathrm{SO}_{3}, 2$ $\mathrm{MgCl}_{2}$, 5 EGTA, 10 NaHEPES, with $0.5 \%$ biocytin, pH 7.4), with resistances of 3-6 $\mathrm{M} \Omega$ in the external Ringer's solution. Data were acquired using EPC-9 or EPC-10 patch-clamp amplifiers using PatchMaster software (HEKA Elektronik). The series resistance ranged from 10 to $15 \mathrm{M} \Omega$ and was not compensated. Bessel filter frequency was $10 \mathrm{kHz}$, and sampling frequency was at $7 \mathrm{kHz}$ for voltage-clamp and $12 \mathrm{kHz}$ for current-clamp recordings.

Cell inclusion criteria for electrophysiological analyses were as follows: resting membrane potential $\left(\mathrm{V}_{\mathrm{r}}\right) \leq-55 \mathrm{mV}$, stable access resistance, action potential (AP) overshoot, and repetitive firing responses (Amatrudo et al., 2012). To measure passive membrane properties $\left(V_{r}\right.$; input resistance, $\mathrm{R}_{\mathrm{n}}$; and passive membrane time constant, tau) a series of $200 \mathrm{~ms}$ depolarizing and hyperpolarizing current steps was used, as described previously (Chang et al., 2005; Amatrudo et al., 2012; Medalla and Luebke, 2015; Medalla et al., 2017). $R_{n}$ was calculated as the slope of the best-fit line of the voltage-current linear relationship. tau was assessed by fitting a single exponential function to the membrane potential response to a $-10 \mathrm{pA}$ hyperpolarizing current step. Single AP firing properties (threshold, amplitude, rise time, fall time, and duration at half-maximal amplitude) were measured from the second AP in a train of three or more spikes generated by the smallest current step in the series. Rheobase was determined as the minimum current required to evoke a single AP during a $10 \mathrm{~s}$ depolarizing current ramp $(0-200 \mathrm{pA})$. A series of $2 \mathrm{~s}$ hyperpolarizing and depolarizing current steps $(-170$ to $380 \mathrm{pA}$, using either 20 or $50 \mathrm{pA}$ increments) was used to assess active and repetitive firing properties. Traces were exported to MATLAB (The MathWorks) to assess AP firing and adaptation properties. Interspike intervals (ISIs) between individual spikes in each $2 \mathrm{~s}$ train were measured and used to calculate firing frequency adaptation (FFA) properties, as described previously (Zaitsev et al., 2012). The rate of initial and late FFA was measured at the $2 \mathrm{~s}$ current step closest to $1.5 \times$ rheobase. The first and second instantaneous frequencies ( $\mathrm{fl}$ and $\mathrm{f} 2$ ) were calculated as the reciprocals of the first and second ISIs $\left(\mathrm{fl}=1 / \mathrm{ISI}_{1} ; \mathrm{f} 2=1 / \mathrm{ISI}_{2}\right.$ ), respectively. Steady-state firing frequencies (fss) were calculated as the reciprocal of the average ISIs within the last quarter of the current step. Initial $\left(\mathrm{FFA}_{\text {initial }}\right)$ and late $\left(\mathrm{FFA}_{\text {late }}\right) \mathrm{FFA}$ were calculated as the percent decrease in frequency between $\mathrm{f} 1$ and $\mathrm{f} 2$, and between $\mathrm{f} 1$ and fss, respectively. To assess the relationship between FFA and input current, an adaptation ratio between the first and last ISI was calculated for each current step.

Spontaneous excitatory (EPSCs) and inhibitory (IPSCs) postsynaptic currents recorded for a minimum of $2 \mathrm{~min}$ at a holding potential of $-80 \mathrm{mV}$ and $-40 \mathrm{mV}$, respectively (Medalla et al., 2017). Analyses of synaptic event data were performed using Mini-Analysis software (Synaptosoft), with event detection threshold set at maximum root mean squared noise level $(5 \mathrm{pA})$. Recordings of synaptic events were assessed for frequency, mean amplitude, area under the curve, and kinetics (rise and decay time, and half-width). 
Immunohistochemical (IHC) labeling procedures on $300 \mu \mathrm{m}$ slices Processing of filled neurons and IHC labeling of vesicular GABAergic transporter (VGAT). To visualize recorded cells filled with biocytin, 300 $\mu \mathrm{m}$ slices were fixed for $48 \mathrm{~h}$ in $4 \% \mathrm{PFA}$ in $0.1 \mathrm{M}$ PBS, pH 7.4, then rinsed and incubated for $2 \mathrm{~h}$ in $1 \%$ Triton $\mathrm{X}$ (in $0.1 \mathrm{M} \mathrm{PBS}$ ), followed by $48 \mathrm{~h}$ in streptavidin-Alexa 488 (1:500 in 0.1 M PBS; Invitrogen). To assess inhibitory terminals apposed to filled neurons, slices were incubated in $50 \mathrm{~mm}$ glycine ( $2 \mathrm{~h}$ at room temperature), then in $10 \mathrm{~mm}$ sodium citrate antigen retrieval buffer $\left(\mathrm{pH} .8 .4\right.$, at $\left.60^{\circ} \mathrm{C}-70^{\circ} \mathrm{C}\right)$, and preblocked (5\% normal donkey serum and 5\% BSA with $0.1 \%$ Triton-X; $2 \mathrm{~h}$ at room temperature) as described previously (Medalla and Luebke, 2015; Medalla et al., 2017). All antibodies were diluted in 1\% normal donkey serum, $0.2 \%$ acetylated BSA (BSA-c, Aurion), and $0.1 \%$ Triton-X in $0.1 \mathrm{M} \mathrm{PB}$. Slices were incubated in the primary antibody against VGAT (1:400, guinea pig polyclonal, Synaptic Systems, catalog \#131004; RRID:AB_887873) for over $7 \mathrm{~d}$ at $4^{\circ} \mathrm{C}$, with $8 \times 10 \mathrm{~min} 150 \mathrm{~W}$ microwave sessions at $35^{\circ} \mathrm{C}$ (Biowave, Ted Pella) to assist in antibody penetration. Slices were incubated in donkey anti-guinea pig $\mathrm{F}\left(\mathrm{ab}^{\prime}\right) 2$ IgG conjugated to Alexa-647 (Jackson ImmunoResearch Laboratories) for $4 \mathrm{~d}$ (at $4^{\circ} \mathrm{C}$, with $4 \times 10 \mathrm{~min} 150 \mathrm{~W}, 35^{\circ} \mathrm{C}$ microwave).

IHC labeling of SMI-32 for cytoarchitectural verification of recorded slices. To verify the area of recording, a subset of serial coronal slices collected across the rostral to caudal extent of the block were resectioned to $100 \mu \mathrm{m}$ and immunolabeled for SMI32, a nonphosphorylated neurofilament cytoskeletal protein that labels pyramidal neurons in layers 3 and 5 (Campbell and Morrison, 1989) (see Fig. 1B). SMI32 is a marker used to delineate cytoarchitectonic areas, which is especially useful to identify the large layer 5 Betz cells present in primary motor cortex (Campbell and Morrison, 1989; Preuss et al., 1997; Gabernet et al., 1999; GarciaCabezas and Barbas, 2014). Slices were incubated in the primary antibody against SMI32 (1:1000 mouse monoclonal, Biolegend; RRID:AB_ 10719742), followed by an incubation in donkey anti-mouse Alexa-405 $\mathrm{F}\left(\mathrm{ab}^{\prime}\right) 2 \operatorname{IgG}$ (as above).

For all IHC labeling experiments, slices were mounted on glass slides and coverslipped with Prolong antifade medium (Invitrogen). Control experiments wherein the primary antibody was omitted showed no labeling.

IHC labeling of c-fos activated task-related neurons and inhibitory neuron markers. Quadruple-immunofluorescence labeling was used to assess the distribution of $\mathrm{c}^{-} \mathrm{fos}^{+}$neurons, an immediate early gene transcription factor that peaks 1-4 h after neuronal activation begins (Dragunow and Faull, 1989; Rosene et al., 2004; for review, see Hoffman et al., 1993; Kovacs, 2008), therefore labeling neurons activated during a final motor HDT testing session before sacrifice and tissue harvesting (Orczykowski et al., 2018). We batch-processed two serial $30 \mu \mathrm{m}$ coronal sections through vPMC (area 6Va/F5), from each lesioned monkey.

To assess cell-type specific task-related activation, sections were coincubated overnight in primary antibodies against $\mathrm{c}-\mathrm{fos}$ (1:400, guinea pig polyclonal, Synaptic Systems, catalog \#226005; RRID:AB_2800522), parvalbumin (PV) (1:1000, goat polyclonal, Swant, catalog \#PVG213; RRID: AB_2721207), calbindin (CB) (1:1000, mouse monoclonal, Swant, cata$\log$ \#300; RRID:AB_10000347), and calretinin (CR) (1:2000, rabbit polyclonal, Swant, catalog \#CR7696; RRID:AB_2619710). Sections were then coincubated overnight $\left(4^{\circ} \mathrm{C}\right)$ in the following secondary antibodies raised in donkey (1:200): anti-guinea pig 488 (Jackson ImmunoResearch Laboratories), anti-goat 546 (Jackson ImmunoResearch Laboratories), anti-rabbit 633 (Invitrogen), and biotinylated anti-mouse IgG (Jackson ImmunoResearch Laboratories) followed by Streptavidin 405 (1:200 Invitrogen; overnight $4^{\circ} \mathrm{C}$ ).

IHC to assess dendritic structure. To assess dendritic integrity and damage, $30 \mu \mathrm{m}$ sections through vPMC (area 6Va/F5) were immunolabeled for the microtubule-associated protein-2 (MAP2; 1:2000, chicken polyclonal, Abcam, RRID:AB_2138153), a marker for apical dendrites of pyramidal neurons (Caceres et al., 1984; Peters and Sethares, 1991). Sections were then incubated in donkey anti-chicken Alexa-488 F(ab')2 IgG (as above). After IHC procedures, $30 \mu \mathrm{m}$ sections were mounted on gelatin-coated glass slides and coverslipped with Prolong antifade medium (Invitrogen). Control experiments wherein the primary antibody was omitted showed no labeling.
Verification of rostrocaudal slice level and location of recorded neurons To map the location of recorded neurons, the distance of each slice from the central sulcus was estimated based on the location of the harvested block, and the series of slices harvested along the rostrocaudal extent of each block, and subsequently resectioned and labeled with SMI-32 (above). The caudal-most coronal slice in this SMI-32 series was estimated to be $\sim 2 \mathrm{~mm}$ from the central sulcus and was used as the reference to calculate the relative distances of the subsequent serial slices. Each slice with a recorded cell was then matched to a slice within this reference SMI-32 series to estimate the distance of each recorded cell from the central sulcus, and plot the estimated cell location on a 2D map (see Fig. 1B).

Post hoc verification of the regional and laminar location of each recorded cell was used by measuring soma-to-pia distances from images of recording electrodes, and cytoarchitectural verification using matched sections stained with SMI-32. A slice within vPMC was identified based on published cytoarchitectonic criteria (Preuss et al., 1997; Gabernet et al., 1999; Liu et al., 2002; Boussaoud et al., 2005; for review, see Belmalih et al., 2007), particularly by the absence of large Betz cells in layer 5 , which are prominent in M1. These Betz cells are very large pyramidal neurons with multiple primary dendrites emanating along the perimeter of the soma (for review, see Belmalih et al., 2007; Garcia-Cabezas and Barbas, 2014). Neurons verified to be recorded in a vPMC slice and localized in layer 3 (soma to pia distance between $350-850 \mu \mathrm{m}$ ) were included in the dataset.

Recorded neurons were verified to be located in caudal vPMC, corresponding to area $6 \mathrm{Vb}$ of the cytoarchitectural maps of (Barbas and Pandya, 1987; Morecraft et al., 2004, 2019) and area F4 of the functional maps of (Matelli and Luppino, 1996; Rizzolatti et al., 1998). This specific subdivision of vPMC has overlapping proximal forelimb and orofacial representations, as described previously (Graziano et al., 2002; Graziano and Aflalo, 2007; Kaas et al., 2012), and as verified in the motor maps from these monkeys (Moore et al., 2019).

\section{Confocal imaging and analyses of pyramidal neuron morphology}

Neurons with complete somata and dendrites with no cut branches in the proximal third of the apical tree were selected for confocal imaging using a Leica SPE confocal microscope (Leica Microsystems). All image stacks were deconvolved using AutoQuant (Media Cybernetics). Dendritic arbors of whole cells imaged at $0.3 \times 0.3 \times 0.3 \mu \mathrm{m}$ per voxel $(40 \times 1$ 1.3 NA oil-immersion; $488 \mathrm{~nm}$ ) were reconstructed using NeuronStudio (Rodriguez et al., 2006) (RRID:SCR_013798), according to our established protocols (Amatrudo et al., 2012; Medalla et al., 2017).

For assessment of filled spines and appositions of filled neurons with $\mathrm{VGAT}^{+}$boutons, a second series of image stacks were acquired via 2channel confocal imaging at a resolution of $0.04 \times 0.04 \times 0.3 \mu \mathrm{m}$ per voxel $(63 \times / 1.4 \mathrm{NA}$ oil-immersion objective and 488 and $647 \mathrm{~nm}$ diode lasers), as described previously (Medalla et al., 2017). For each neuron, confocal stacks were acquired to image the soma, one complete basilar dendritic branch, and the main apical trunk followed to the end of one complete distal apical dendritic branch. Image stacks were deconvolved (as above), and tiled and analyzed using Neurolucida 360 (RRID:SCR 016788; MBF Bioscience). Spines along the imaged dendrite were counted and classified into subtypes according to previous criteria (Medalla and Luebke, 2015; Medalla et al., 2017) as follows: thin (head width $<0.6 \mu \mathrm{m}$ ); mushroom (head width $\geq 0.6$ ); stubby (no neck); and filopodia (neck length $>3 \mu \mathrm{m}$ ). Densities of total spines and of each subtype were calculated as the number of spines per micron of dendritic length.

Appositions between the neurons and $\mathrm{VGAT}^{+}$puncta were classified as follows: apposed to dendritic shafts; spine head or neck of each subtype; or somata. An apposition was identified as a spatial overlap between the saturated red and green signal $>2$ pixels in the $x-y,>2$ optical slices in the $z$ for thin dendrites and axons, or $>4$ optical slices in the $z$ for highly saturated somata, as described previously (Medalla et al., 2017). Appositions on dendritic shafts and spines were expressed as the number per micron of dendritic length. Appositions on somata were expressed as number per surface area of somata. Profiles of somata were automatically traced section-by-section, and surface area was calculated 
by the Neurolucida software as a series of cylindrical sections capped by the end profiles. Sholl analyses with concentric spheres placed at $20 \mu \mathrm{m}$ increments from the center of the soma were used to determine dendritic parameters of apical and basal arbors, and the spine and VGAT apposition density as a function of distance from the center of the soma (Sholl, 1953).

\section{Cell counting of $c$-fos ${ }^{+}$labeled inhibitory neurons}

To assess the density of $\mathrm{c}^{-\mathrm{fos}^{+}}$neurons co-labeled with inhibitory markers (CB, PV, or CR), 4-channel confocal image stacks were acquired from $30 \mu \mathrm{m}$ sections $(20 \times, 0.8 \mathrm{NA} ; 0.3 \times 0.3 \times 1 \mu \mathrm{m}$ per voxel; Zeiss 710, Carl Zeiss). Four fields, spaced $500 \mu \mathrm{m}$ apart, were randomly sampled in layer 3 of the subregion of vPMC located dorsal and rostral to the fresh tissue biopsy from each monkey (see Fig. 1B). This vPMC subregion corresponded to area 6Va of (Barbas and Pandya, 1987; Morecraft et al., 2004, 2019), area F5 of (Matelli and Luppino, 1996; Rizzolatti et al., 1998), and "hand and digit/grasp" area PMv of (Dum and Strick, 2002) and (Kaas et al., 2012). A $z$ stack from the top to the bottom of the tissue was captured in each field. In each $z$ stack, singleand double-labeled cells were counted using the FIJI cell counter (https://imagej.net/Fiji; 1997-2016; RRID:SCR_002285) (Schindelin et al., 2012), adapting stereological counting rules (Fiala and Harris, 2001).

\section{Quantification of the density of $M A P 2^{+}$-labeled dendrites}

To assess the density of MAP2 ${ }^{+}$-labeled dendrites on $30 \mu \mathrm{m}$ sections, two columns through L1-L3 of vPMC (area 6Va/F5), spaced $200 \mu \mathrm{m}$ apart, were imaged using a Leica SPE confocal microscope (Leica Microsystems $)$ at high resolution $(0.1 \times 0.1 \times 0.3 \mu \mathrm{m} ; 40 \times$ oil-immersion 1.3 NA objective), and deconvolved as described above. The optical density of $\mathrm{MAP}^{+}$labeling was quantified using particle analyses in ImageJ/FIJI, as described previously (Medalla et al., 2017). The signal threshold for the analyses was automatically set in the first L1 field, and then applied to subsequent fields within the same section. The total percent area covered by $\mathrm{MAP}^{+}$label and the average size of individual $\mathrm{MAP}^{+}{ }^{+}$-labeled pixels were calculated for each field. The average measures of all the fields was calculated for each monkey and compared between the two treatment groups.

\section{Experimental design and statistics}

All data are expressed as box-and-whisker plots or vertical scatter plots, together with tabulated mean \pm SEM. Statistical analyses were conducted in MATLAB (R2018, RRID:SCR_001622). Outcome measures of pyramidal neuron properties were compared between cells from multiple animals in each group using multifactorial ANOVAs with post hoc Fisher's LSD in MATLAB. For pairwise comparisons of $\mathrm{cfos}^{+}$cell densities between treatment groups, Student's $t$ test was used. We recorded and compared a total of 130 neurons from vPMC (area 6Vb/F4; $\mathrm{vPMC}_{\text {nonlesion }}, n=22$ neurons from 2 monkeys; $\mathrm{vPMC}_{\mathrm{veh}}, n=69$ from 4 monkeys; $\mathrm{vPMC}_{\mathrm{EV}}, n=39$ from 2 monkeys) and reconstructed and compared a total of 47 neurons ( $\mathrm{vPMC}_{\text {nonlesion }}, n=15$ neurons from 2 monkeys; $\mathrm{vPMC}_{\mathrm{veh}}, n=17$ from 4 monkeys; and $\mathrm{vPMC}_{\mathrm{EV}}, n=15$ from 2 monkeys) layer 3 pyramidal neurons. Animal was included as an independent variable and showed no significant main effect in any outcome measure. Sex was compared within the nonlesion group and showed no significant differences in any outcome measure; thus, the data were pooled.

Measurements of $c-$ fos $^{+}$cell densities (CB, PV, and CR) in vPMC (area $6 \mathrm{Va} / \mathrm{F5}$ ) were compared between monkeys of the two treatment groups ( $n=5$ vehicle vs $n=5 \mathrm{EV}$-treated female monkeys). Relationships between outcome variables were determined using linear regression analyses. Power analyses show that, for outcome measures in this study, tests can detect an effect size of at least $\mathrm{f}=0.46$ at a significance level of 0.05 with $80 \%$ power. Because of the limitation of the number of subjects in the experimental cohort, we cannot investigate the independent effect of sex on all the conditions and variables.

Nonmetric multidimensional scaling (NMDS) was performed to analyze similarities among individual neurons in the experimental groups, based on three sets of electrophysiological outcome measures as follows: passive (tau, $R_{n}, V_{r}$ ); active (rheobase, AP threshold, AP amplitude, AP rise time, AP fall time, AP duration, depolarizing sag potential, AP firing frequency response to $20,40,60$, and $80 \mathrm{pA}$ injections, initial and late FFA); synaptic (EPSC and IPSC frequency, amplitude, rise time, decay time, area, half-width and total charge, E:I ratio) properties. For each set of outcome measures, $z$ scores were obtained for each variable, and pairwise comparisons were used to calculate a distance matrix based on squared Euclidean distances. The multidimensional distance matrix was then reduced to two dimensions via NMDS, and the resulting values of each neuron were plotted, with the distances between data points representing the relative similarities based on the set of variables.

One-way multivariate ANOVA (MANOVA) was used to compare the relative degree of influence each neuronal electrophysiological outcome measure contributes to the separation of the three experimental groups (nonlesioned control, lesion + vehicle, lesion + EV). Only outcome measures with significant differences based on ANOVA were included for the analysis. Outcome measures included in the MANOVA are as follows: rheobase; AP threshold; AP amplitude; AP rise time; AP fall time; AP duration; AP firing frequency response to $20,40,60$, and 80 pA current injections; initial and late FFA; EPSC amplitude; EPSC frequency; EPSC total charge; IPSC frequency; and E:I ratio. The $z$ scores were obtained for each of the measured outcome variables, and two canonical variables (weighted linear sums of all individual outcome variables) that best separate out the three experimental groups were computed. For each canonical variable, the absolute value of the coefficient for each outcome measure represents the degree of influence that specific measure contributes to the separation of the groups, with higher absolute values representing a greater influence.

\section{Results}

\section{Lesion-related changes in active membrane properties of vPMC pyramidal neurons are consistent with hyperexcitability}

The excitability and signaling properties of pyramidal neurons are governed by passive intrinsic membrane properties and an assortment of ion channels mediating active conductances (for review, see Spruston, 2008). In this study, we assessed lesionassociated changes in the biophysical and structural properties of layer 3 pyramidal neurons in $\mathrm{VPMC}$, after injury in the hand representation of M1 (Fig. 1A). Layer 3 vPMC pyramidal neurons mediate corticocortical pathways (for review, see Callaway, 2002; Barbas, 2015) that are thought to reorganize after M1 injury to promote recovery of function (e.g., Carmichael, 2003; Ward, 2004; Kantak et al., 2012). The monkeys were first trained on our HDT and then underwent surgery to induce cortical damage in the hand representation of M1, as described previously (Moore et al., 2019). Monkeys then received infusions of MSC EVs or vehicle (PBS) intravenously $24 \mathrm{~h}$ and again $14 \mathrm{~d}$ after the cortical injury. Postoperative testing on the HDT began 2 weeks after surgery and continued for 12 weeks. As reported in our previous study, EV-treated monkeys exhibited significantly faster recovery rates (fewer days to full recovery) of preoperative grasp pattern and latency to retrieve than vehicle-treated monkeys (Fig. $1 \mathrm{~A}$, left; data adapted from Moore et al., 2019). Following the completion of postoperative testing, at $\sim 14$-16 weeks after injury, live acute slices of vPMC were harvested from all monkeys during perfusion with aCSF (Kreb's buffer) for whole-cell patchclamp recordings and intracellular filling of layer 3 pyramidal neurons (Fig. 1A, right). The location of each recorded neuron relative to central sulcus was estimated and mapped (Fig. 1B, insets, white boxes). ROI in vPMC was histologically verified for each block using SMI-32 labeling, a cytoarchitectural marker for a subset of L3 and L5 pyramidal neurons that delineates M1 and PMC based on previous cytoarchitectonic criteria (Preuss et al., 1997; Gabernet et al., 1999; Liu et al., 2002; Boussaoud et al., 2005; Belmalih et al., 2007). Specifically, vPMC is marked by the 
Table 1. Electrophysiological properties of vPMC layer 3 pyramidal neurons

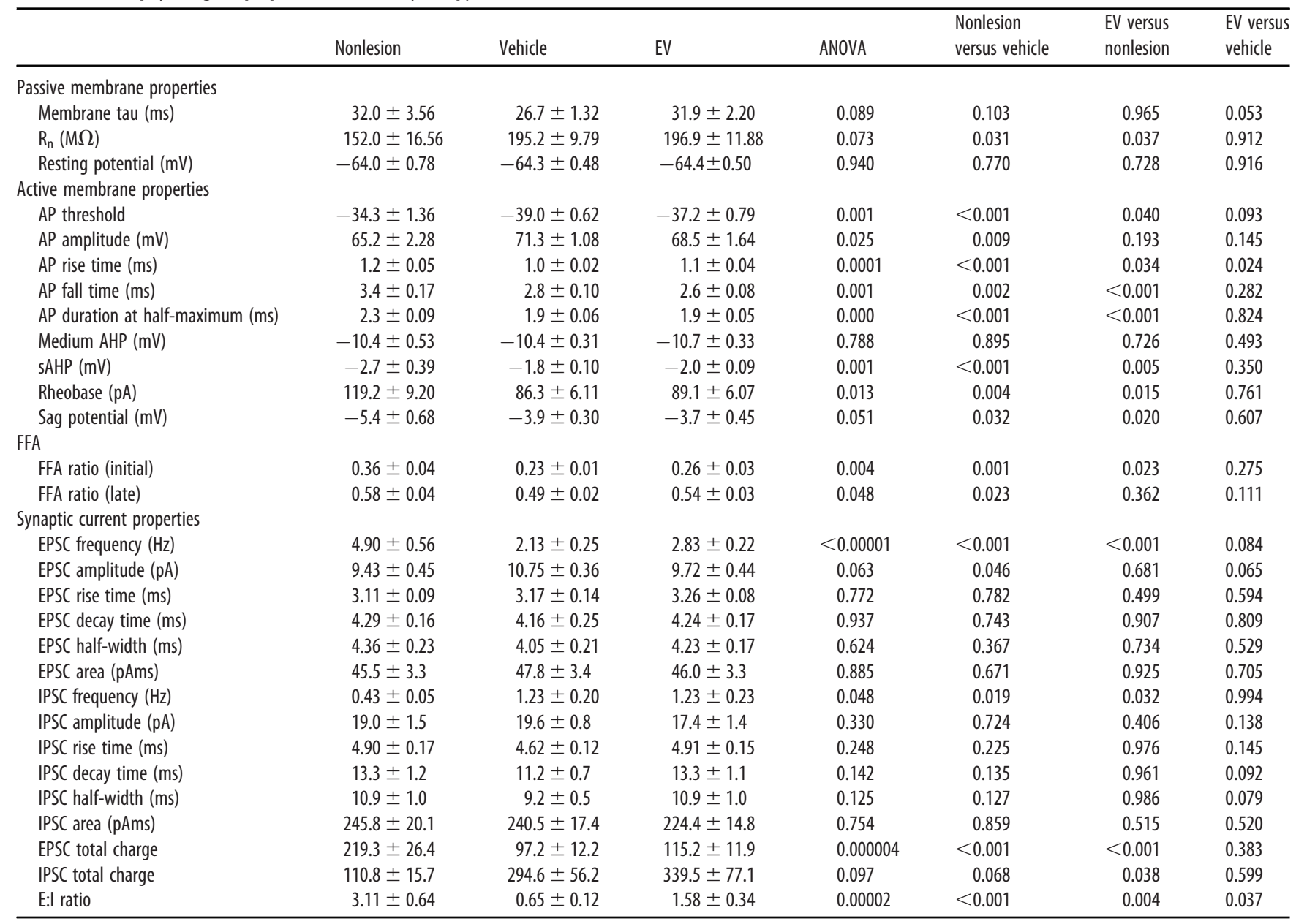

absence of Betz cells, the very large pyramidal neurons in L5 with multiple primary dendrites emanating from the soma, which are predominant in M1 (for review, see Belmalih et al., 2007; GarciaCabezas and Barbas, 2014) (Fig. 1B). Mapping and histologic analyses verified that recorded neurons were located in caudal $\mathrm{vPMC}$, corresponding to the area $6 \mathrm{Vb}$ or area $\mathrm{F} 4$, involved in both forelimb and orofacial movements (Matelli and Luppino, 1996; Rizzolatti et al., 1998; Graziano et al., 2002; Morecraft et al., 2004, 2019; Graziano and Aflalo, 2007). We compared properties of vPMC neurons from nonlesioned control brains ( $\mathrm{vPMC}_{\text {nonlesion }}, n=22$ neurons from 2 monkeys) and lesioned brains with either vehicle ( $\mathrm{vPMC}_{\mathrm{veh}}, n=69$ neurons from 4 monkeys) or $\mathrm{EV}$ ( $\mathrm{vPMC}_{\mathrm{EV}}, n=39$ neurons from 2 monkeys) treatment.

Intrinsic passive membrane properties $\left(\mathrm{V}_{\mathrm{r}}\right.$, tau, and $\mathrm{R}_{\mathrm{n}}$ ) of pyramidal neurons were not significantly different across groups (ANOVA, main effect $p>0.05$ for all comparisons; Fig. 1C,D; Table 1). In contrast, significant lesion-related differences in single AP properties of vPMC neurons, consistent with hyperexcitability, were found. In vPMC neurons from both lesion groups, APs exhibited faster kinetics (ANOVA main effect: faster rise, $p=0.0001$; fall, $p=0.0008$; duration, $p=0.0002$ ) compared with neurons in the nonlesion control group (Fisher's LSD post hoc, $p<0.04$ for all comparisons; Fig. 2A,B). However, post hoc comparisons between treatment groups showed that $\mathrm{vPMC}_{\mathrm{EV}}$ neurons exhibited slower rise times (EV vs veh, $p=0.02$ ) and greater amplitude (EV vs veh, $p=0.009$ ) than $\mathrm{vPMC}_{\mathrm{veh}}$ neurons.

Further, neurons from both lesion groups had significantly lower AP firing thresholds (ANOVA main effect, $p=0.001$;
Fisher's LSD post hoc veh vs nonlesion, $p=0.0003$; EV vs nonlesion, $p=0.04$; Fig. $2 A, B$ ), and a smaller slow afterhyperpolarization (sAHP) compared with $\mathrm{vPMC}_{\text {nonlesion }}$ neurons (ANOVA main effect, $p=0.001$; veh vs nonlesion, $p=0.0002$; EV vs nonlesion, $p=0.005$; Fig. $2 C$ ). Similarly, rheobase, the minimum current to elicit an AP, was significantly lower in vPMC neurons from the two lesion groups compared with those in the nonlesion control group (ANOVA main effect, $p=0.01$; veh vs nonlesion, $p=0.003$; EV vs nonlesion, $p=0.015$; Fig. $2 D, E$ ). For all three groups, rheobase exhibited significant linear relationships with $R_{n}$, which was expected, as the same current injection elicits higher voltage responses in neurons with higher $R_{n}$. However, pairwise comparisons of linear regressions with experimental group as an additional response variable revealed that the slope of linear regression was significantly greater for $\mathrm{vPMC}_{\text {nonlesion }}$ neurons compared with that of $\mathrm{vPMC}_{\mathrm{veh}}$ neurons $(p=0.025)$. In contrast, the slope of linear regression did not differ between $\mathrm{vPMC}_{\mathrm{EV}}$ and the two other groups (vs nonlesion, $p=0.053$; vs veh, $p=0.49$ ). These results indicate that lesion-associated changes in excitability cannot be explained by passive properties alone. Further, these results suggest that cortical lesion alters active conductances that, in turn, lead to more rapid AP firing kinetics and greater excitability in perilesional vPMC neurons.

\section{Lesion-related increase in repetitive AP firing rate is reduced by EV treatment}

$\mathrm{vPMC}_{\mathrm{veh}}$ and $\mathrm{vPMC}_{\mathrm{EV}}$ neurons both exhibited greater repetitive AP firing rates in response to $2 \mathrm{~s}$ current injections compared 
A
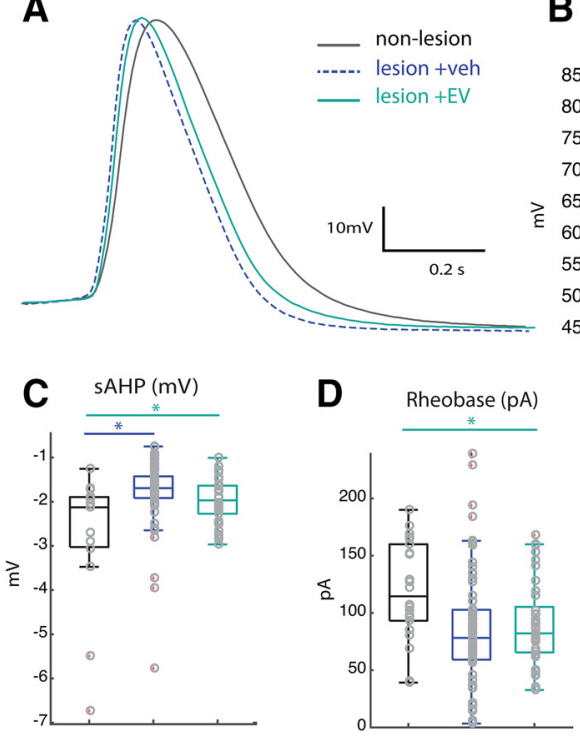

$\mathbf{F}$

lesion +vehicle

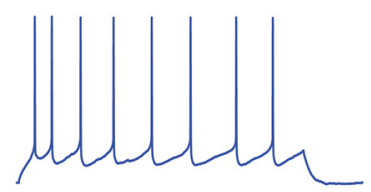

lesion $+\mathrm{EV}$
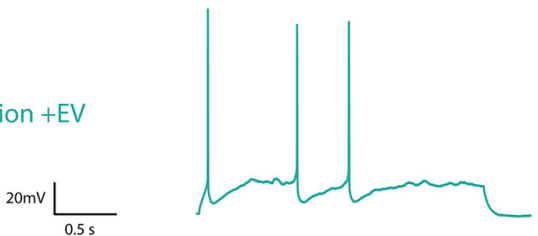

B AP amp (mV)

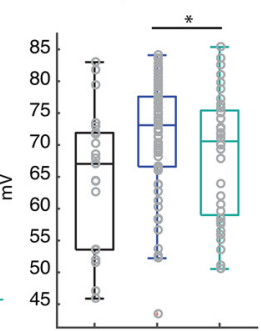

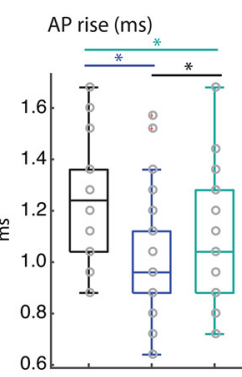

Rn vs Rheobase
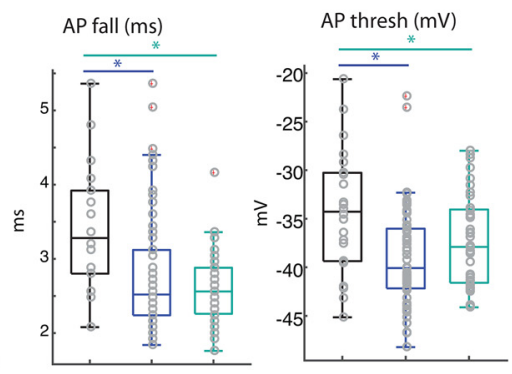

E

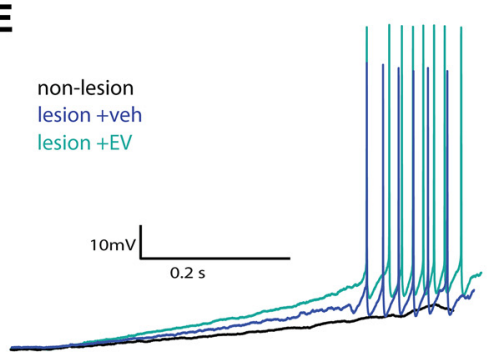

$+120 \mathrm{pA}$
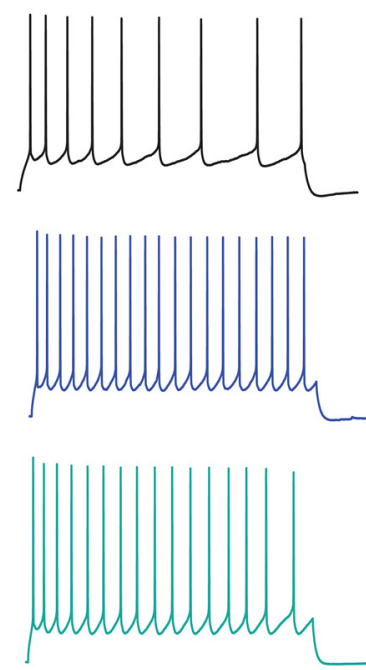

G

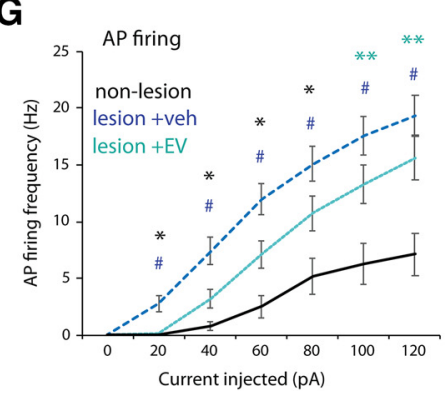

H

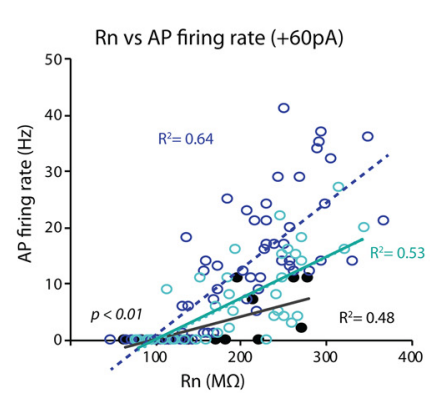

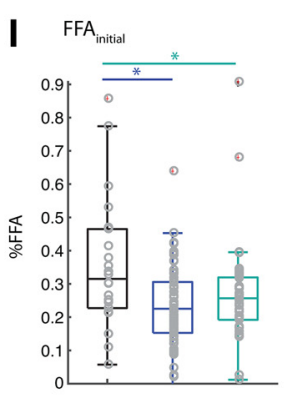

Figure 2. AP firing properties of $\mathrm{VPMC}$ pyramidal neurons are altered by lesion and EV treatment $A$, Representative single AP waveforms from the three groups, superimposed, showing differences in AP kinetics (rise, fall, duration at half-maximum amplitude). $\boldsymbol{B}$, Box-and-whisker and vertical scatter plots of individual data points of single AP properties: amplitude (ANOVA Fisher's LSD post hoc, EV vs veh, $p=0.009$ ), rise (veh vs nonlesion, $p=0.03$; EV vs nonlesion, $p=0.00004$; EV vs veh, $p=0.02$ ), fall (veh vs nonlesion, $p=0.0003$; EV vs nonlesion, $p=0.002$ ), and threshold (veh vs nonlesion, $p=0.0003$; EV vs nonlesion, $p=0.04$ ). C, Amplitude of sAHP (veh vs nonlesion, $p=0.0002$; EV vs nonlesion, $p=0.005$ ). $\boldsymbol{D}$, Box-and-whisker and vertical scatter plots (left) of rheobase current, and linear relationships of rheobase versus $R_{n}$ (right, $p<0.01$ for all correlations). $\boldsymbol{E}$, Representative voltage responses to a low-amplitude current ramp stimulus in $\mathrm{PPMC}_{\text {veh }}$ and $\mathrm{VPMC}$ Ev neurons; the $\mathrm{VPMC}$ nonlesion neuron did not fire APs at this current ramp stimulus. $\boldsymbol{F}$, Representative voltage traces showing steady-state AP firing in response to 2 s current steps at 40,80, $120 \mathrm{pA}$. G. Mean AP firing rates in response to a series of depolarizing current steps (Fisher's LSD post hoc, 20, 40, 60, 80 pA: *veh vs EV, $p<0.04$; " veh vs nonlesion, $p<0.009 ; 100,120 \mathrm{pA}$ : "veh vs nonlesion, $p<0.0002$; ${ }^{* *} \mathrm{EV}$ vs nonlesion, $\left.p<0.03\right)$. $\boldsymbol{H}$, Linear relationships of $\mathrm{R}_{\mathrm{n}}$ and firing rate at lower current steps (60 pA; $\left.p<0.01\right)$. Slopes significantly different between groups at all steps (40,60,80, 120: veh vs EV, $p<0.001$; veh vs nonlesion, $p<0.048)$. I, Box-and-whisker and vertical scatter plots of percent initial and late FFA

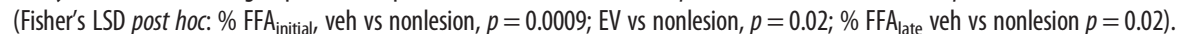


with control $\mathrm{vPMC}_{\text {nonlesion }}$ neurons (ANOVA main effect, $p<0.03$ for all significantly different comparisons; Fig. $2 F, G$ ). However, at low-amplitude current injections, $\mathrm{vPMC}_{\mathrm{EV}}$ neurons exhibited significantly lower firing rates than $\mathrm{vPMC}_{\mathrm{veh}}$ (ANOVA, Fisher's LSD post hoc, 20, 40, 60, $80 \mathrm{pA} ; p=0.002$, $0.0058,0.0078,0.038$; Fig. $2 F, G)$. While firing rates exhibited significant linear relationships to $\mathrm{R}_{\mathrm{n}}(\mathrm{Fig}$. $2 \mathrm{H}$ ), the slope of linear regression in $\mathrm{vPMC}_{\mathrm{veh}}$ neurons was significantly steeper than in the other groups $(40,60,80,120 \mathrm{pA}$ : veh vs $\mathrm{EV}$, $p=0.001,0.0002,0.0004,0.005$; veh vs nonlesion $=0.048,0.003$, $0.0005,0.009)$, while $\mathrm{vPMC}_{\mathrm{EV}}$ did not differ from $\mathrm{vPMC}_{\text {nonlesion }}$ neurons.

We assessed whether higher AP firing rates were due to reduced FFA in neurons from nonlesioned versus lesioned brains (Fig. 2I). The FFA $A_{\text {initial, }}$ percentage decrease from onset to second instantaneous firing frequency $((\mathrm{f} 1-\mathrm{f} 2) / \mathrm{f} 1)$, was reduced in lesion groups compared with nonlesion control (ANOVA, main effect, $p=0.004$; veh vs nonlesion, $p=0.0009$; EV vs nonlesion, $p=0.02$; Fig. $2 I$ ). However, $\mathrm{FFA}_{\text {late }}$, percentage decrease from onset to steady-state frequency ((f1 - fss)/f1), was only reduced compared with $\mathrm{vPMC}_{\text {nonlesion }}$ neurons in $\mathrm{vPMC}_{\mathrm{veh}}$ neurons, and not in $\mathrm{vPMC}_{\mathrm{EV}}$ neurons (ANOVA, main effect, $p=0.048$; Fisher's LSD post hoc, veh vs nonlesion, $p=0.02$; Fig. $2 I$ ). Thus, EV treatment appears to reduce lesion-related hyperexcitability in vPMC neurons, in part by increasing FFA late adaptation, and therefore lowering AP firing rates.

\section{EV treatment is associated with greater E:I synaptic current ratio}

In addition to membrane biophysical properties, network excitability and output of pyramidal neurons are shaped by excitatory and inhibitory synaptic inputs (for review, see Spruston, 2008). Thus, we compared the properties of EPSCs and IPSCs of vPMC $_{\text {nonlesion }}(n$ of neurons: $n=18$ EPSC, $n=19$ IPSC, from 2 monkeys), $\mathrm{vPMC}_{\mathrm{veh}}(n=37$ EPSC, $n=44$ IPSC from 4 monkeys), and $\operatorname{vPMC}_{\mathrm{EV}}(n=30$ EPSC, $n=30$ IPSC from 2 monkeys $)$ neurons.

$\mathrm{vPMC}_{\mathrm{veh}}$ and $\mathrm{vPMC}_{\mathrm{EV}}$ neurons from lesion brains showed significantly lower EPSC frequency compared with $\mathrm{vPMC}_{\text {nonlesion }}$ neurons (ANOVA main effect, $p=0.00000052$; Fisher's LSD post hoc, veh vs nonlesion, $p=0.0000001$; EV vs nonlesion $=0.0001$; Fig. $3 A, C$; Table 1). In contrast, IPSC frequency was greater in vPMC neurons from lesioned versus nonlesioned brains (ANOVA main effect, $p=0.048$, Fig. 3B,D; Table 1). Both $\mathrm{vPMC}_{\mathrm{veh}}$ (ANOVA, Fisher's LSD post hoc, $p=0.019$ ) and ${ }_{\text {vPMC }}$ EV neurons $(p=0.032)$ exhibited $\sim 3 \times$ increase in IPSC frequency relative to $\mathrm{vPMC}_{\text {nonlesion }}$ neurons, without differences in IPSC amplitude and kinetics (Fig. $3 B, D$ ). However, while no statistical differences between the treatment groups were found for both EPSC and IPSC properties, the measured values for $\mathrm{vPMC}_{\mathrm{EV}}$ neurons were consistently intermediate to $\mathrm{vPMC}_{\mathrm{veh}}$ neurons and $\mathrm{vPMC}_{\text {nonlesion }}$ neurons. Thus, we calculated the ratio of total excitatory to inhibitory charge transfer (E:I ratio) and found significant effects of both lesion and treatment. The E:I ratio was significantly lower in neurons from both lesion groups compared with $\mathrm{vPMC}_{\text {nonlesion }}$ neurons (ANOVA main effect, $p=0.000016$; Fisher's LSD post hoc, veh vs nonlesion, $p=0.000003 ; \mathrm{EV}$ vs nonlesion, $p=0.004$ ). However, this lesion-related difference was less pronounced in $\mathrm{PMC}_{\mathrm{EV}}$ compared with $\mathrm{vPMC}_{\mathrm{veh}}$ neurons (Fig. $3 E$ ). $\mathrm{vPMC}_{\mathrm{EV}}$ neurons had significantly greater E:I ratio compared with $\mathrm{vPMC}_{\mathrm{veh}}$ neurons (Fisher's LSD post hoc, $p=0.037$ ). In both

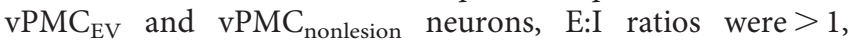

indicative of a predominance of excitation over inhibition (Fig. 3E). In contrast, mean E:I ratio of $\mathrm{vPMC}_{\mathrm{veh}}$ neurons was $<1$, hence showing a predominance of inhibition over excitation. Scatter plots of EPSC versus IPSC properties showed that $\mathrm{vPMC}_{\text {nonlesion }}$ neurons and the majority of the ${ }_{\mathrm{vPMC}} \mathrm{EV}$ neurons were scattered on the left side of the line representing $\mathrm{E}=\mathrm{I}$ frequency and total charge (Fig. $3 F$ ). In contrast, $\mathrm{vPMC}_{\mathrm{veh}}$ neurons were scattered closer to the $\mathrm{E}=\mathrm{I}$ line, with a substantial population scattered on the right side, dominated by inhibition (Fig. 3F, blue circles, left, right). These data suggest an overdominance of inhibition occurs after cortical injury, but EV treatment restores normative E:I balance in perilesional vPMC neurons.

\section{EV treatment is associated with greater apical dendritic complexity and $\mathrm{MAP2}^{+}$expression}

Plasticity after injury integrally involves dendritic remodeling and synapse turnover in surviving neural circuits (Brown et al., 2007; Kim et al., 2008; Gao et al., 2011; Ueno et al., 2012; for review, see Xiong et al., 2019). Thus, the effects of lesion and EV treatment on dendritic branching topology were assessed in $\mathrm{vPMC}_{\mathrm{EV}}$ ( $n=15$ neurons from 2 monkeys), $\mathrm{vPMC}_{\mathrm{veh}}(n=17$ from 4 monkeys), and $\mathrm{vPMC}_{\text {nonlesion }}(n=15$ neurons from 2 monkeys) pyramidal neurons intracellularly filled during recording (Fig. $4 A, B$ ). No significant differences were found among groups with regards to mean total dendritic length, branch nodes, and extents (Fig. 4C,D; Table 2). However, apical dendritic tufts exhibited significant lesion- and treatment-related changes (ANOVA main effect: number of nodes, $p=0.045$; nodes/ $\mu \mathrm{m}, p=0.0097)$. Specifically, $\mathrm{vPMC}_{\mathrm{veh}}$ neurons from vehicle-treated lesioned monkeys had less complex apical tufts compared with control nonlesion monkeys, with significantly lower number of apical tuft branch nodes compared with $\mathrm{vPMC}_{\text {nonlesion }}$ control neurons (Fisher's LSD post hoc; $p=0.04$; Fig. 4E). However, this lesion-related reduction of apical tuft complexity was ameliorated in EV-treated monkeys, with $\mathrm{vPMC}_{\mathrm{EV}}$ neurons not significantly different from nonlesion control monkeys. Importantly, $\mathrm{vPMC}_{\mathrm{EV}}$ neurons exhibited a significantly greater number (Fisher's LSD post hoc; $p=0.03$ ) and density $(p=0.003)$ of branch nodes in apical tufts compared with $\mathrm{vPMC}_{\mathrm{veh}}$ neurons (Fig. $4 E$ ). Further, Sholl analyses revealed a significant peak in dendritic length within distal apical segments, $480-500 \mu \mathrm{m}$ from the soma (ANOVA main effect, $p=0.003$, $0.01)$ of $\mathrm{vPMC}_{\mathrm{EV}}$ neurons relative to $\mathrm{vPMC}_{\mathrm{veh}}$ (Fisher's LSD post hoc, $p=0.001,0.0072$ ) and $\mathrm{vPMC}_{\text {nonlesion }}$ neurons (Fisher's LSD post hoc, $p=0.028,0.04$; Fig. $4 H$ ). Interestingly, $\mathrm{vPMC}_{\mathrm{EV}}$ neurons also exhibited significantly shorter main apical trunk lengths (ANOVA main effect, $p=0.015$; Fisher's LSD post hoc veh vs EV, $p=0.01$; Fig. $4 F$ ) and more complex apical obliques (ANOVA main effect, $p=0.00007$; number of nodes $/ \mu \mathrm{m} ; p=0.00003$; Fig. $4 G)$ compared with $\mathrm{vPMC}_{\text {vehneurons. }}$ Basal arbors were similar in topology, length, and extents among groups (Fig. 4C,D,I; Table $2)$. These data show that EV treatment is associated with an elaboration of apical tuft and oblique compartments of vPMC pyramidal neurons after lesion in $\mathrm{M} 1$, indicative of recoveryassociated dendritic remodeling. Thus, we assessed whether these changes in dendritic arbor complexity are also associated with differences in MAP2, a microtubule-associated protein known to be destabilized and altered after neuronal injury (Dawson and Hallenbeck, 1996; Y. Li et al., 1998; G. L. Li et al., 2000). Optical density of analyses revealed a significantly lower density (percent area labeled; ANOVA main effect, $p=0.01$ ) and smaller size (pixel area, ANOVA main effect, $p=0.039$ ) of $\mathrm{MAP}^{+}$ 
A

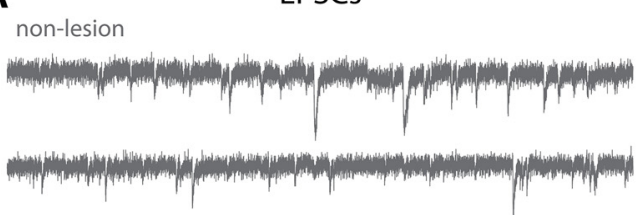

lesion+vehicle

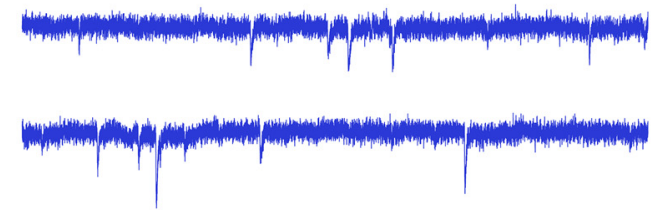

lesion+EV
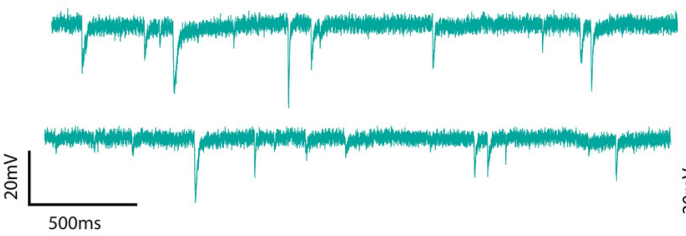

B

non-lesion

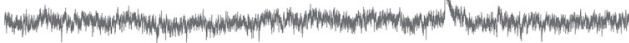

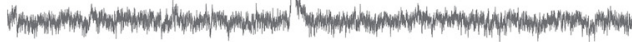

lesion+vehicle

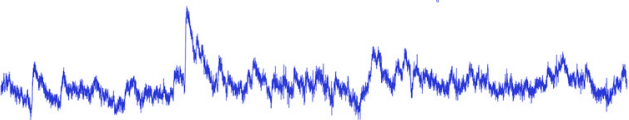

lesion+EV

Mum 享

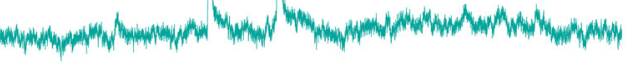

C ESPC Freq EPSC Amp ESPCArea

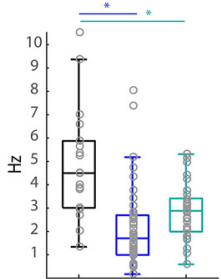

D

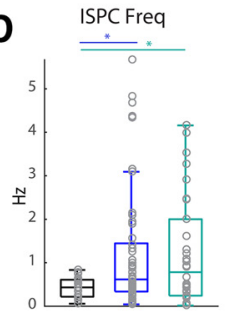

$\mathbf{F}$

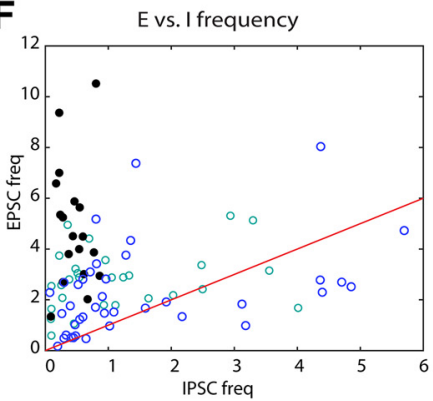

IPSCamp
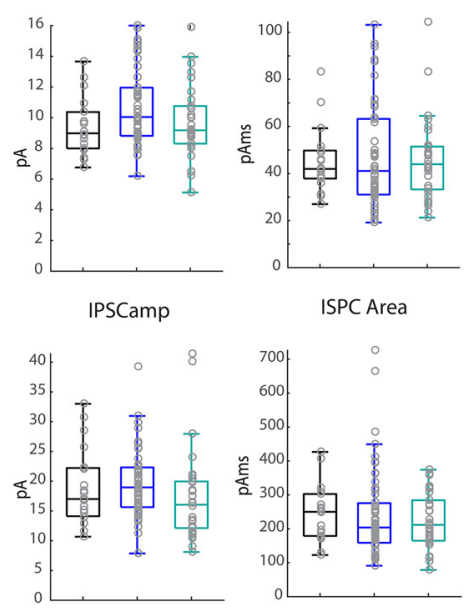

ISPC Area
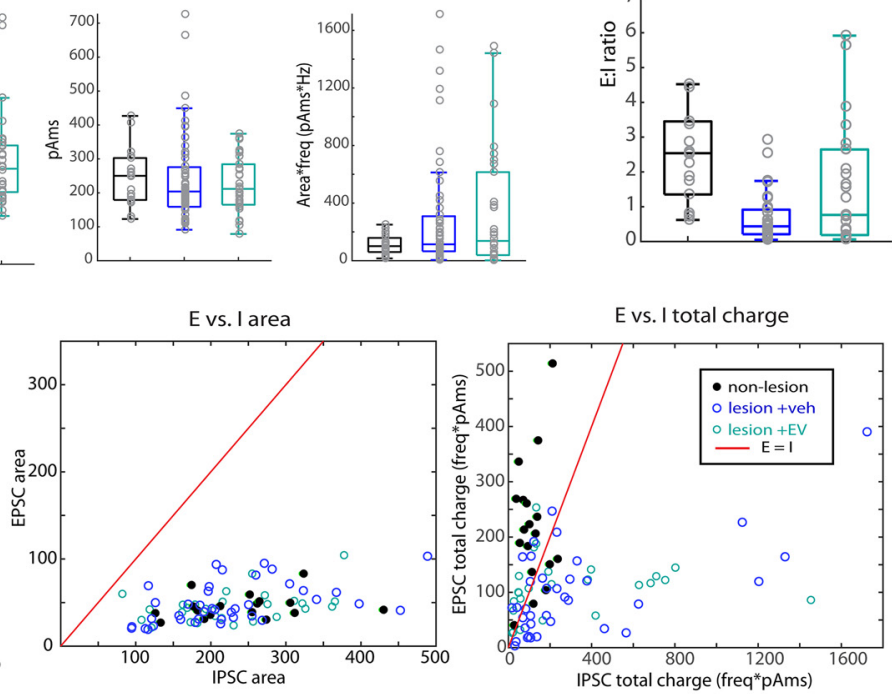

non-lesion

lesion +EV

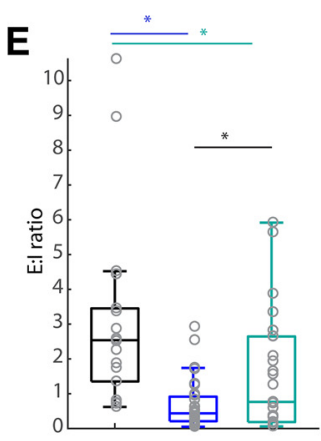

Figure 3. Reduced EPSCs and increased IPSCS in perilesional vPMC neurons. $A$, Representative traces of ESPCs $\left(V_{\text {hold }}-80 \mathrm{mV}\right)$ recorded in voltage clamp from vPMC $C_{\text {nonlesion }}(n=18$ neurons from 2 monkeys), $\mathrm{vPMC}_{\text {veh }}\left(n=37\right.$ from 4 monkeys), and $\mathrm{VPMCEV}$ ( $n=30$ from 2 monkeys) layer 3 pyramidal neurons. $\boldsymbol{B}$, Representative traces of IPSCS ( $\left.V_{\text {hold }}-40 \mathrm{mV}\right)$ recorded in voltage clamp from $\mathrm{vPMC}_{\text {nonlesion }}\left(n=19\right.$ neurons from 2 monkeys), $\mathrm{vPMC}_{\mathrm{veh}}\left(n=44\right.$ from 4 monkeys), and $\mathrm{vPMC}_{\mathrm{Ev}}(n=30$ from 2 monkeys) layer 3 pyramidal neurons. $C$, Box-and-whisker plots and vertical scatter plots of individual cells of EPSC properties: ESPC frequency (ANOVA Fisher's LSD post hoc, veh vs nonlesion, $p=0.0000001$; EV vs nonlesion $=0.0001$ ), EPSC amplitude, EPSC area, and EPSC total charge (frequency $\times$ area; Fisher's LSD post hoc, veh vs nonlesion, $p=0.00,008$; EV vs nonlesion $=0.000001$ ). $\boldsymbol{D}$, Box-and-whisker plots and vertical scatter plots of individual cells of ISPC properties: IPSC frequency (Fisher's LSD post hoc, veh vs nonlesion, $p=0.019$; EV vs nonlesion, $p=0.032$ ), IPSC amplitude, IPSC area, and IPSC total charge (frequency $\times$ area). $\boldsymbol{E}$, The estimated E:I ratio based on the frequency and mean area of each cell (Fisher's LSD post hoc, veh vs nonlesion, $p=0.000003 ; \mathrm{EV}$ vs nonlesion, $p=0.004 ; \mathrm{EV}$ vs veh $p=0.037$ ). $\boldsymbol{F}$, Scatter plots showing the relative distribution of neurons from each group based on the relationship of excitatory and inhibitory properties: frequency, area, and total charge. Red line in each plot indicates the linear relationship where $\mathrm{E}=\mathrm{I}$. EPSC total charge dominates IPSC total charge in $\mathrm{VPMC}_{\text {nonlesion }}$ neurons, mainly due to $\mathrm{E}-\mathrm{I}$ difference in frequency. VPMC $\mathrm{veh}_{\text {neurons }}$ exhibit a significant proportion with greater IPSC frequency and total charge than EPSC. Compared with $\mathrm{VPMC}_{\text {veh }}$ neurons, $\mathrm{VPMC}_{\mathrm{EV}}$ neurons are distributed closer to $\mathrm{vPMC}_{\text {nonlesion, }}$ with most neurons exhibiting greater excitatory than inhibitory tone, some scattered close to the $E=I$ line, and very few below the $E=I$ line. 

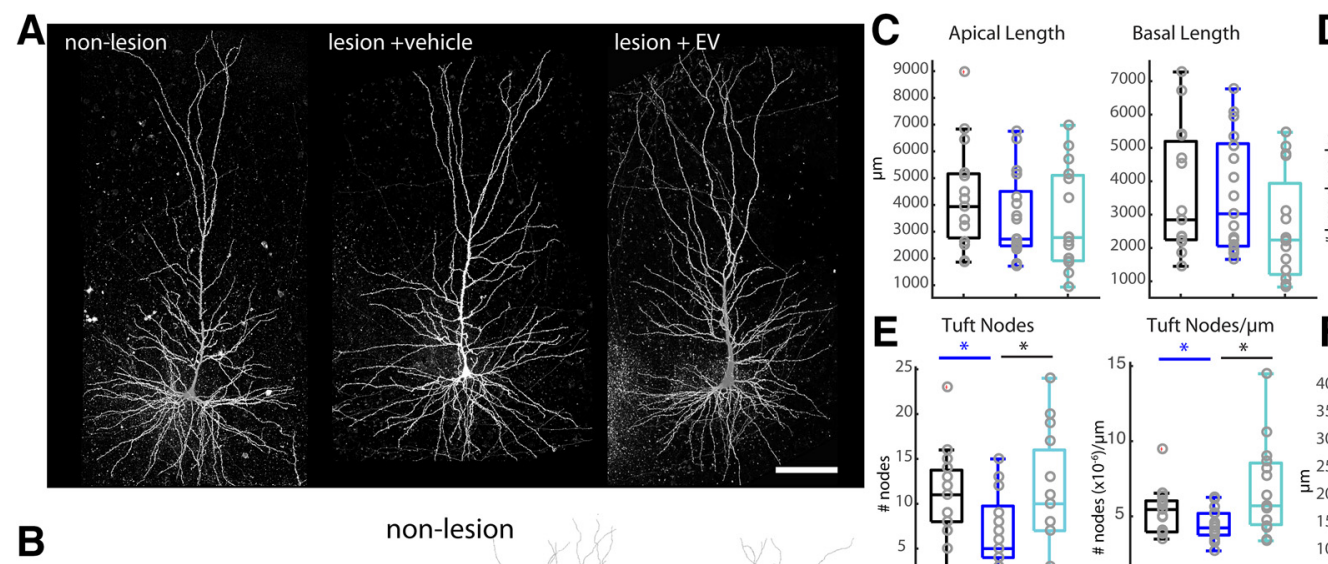

D Apical Nodes Basal Nodes
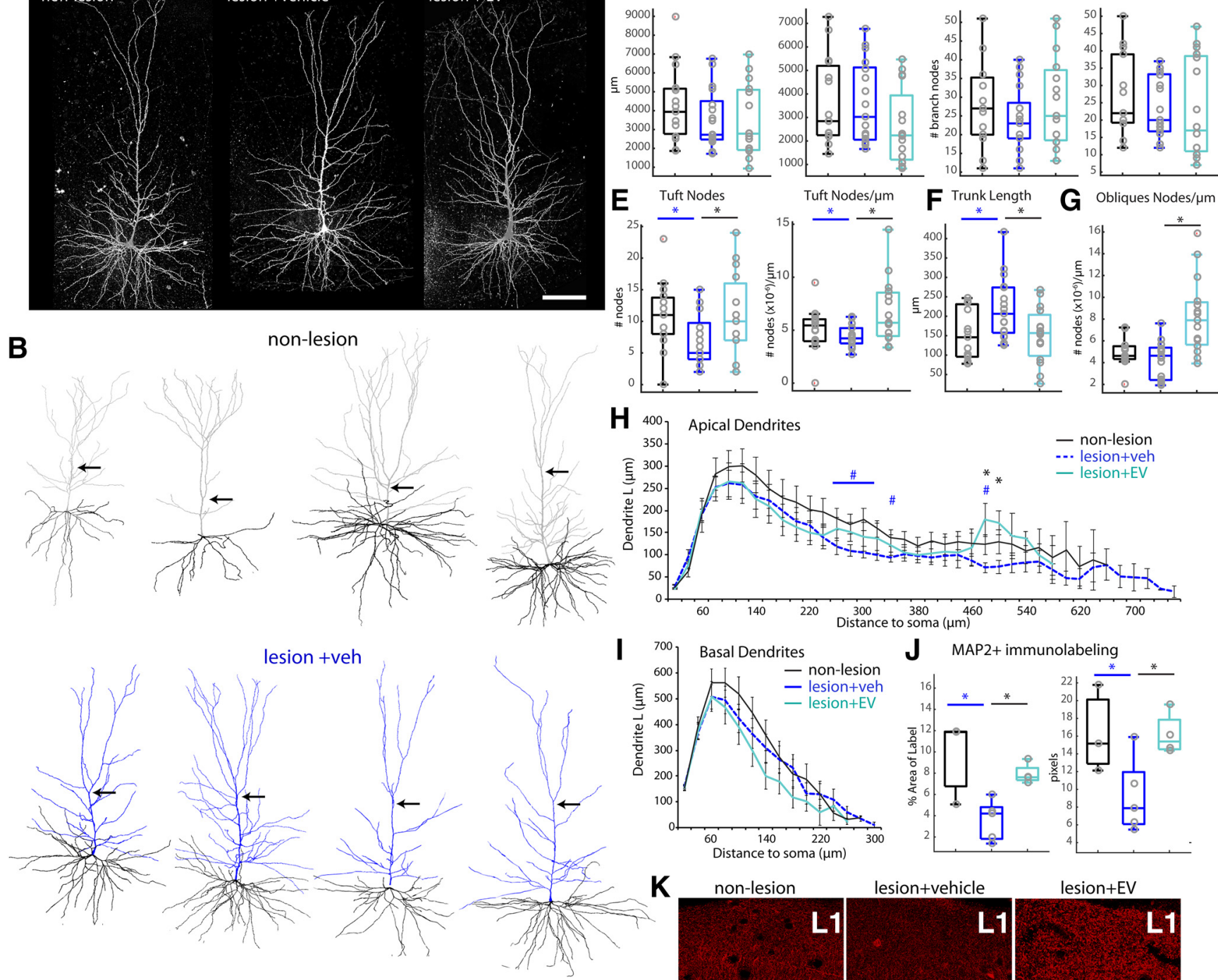

lesion $+\mathrm{EV}$
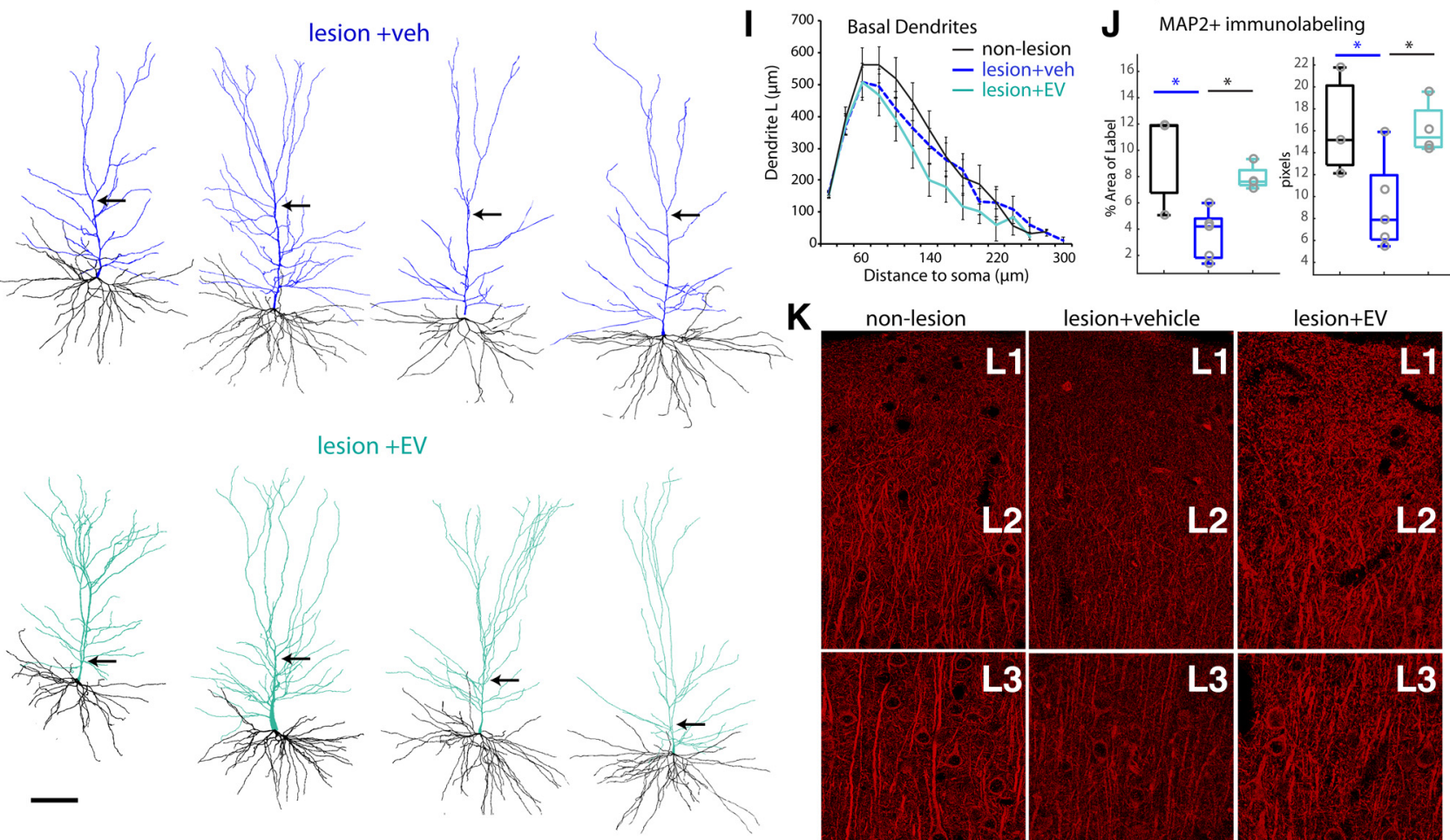

\section{K}
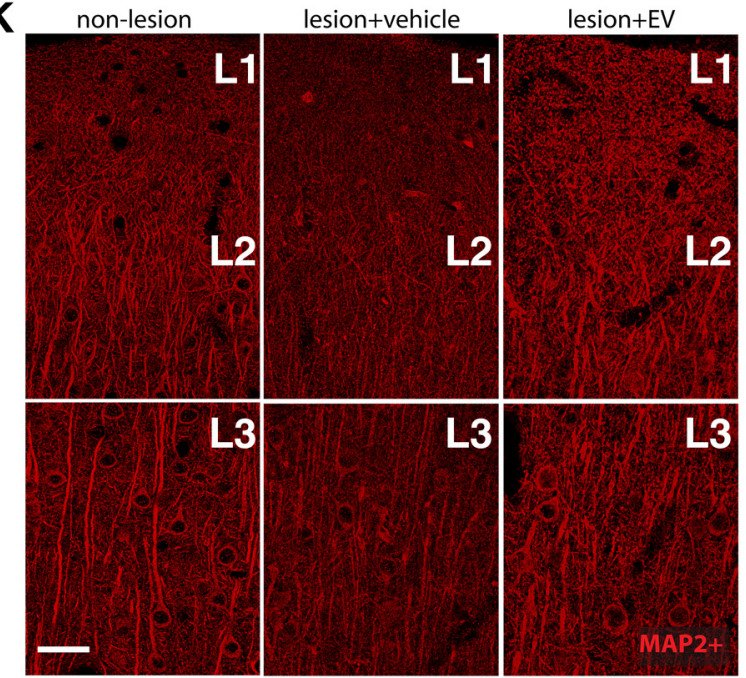

lesion+vehicle

lesion+EV

Figure 4. EV treatment increases apical dendrite complexity and MAP2 expression in perilesional vPMC. $A, x-y$ maximum projections of confocal image stacks of representative L3 VPMC pyramidal neurons. $\boldsymbol{B}$, Representative 3D reconstructions of $\mathrm{VPMC}_{\text {nonlesion }}\left(n=15\right.$ neurons from 2 monkeys), $\mathrm{VPMC}_{\mathrm{veh}}(n=17$ from 4 monkeys), and $\mathrm{VPMC}$ ( $n=15$ from 2 monkeys) layer 3 pyramidal neurons. Note the point where the main apical trunk branches into an apical tuft. $\mathbf{C}-\mathbf{G}$, Box-and-whisker plots and vertical scatter plots of dendritic morphologic outcome measures of individual neurons: $(\boldsymbol{C}$ apical and basal dendritic length and $(\boldsymbol{D})$ branch nodes; $(\boldsymbol{E})$ morphologic properties of apical tufts: apical tuft branch nodes and nodes/length. $\boldsymbol{F}$, Main apical trunk length. $\boldsymbol{G}$, Apical oblique dendrites nodes/length. $\boldsymbol{H}$, Sholl analyses of mean apical dendritic length length (ANOVA main effect, 280, 480, 500 $\mu$ m, $p=0.029,0.003,0.01$; Fisher's LSD post hoc: ${ }^{*}$ EV vs veh, $p<0.013$; " veh vs nonlesion, $p<0.04$ ). I, Sholl analyses of mean basal dendritic length. J, Box-and-whisker plots and vertical scatter plots of percent area labeled and average particle size of MAP2 ${ }^{+}$immunolabel in VPMC. Multiple comparisons were done between animals (lesion EV-treated, $n=4$; lesion vehicle-treated, $n=5$; nonlesion control, $n=3$; ANOVA Fisher LSD post hoc, $p<0.05)$. $\boldsymbol{K}$, Maximum projection of confocal image stacks showing MAP2 ${ }^{+}$immunolabel in layers 1 (L1), 2 (L2), and 3 (L3) of vPMC. Scale bars: $A, B, K, 100 \mu \mathrm{m}$. 
Table 2. Morphologic properties of vPMC layer 3 pyramidal neurons

\begin{tabular}{|c|c|c|c|c|c|c|c|}
\hline & Nonlesion & Vehicle & EV & ANOVA & $\begin{array}{l}\text { Nonlesion } \\
\text { versus vehicle }\end{array}$ & $\begin{array}{l}\text { EV versus } \\
\text { nonlesion }\end{array}$ & $\begin{array}{l}\text { EV versus } \\
\text { vehicle }\end{array}$ \\
\hline \multicolumn{8}{|l|}{ Apical dendritic morphology } \\
\hline Dendritic length $(\mu \mathrm{m})$ & $4308.8 \pm 525.9$ & $3542.2 \pm 389.7$ & $3471.7 \pm 509.5$ & 0.375 & 0.913 & 0.238 & 0.212 \\
\hline Vertical extent ( $\mu \mathrm{m})$ & $497.8 \pm 34.6$ & $551.9 \pm 29.1$ & $433.3 \pm 41.2$ & 0.055 & 0.017 & 0.254 & 0.190 \\
\hline Tuft Hor extent $(\mu \mathrm{m})$ & $243.2 \pm 11.4$ & $183.6 \pm 22.1$ & $199.8 \pm 20.9$ & 0.065 & 0.535 & 0.024 & 0.105 \\
\hline Obliques Hor extent $(\mu \mathrm{m})$ & $283.9 \pm 28.7$ & $298.1 \pm 22.1$ & $230.5 \pm 29.1$ & 0.165 & 0.070 & 0.693 & 0.155 \\
\hline Distal apical L $(\mu \mathrm{m})$ & $1042.0 \pm 121.3$ & $745.4 \pm 75.2$ & $904.3 \pm 135.3$ & 0.139 & 0.285 & 0.049 & 0.380 \\
\hline No. of obliques & $7.7 \pm 1.0$ & $8.4 \pm 0.6$ & $6.6 \pm 0.7$ & 0.217 & 0.083 & 0.478 & 0.304 \\
\hline Obliques length $(\mu \mathrm{m})$ & $2105.7 \pm 412.5$ & $1783.4 \pm 235.0$ & $1498.7 \pm 299.1$ & 0.400 & 0.512 & 0.458 & 0.178 \\
\hline Obliques no. of nodes & $9.9 \pm 1.9$ & $8.2 \pm 1.4$ & $10.5 \pm 2.0$ & 0.612 & 0.342 & 0.499 & 0.788 \\
\hline Obliques no. of nodes $/ \mu \mathrm{m}$ & $0.0050 \pm 0.0004$ & $0.0044 \pm 0.0005$ & $0.0083 \pm 0.0009$ & 0.00007 & 0.00003 & 0.444 & 0.001 \\
\hline Trunk length $(\mu \mathrm{m})$ & $153.1 \pm 17.6$ & $219.8 \pm 19.8$ & $151.9 \pm 19.2$ & 0.015 & 0.012 & 0.013 & 0.963 \\
\hline Dendritic length $(\mu \mathrm{m})$ & $3676.7 \pm 493.7$ & $3595.4 \pm 432.6$ & $2608.5 \pm 410.8$ & 0.162 & 0.107 & 0.895 & 0.091 \\
\hline No. of nodes & $27.3 \pm 3.2$ & $23.6 \pm 2.2$ & $23.2 \pm 3.7$ & 0.574 & 0.912 & 0.387 & 0.338 \\
\hline Vertical extent $(\mu \mathrm{m})$ & $237.9 \pm 21.2$ & $259.8 \pm 20.1$ & $204.0 \pm 18.0$ & 0.135 & 0.047 & 0.417 & 0.241 \\
\hline Horizontal extent $(\mu \mathrm{m})$ & $347.0 \pm 24.9$ & $317.7 \pm 27.1$ & $276.6 \pm 25.8$ & 0.180 & 0.258 & 0.409 & 0.066 \\
\hline Proximal basal L $(\mu \mathrm{m})$ & $1629.2 \pm 242.9$ & $1399.6 \pm 184.3$ & $1099.2 \pm 169.1$ & 0.209 & 0.294 & 0.407 & 0.079 \\
\hline Mid basal L $(\mu \mathrm{m})$ & $1654.3 \pm 218.6$ & $1412.3 \pm 205.6$ & $1192.5 \pm 190.0$ & 0.364 & 0.513 & 0.397 & 0.159 \\
\hline Distal basal L $(\mu \mathrm{m})$ & $407.6 \pm 76.4$ & $434.2 \pm 79.2$ & $366.9 \pm 74.6$ & 0.867 & 0.596 & 0.805 & 0.788 \\
\hline \multicolumn{8}{|c|}{ Spine density (no. of spines/ $\mu \mathrm{m}$ length) } \\
\hline Proximal apical & $0.928 \pm 0.126$ & $0.916 \pm 0.130$ & $1.162 \pm 0.112$ & 0.294 & 0.162 & 0.946 & 0.181 \\
\hline Mid apical & $1.050 \pm 0.114$ & $0.835 \pm 0.091$ & $1.243 \pm 0.122$ & 0.034 & 0.010 & 0.141 & 0.204 \\
\hline Distal apical & $0.639 \pm 0.079$ & $0.492 \pm 0.046$ & $0.918 \pm 0.088$ & 0.001 & 0.0002 & 0.130 & 0.008 \\
\hline Proximal basal & $0.487 \pm 0.090$ & $0.369 \pm 0.073$ & $0.408 \pm 0.091$ & 0.591 & 0.765 & 0.332 & 0.496 \\
\hline Distal apical spine & $0.045 \pm 0.010$ & $0.027 \pm 0.005$ & $0.070 \pm 0.024$ & 0.095 & 0.031 & 0.337 & 0.195 \\
\hline Proximal basal shaft & $0.156 \pm 0.025$ & $0.145 \pm 0.028$ & $0.139 \pm 0.015$ & 0.473 & 0.234 & 0.424 & 0.674 \\
\hline Mid basal shaft & $0.112 \pm 0.020$ & $0.139 \pm 0.037$ & $0.116 \pm 0.015$ & 0.032 & 0.017 & 0.030 & 0.765 \\
\hline Distal basal shaft & $0.102 \pm 0.016$ & $0.149 \pm 0.045$ & $0.194 \pm 0.045$ & 0.024 & 0.007 & 0.137 & 0.166 \\
\hline Proximal basal spine & $0.032 \pm 0.007$ & $0.019 \pm 0.012$ & $0.040 \pm 0.008$ & 0.169 & 0.167 & 0.641 & 0.071 \\
\hline Mid basal spine & $0.047 \pm 0.009$ & $0.078 \pm 0.023$ & $0.094 \pm 0.016$ & 0.128 & 0.048 & 0.501 & 0.172 \\
\hline Distal basal spine & $0.061 \pm 0.009$ & $0.070 \pm 0.030$ & $0.120 \pm 0.043$ & 0.096 & 0.034 & 0.453 & 0.149 \\
\hline
\end{tabular}

immunolabeling in layers 1-3 of perilesional vPMC (area 6Va/ F5) in vehicle-treated lesioned monkeys ( $n=5$ monkeys) compared with both EV-treated lesioned ( $n=4$ monkeys; Fisher's LSD post hoc $\%$ area, $p=0.02$; average size, $p=0.03$ ) and nonlesioned control monkeys ( $n=3$ monkeys; Fisher's LSD post hoc $\%$ area, $p=0.006$, average size, $p=0.026$; Fig. $4 J, K)$. In contrast, EVtreated monkeys exhibited no significant differences in $\mathrm{MAP}^{+}$ labeling in vPMC compared with nonlesioned control monkeys. These data suggest that EV treatment either reduced initial dendritic damage or stimulated dendritic remodeling in vPMC after cortical injury in M1.

\section{EV treatment is associated with greater excitatory and inhibitory inputs on apical dendrites}

Consistent with an elaboration of apical dendrites, we found significantly greater mean densities of dendritic spines, the major sites of excitatory inputs, specifically on apical dendrites of $\mathrm{vPMC}_{\mathrm{EV}}$ neurons ( $n=11$ neurons from 2 monkeys) compared with $\mathrm{vPMC}_{\mathrm{veh}}\left(n=12\right.$ from 4 monkeys) and $\mathrm{vPMC}_{\text {nonlesion }}$ neurons ( $n=11$ neurons from 2 monkeys; ANOVA main effect, $p=0.02$; Fisher's LSD post hoc, EV vs veh $p=0.00962$; EV vs nonlesion $p=0.049$; Fig. $5 A-C$ ). This difference in apical spine density was mainly due to significantly greater densities of stubby spines (ANOVA main effect, $p=0.0016$; Fisher's LSD post hoc EV vs veh, $p=0.04$; vs nonlesion, $p=0.0004$ ) and filopodia (ANOVA main effect, $p=0.04$; Fisher's LSD post hoc EV vs veh, $p=0.02$; vs nonlesion, $p=0.03$ ) on $\mathrm{vPMC}_{\mathrm{EV}}$ neurons (Fig. $5 B, C$ ). Sholl analyses of spine density show that greater densities of spines on $\mathrm{VPMC}_{\mathrm{EV}}$ neurons were found mainly on middle to distal segments, $\sim 340-580 \mu \mathrm{m}$ from the soma (ANOVA main effect, $p<0.04$ for all significantly different comparisons; Fig. $5 D)$. Interestingly, this pattern was consistent across all subtypes, except for stubby spines, which had the greater densities in both 

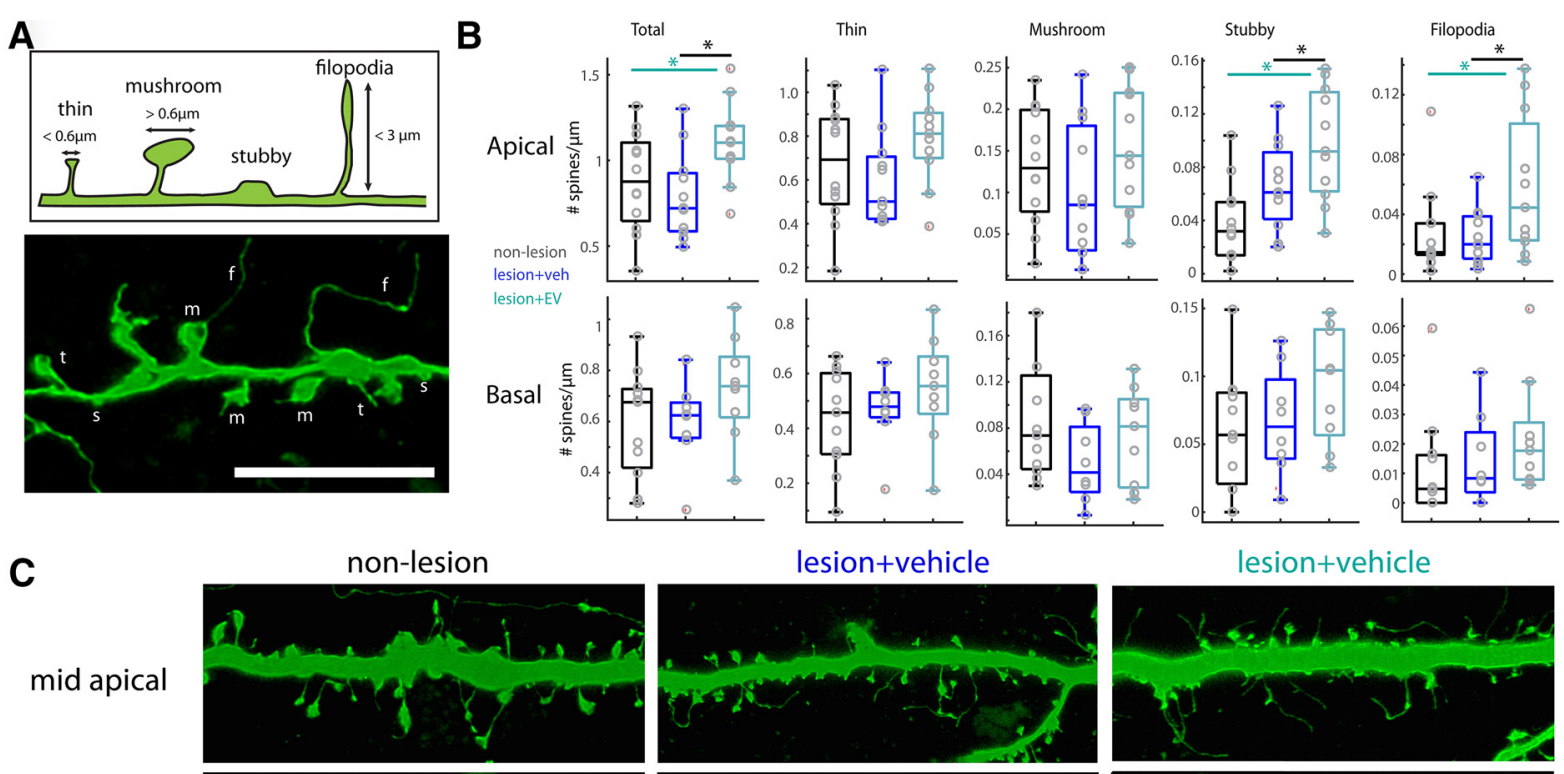

distal apical
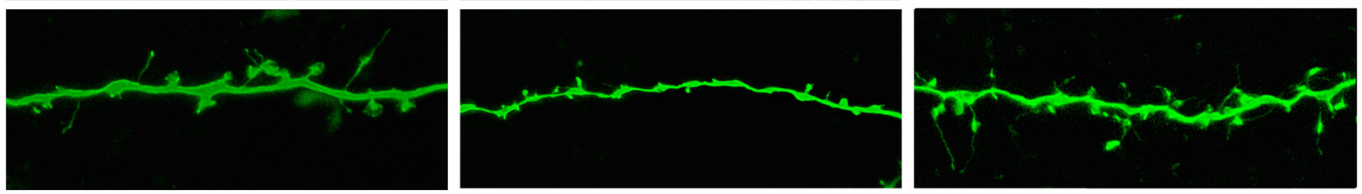

basal
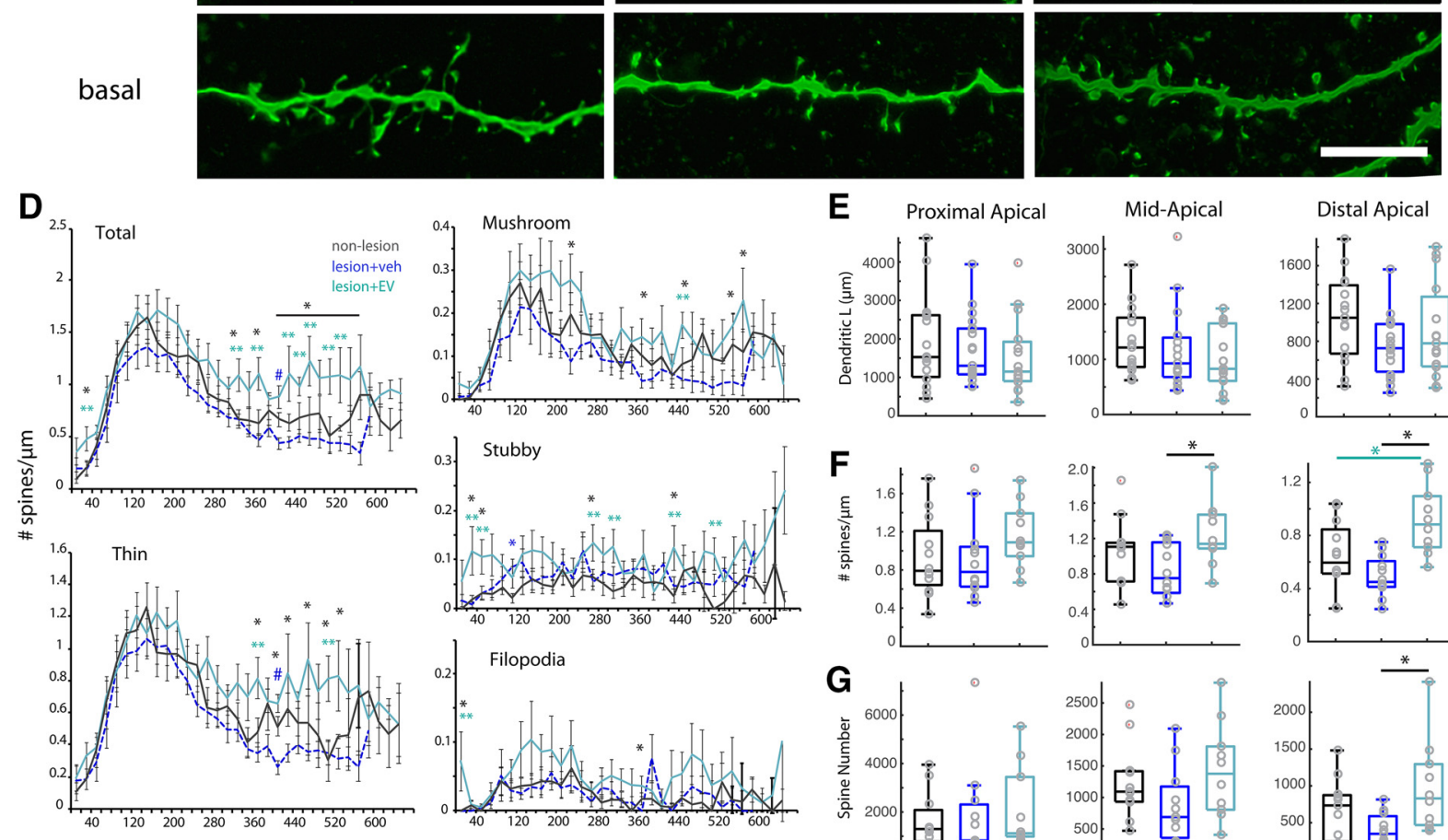

\section{E}
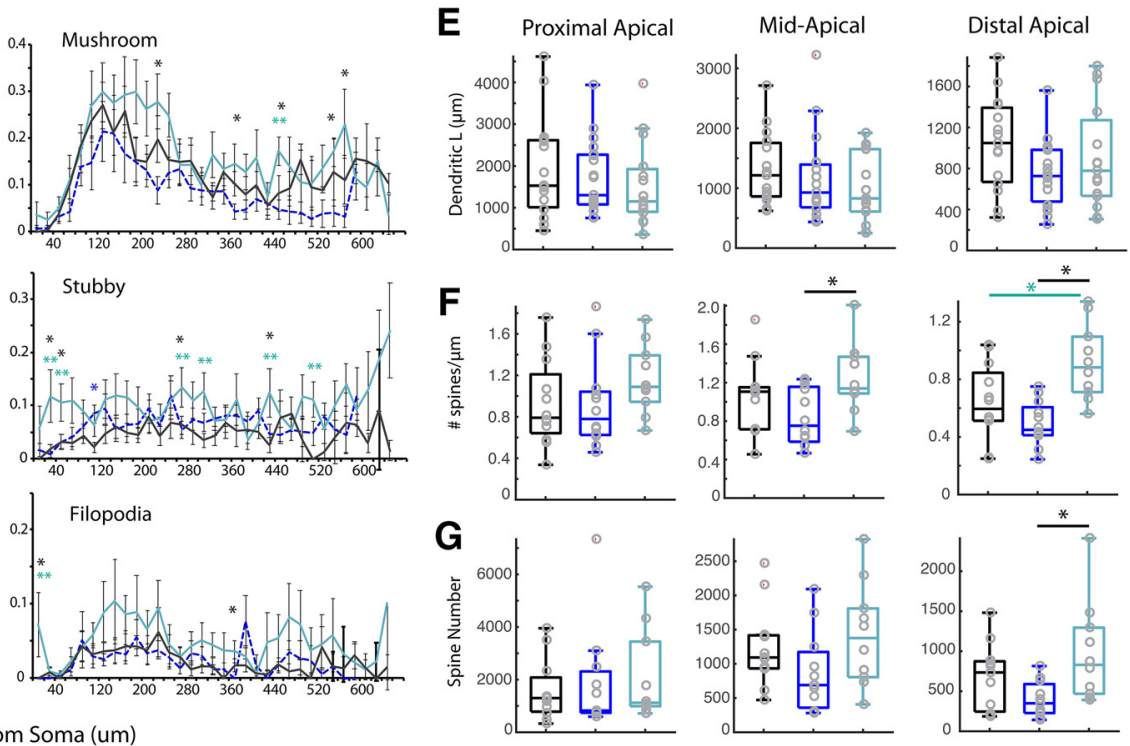

Figure 5. EV treatment increases spine density on apical dendrites of perilesional vPMC neurons. A, Schematic of spine classification criteria (top) and representative confocal $z$-maximum projection image (bottom) of spine subtypes ( $\mathrm{t}$, Thin; $\mathrm{m}$, mushroom; $\mathrm{s}$, stubby; $\mathrm{f}$, filopodia). $\boldsymbol{B}$, Box-and-whisker and vertical scatter plots of spine density (total spines and by subtype) in apical and basal dendrites of individual $\mathrm{vPMC}_{\text {nonlesion }}\left(n=11\right.$ neurons from 2 monkeys), $\mathrm{VPMC}_{\text {veh }}\left(n=12\right.$ from 4 monkeys), and $\mathrm{VPMC}_{\mathrm{EV}}(n=11$ from 2 monkeys) layer 3 pyramidal neurons. $C$, Representative confocal z-maximum projection images of mid apical, distal apical, and basal dendritic segments. $\boldsymbol{D}$, Sholl analyses of mean total spine density and spine density by subtype at each $20 \mu \mathrm{m}$ incremental proximal to distal distance from the soma, along the extent of a subsampled apical dendritic segment from each neuron. Total spine density (ANOVA main effect, 40, $340,380 \mu \mathrm{m}, p<0.03 ; 420-580 \mu \mathrm{m}, p<0.04$; Fisher's LSD post hoc, *EV vs veh, $p<0.02$; " veh vs nonlesion $420 \mu \mathrm{m}, p=0.03$; **EV vs nonlesion, $p<0.045$ ). Thin spine density (ANOVA main effect, 380, 420, 440,480, 520,540 $\mu \mathrm{m}, p<0.04$; Fisher's LSD post hoc, *EV vs veh, $p<0.01$; "veh vs nonlesion $420 \mu \mathrm{m}, p=0.001$; **EV vs nonlesion $380520 \mu \mathrm{m}, p=0.017,0.005$ ). Stubby spine density (ANOVA main effect, 40,60, 120, 280, 320, 440,520 $\mu \mathrm{m}, p<0.048$; Fisher's LSD post hoc, ${ }^{*}$ EV vs veh, $p<0.02$; ${ }^{*}$ EV vs nonlesion $p<0.03$ ). Mushroom spine density (ANOVA main effect, 240, 380, 460, 560, $580 \mu \mathrm{m}, p<0.04$; Fisher's LSD post hoc, *EV vs veh, $p<0.016$; **EV vs nonlesion $460 \mu \mathrm{m}, p=0.04$ ). Filopodia spine density (ANOVA main effect, $20,380 \mu \mathrm{m}, p<0.03$; Fisher's LSD post hoc. ${ }^{*} \mathrm{EV}$ vs veh, $p<0.02$ ). $\boldsymbol{E}$, Total dendritic length, $(\boldsymbol{F})$ spine density, and $(\boldsymbol{G})$ estimated spine number (total dendritic length $\times$ spine density) in the proximal, middle, and distal thirds of apical dendrites, normalized by total length. Scale bars: $A, C, 10 \mu \mathrm{m}$. 
proximal (ANOVA main effect, 40, $60 \mu \mathrm{m} ; p=0.007,0.03$ ), and distal $(280,440 \mu \mathrm{m} ; p=0.038,0.048)$ apical segments of $\mathrm{vPMC}_{\mathrm{EV}}$ neurons compared with $\mathrm{vPMC}_{\mathrm{veh}}$ (Fisher's LSD post hoc, 40, 60, $280,440 \mu \mathrm{m} ; p=0.003,0.018,0.019,0.043)$ and $\mathrm{vPMC}_{\text {nonlesion }}$ neurons $(40,60,280,440 \mu \mathrm{m} ; p=0.007,0.017,0.032$, 0.023; Fig. $5 D)$. We further analyzed spine distribution by normalizing dendritic lengths for each neuron into proximal, middle, and distal apical thirds, and calculated spine density and extrapolated total spine numbers within each of these compartments (Fig. 5E-G). Consistent with Sholl analyses, we found greater total spine density on the middle (ANOVA main effect, $p=0.03$ ) and distal third $(p=0.00061)$ compartments of apical dendrites of $\mathrm{vPMC}_{\mathrm{EV}}$ neurons compared with $\mathrm{vPMC}_{\mathrm{veh}}$ (Fisher's LSD post hoc EV vs veh: middle, $p=0.01$; distal, $p=0.00,015)$ and $\mathrm{vPMC}_{\text {nonlesion }}(\mathrm{EV}$ vs nonlesion, distal, $p=0.008$ ) neurons (Fig. $5 F$ ). A similar pattern was found for estimated spine number along the distal apical third compartment, with $\mathrm{vPMC}_{\mathrm{EV}}$ neurons exhibiting significantly greater spine number than $\mathrm{vPMC}_{\mathrm{veh}}$ neurons (ANOVA main effect, $p=0.021$, Fisher's LSD post hoc EV vs veh, $p=0.006$; EV vs nonlesion; Fig. $5 G$ ).

Consistent with greater apical spine densities, ${ } P M C_{E V}$ neurons also exhibited a significantly greater total density of $\mathrm{VGAT}^{+}$appositions (putative inhibitory inputs) especially on apical dendritic spines (ANOVA main effect, $p=0.007$ ) compared with $\mathrm{vPMC}_{\mathrm{veh}}$ (Fisher's LSD post hoc, $p=0.006$ ) and $\mathrm{vPMC}_{\text {nonlesion }}$ neurons $(p=0.006$; Fig. $6 A, C)$. Sholl analyses revealed that, compared with $\mathrm{vPMC}_{\mathrm{veh}}$ neurons, $\mathrm{vPMC}_{\mathrm{EV}}$ neurons exhibited significantly greater total densities of $\mathrm{VGAT}^{+}$ appositions within the most proximal $20 \mu \mathrm{m}$ from the soma, and within the distal $300-480 \mu \mathrm{m}$ from the soma (ANOVA main effect, 20,300,320, 340, 420, $480 \mu \mathrm{m} ; p=0.001,0.03,0.02,0.02$, 0.04, 0.01; Fisher's LSD post hoc, EV vs veh, $p=0.001,0.009$, $0.008,0.006,0.01,0.004$; Fig. $6 F$, top). Further analyses of apical compartments normalized to total dendritic length showed that the proximal apical third of $\mathrm{vPMC}_{\mathrm{EV}}$ neurons exhibited a significantly greater density of $\mathrm{VGAT}^{+}$appositions on spines (ANOVA main effect, $p=0.02$ ) and shafts (ANOVA main effect, $p=0.049$ ) compared with $\mathrm{vPMC}_{\mathrm{veh}}$ neurons (Fisher's LSD post hoc on spines, $p=0.02$, on shaft $p=0.015$; Fig. 6G; Table 2). Within the normalized middle and distal apical compartments, $\mathrm{VGAT}^{+}$appositions on shafts were also significantly greater in $\mathrm{vPMC}_{\mathrm{EV}}$ neurons compared with $\mathrm{vPMC}_{\mathrm{veh}}$ neurons (ANOVA main effect, middle, $p=0.009$; distal, $p=0.005$; Fisher's LSD post hoc, $\mathrm{EV}$ vs veh middle, $p=0.007$; distal, $p=0.001$ ). In addition, $\mathrm{vPMC}_{\mathrm{veh}}$ neurons exhibited a significantly lower density of VGAT $^{+}$appositions on shafts within these segments compared with $\mathrm{vPMC}_{\text {nonlesion }}$ control neurons (veh vs nonlesion middle, $p=0.008$; distal, $p=0.04$; Fig. $6 G$ ). These data are indicative of a lesion-related decrease in $\mathrm{VGAT}^{+}$apposition density within middle-distal segments that are normalized in $\mathrm{vPMC}_{\mathrm{EV}}$ neurons, which did not differ significantly from control $\mathrm{vPMC}_{\text {nonlesion }}$ neurons. In contrast to apical dendrites, where the majority of $\mathrm{VGAT}^{+}$appositions are located (Fig. 6E), $\mathrm{VGAT}^{+}$appositions on basal dendrites (Table 2) and somata did not differ across groups (Fig. 6B,D). These data show that EV treatment is associated with an upregulation of apical dendritic inhibition predominantly on spines, and an amelioration of lesion-related loss of $\mathrm{VGAT}^{+}$input on middle-distal apical compartments, which can contribute to the filtering of increased excitatory input on ${ }_{\text {vPMC }}$ neurons.

EV treatment is associated with greater c-fos ${ }^{+}$activation of dendritic-targeting inhibitory neurons

Greater inhibitory inputs on apical dendrites, especially on spines, of $\mathrm{vPMC}_{\mathrm{EV}}$ neurons, suggest that the $\mathrm{EV}$ - and vehicle- treated lesion brains likely differ in inhibitory neurons expressing $\mathrm{CR}, \mathrm{PV}$, and CB, which target distinct somatodendritic compartments of pyramidal neurons (for review, see DeFelipe, 1997). Thus, in layers 2-3 of vPMC of vehicle-treated $(n=5)$ versus EVtreated $(n=5)$ lesion monkeys, we assessed the overlap of inhibitory cell markers with c-fos (Fig. 6G-J), an immediate early gene transcription factor that peaks 1-4 h after the onset of neuronal activation (Dragunow and Faull, 1989; Hoffman et al., 1993; Rosene et al., 2004; for review, see Kovacs, 2008). A previous study from our group showed that $\mathrm{c}-\mathrm{fos}^{+}$cells are upregulated in $\mathrm{vPMC}, 3 \mathrm{~h}$ after performance on the HDT, and is correlated with recovery of function (Orczykowski et al., 2018). Here we assessed c-fos expression in the dorsal-rostral part of vPMC (adjacent to the extracted biopsy), which corresponded to vPMC area 6Va of (Barbas and Pandya, 1987; Morecraft et al., 2004, 2019), area F5 of (Matelli and Luppino, 1996; Rizzolatti et al., 1998), and the "hand and grasp" area PMv of (Dum and Strick, 2002; Kaas et al., 2012), which is involved in hand movement (Fig. 1B).

While there were no differences in the density and proportion of $\mathrm{PV}^{+}, \mathrm{CB}^{+}$, or $\mathrm{CR}^{+}$neurons between groups (data not shown) EV-treated brains exhibited a greater density of $\mathrm{c}-\mathrm{fos}^{+}$neurons in layers 2-3 of vPMC compared with vehicle-treated brains $(n=5 \mathrm{EV}, n=5$ vehicle, paired $t$ test, $p=0.047$; Fig. $6 H, I)$. The majority of these $\mathrm{c}^{-}$fos $^{+}$neurons were co-labeled with either $\mathrm{CB}^{+}$or $\mathrm{CR}^{+}$, or were unlabeled for inhibitory markers, and were likely excitatory (Fig. $6 H, K$ ). There was a significantly greater density ( $t$ test, $p=0.0032$; Fig. $6 J$ ) and proportion $(p=0.0019$; Fig. $6 \mathrm{~K}$ ) of $\mathrm{CB}^{+} / \mathrm{c}$-fos ${ }^{+}$neurons in EV-treated compared with vehicle-treated monkeys (Fig. $6 J, K$ ). These findings show that, compared with vehicle-treated brains, EV-treated brains exhibited a greater degree of $\mathrm{c}$-fos ${ }^{+}$activation predominantly of distal dendrite and spine-targeting $\mathrm{CB}^{+}$inhibitory neurons during the HDT.

\section{EV treatment is associated with a shift in vPMC pyramidal neuron properties toward a nonlesioned state}

Our data revealed significant differences in layer 3 vPMC pyramidal neuron structure and function that are dependent on lesion and treatment. A consistent pattern for electrophysiological outcome variables is that measurements for EV-treated neurons consistently fell between measurements for vehicle-treated and nonlesioned neurons. Thus, we assessed the relative similarity and clustering of neurons in each group by conducting NMDS based on pairwise distance correlations across five sets of outcome measures, as described previously (Gilman et al., 2017) (Fig. $7 A, B$ ). The NMDS plot clusters data points based on a proximity distance matrix, such that points that are closer together are more similar with respect to a set of outcome measures (Hilgetag et al., 2016). NMDS plots based on active membrane and synaptic properties separated neurons belonging to $\mathrm{vPMC}_{\mathrm{veh}}, \mathrm{vPMC}_{\mathrm{EV}}$, and $\mathrm{vPMC}_{\text {nonlesion }}$ groups into three clusters (Fig. 7A). Compared with $\mathrm{vPMC}_{\mathrm{veh}}$ neurons, $\mathrm{vPMC}_{\mathrm{EV}}$ neurons were more similar (closer proximity, smaller distance) to $\mathrm{vPMC}_{\text {nonlesion }}$ control neurons (Fig. $7 A$ ). In contrast, no systematic NMDS clustering was observed based on passive membrane properties. NMDS plots based on dendritic morphologic and spine and VGAT distribution properties also clustered neurons into groups. However, in contrast to electrophysiological properties, these NMDS plots based on morphologic properties show clustering of $\mathrm{vPMC}_{\text {nonlesion }}$ neurons in between $\mathrm{vPMC}_{\mathrm{EV}}$ and $\mathrm{vPMC}_{\mathrm{veh}}$ neurons. These data show that $\mathrm{vPMC}_{\mathrm{EV}}$ and $\mathrm{vPMC}_{\mathrm{veh}}$ neurons were more dissimilar to each other than to 


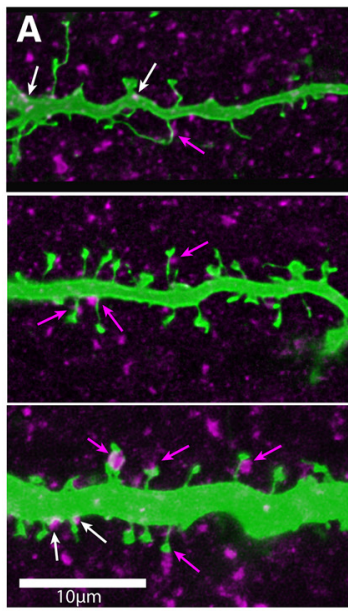

G
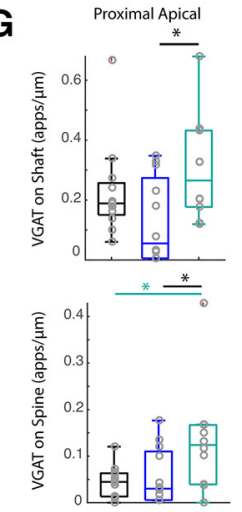

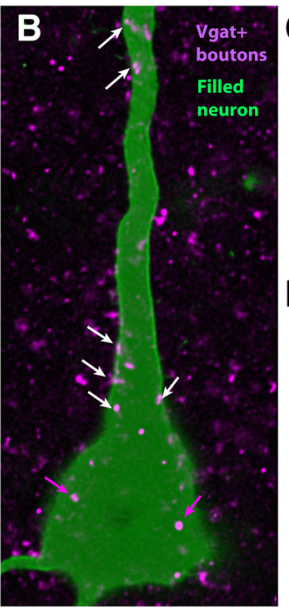

Distal Apical
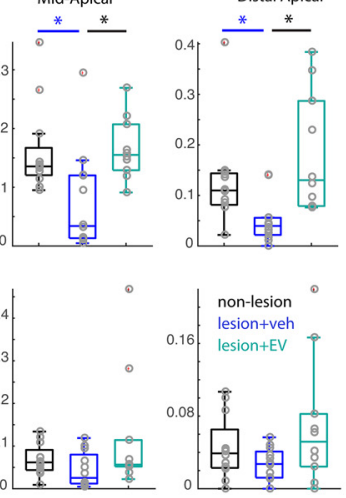
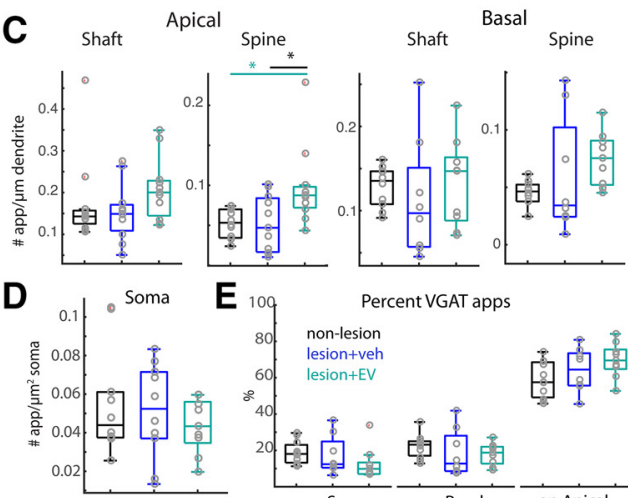

$\mathbf{F}$
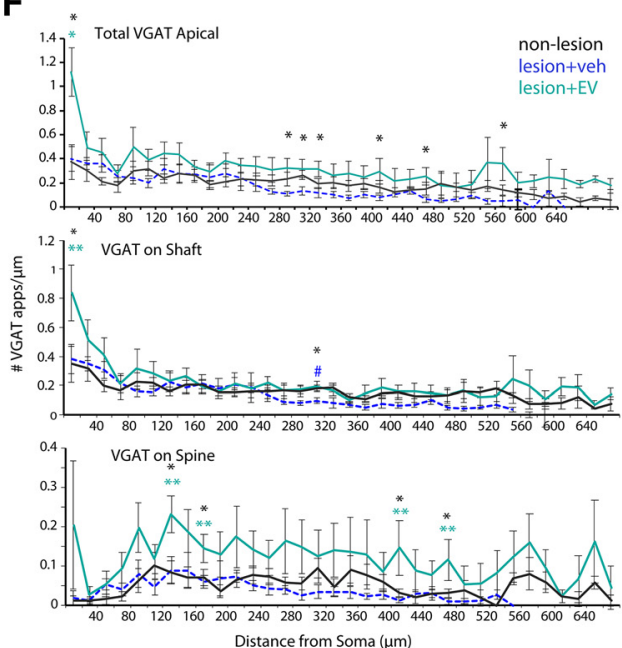

ance from Soma $(\mu \mathrm{m})$
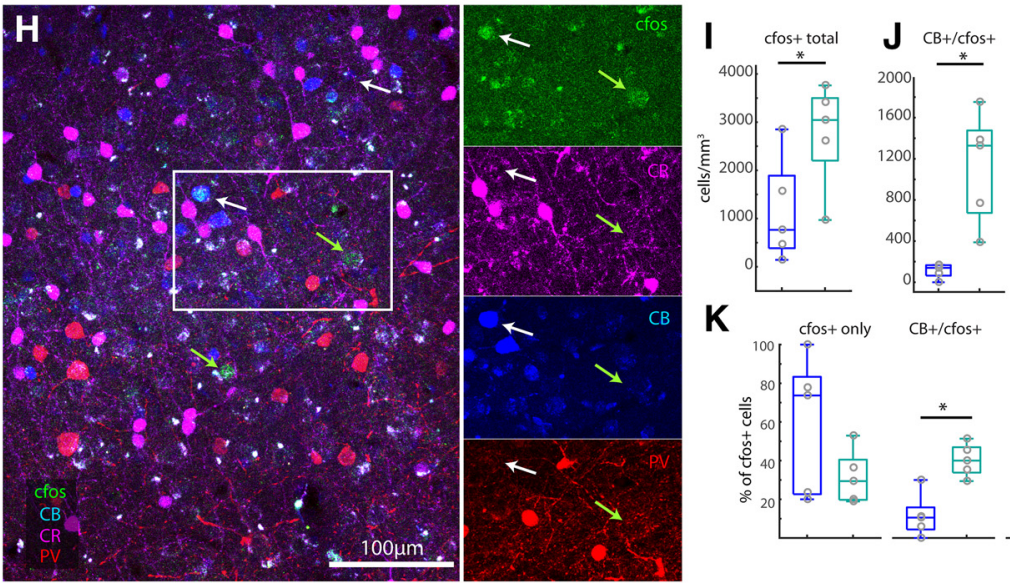

$\mathrm{PV}+/ \mathrm{cfos}+$

$\mathrm{CR}+/ \mathrm{cfos}+$

K

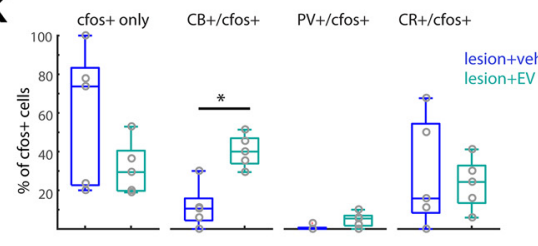

$\mathrm{CB}+/$ cfost

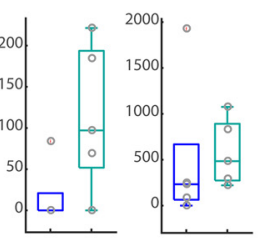

$\mathrm{PV}+/ \mathrm{cfos}+\quad \mathrm{CR}+/ \mathrm{cfos}+$

lesion+veh lesion+EV

Figure 6. Greater density of apical inhibitory inputs and $c-\cos ^{+}$activation of dendritic-targeting inhibitory neurons in EV-treated brains. $A, B$, Single confocal optical slice images showing representative VGAT ${ }^{+}$appositions on dendritic shafts $\left(\boldsymbol{A}\right.$, white arrows), spines $\left(\boldsymbol{A}\right.$, magenta arrows), and somata ( $\boldsymbol{B}$, magenta arrows) of filled vPMC $C_{\text {nonlesion }}(n=11$ neurons from 2 monkeys), $\mathrm{vPMC}_{\text {veh }}$ ( $n=12$ from 4 monkeys), and $\mathrm{VPMC}_{\mathrm{EV}}(\mathrm{n}=11$ from 2 monkeys) layer 3 pyramidal neurons. $C, D$, Box-and-whisker plots and vertical scatter plots of individual data points showing the following: $(\boldsymbol{C})$ density $\mathrm{VGAT}^{+}$dendritic appositions on shafts and spines of subsampled apical and basal dendritic segments from each neuron; (D) density of $\mathrm{VGAT}^{+}$appositions on somata; and $(\boldsymbol{E})$ proportion of total VGAT appositions on somata, apical and basal dendrites. $\boldsymbol{F}$, Sholl analyses showing the mean density of total VGAT $^{+}$dendritic appositions (ANOVA main effect, 20, 300, 320, 340, 420, $480 \mu \mathrm{m}: p<0.04$; Fisher's LSD post hoc, ${ }^{*} \mathrm{EV}$ vs veh, $p<0.01$ ) and mean density of VGAT ${ }^{+}$appositions on shafts and spines at each $20 \mu \mathrm{m}$ incremental proximal to distal distance from the soma, along the extent of a subsampled apical dendritic segment from each neuron (ANOVA main effect, shaft 20, $320 \mu \mathrm{m}: p=0.03,0.014$; Fisher's LSD post hoc, ${ }^{*} \mathrm{EV}$ vs veh, $p<0.02$; ${ }^{* *} \mathrm{EV}$ vs nonlesion, $20 \mu \mathrm{m}, p=0.013$, "veh vs nonlesion, $320 \mu \mathrm{m}, p=0.02$; ANOVA main effect, spines 140, 180, 420, $480 \mu \mathrm{m}$ : $p=0.008,0.03,0.03,0.02$; Fisher's LSD post hoc, ${ }^{*} E V$ vs veh, $p<0.01$; ${ }^{* *}$ EV vs nonlesion, $\left.p<0.04\right)$. G, Box-and-whisker and vertical scatter plots of individual data points showing mean density of $\mathrm{VGAT}^{+}$appositions on normalized proximal, middle, and distal thirds of apical dendrites. $\boldsymbol{H}$, Representative confocal $\boldsymbol{z}$-maximum projection image stack showing co-labeling of CB, PV, and CR with c-fos in perilesional vPMC. Tissue was harvested $3 \mathrm{~h}$ after performance of the HDT to label the intermediate early gene, $C$-fos in VPMC, and quantify neuronal cell types presumably activated during the HDT ( $n=5$ EV-treated, $n=5$ vehicle-treated monkeys). $I$, Total density of neurons labeled with $c$-fos ${ }^{+}$in vPMC. $\boldsymbol{J}$, Cell density and $(\boldsymbol{K})$ proportion of subpopulations of $c$-fos ${ }^{+}$neurons colabeled with calcium binding proteins, $\mathrm{CB}^{+}, \mathrm{PV}^{+}$, or $\mathrm{CR}^{+}$, expressed on inhibitory neurons in layers $2-3$ of vPMC. Scale bars: $\boldsymbol{A}, \boldsymbol{B}, 10 \mu \mathrm{m} ; \boldsymbol{H}, 100 \mu \mathrm{m}$. 
A

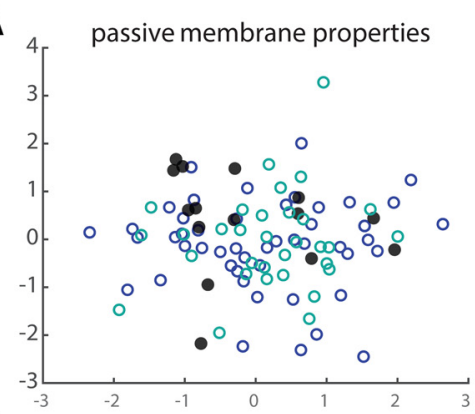

B

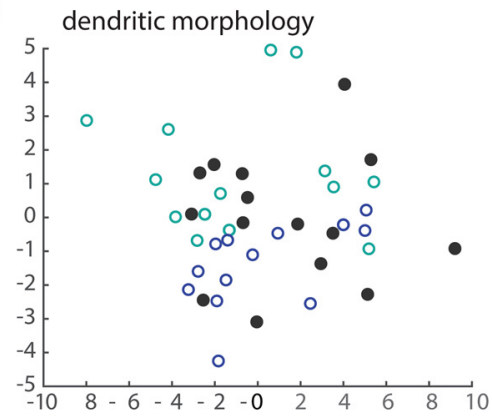

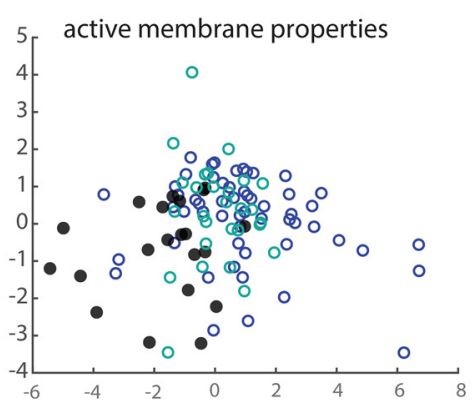
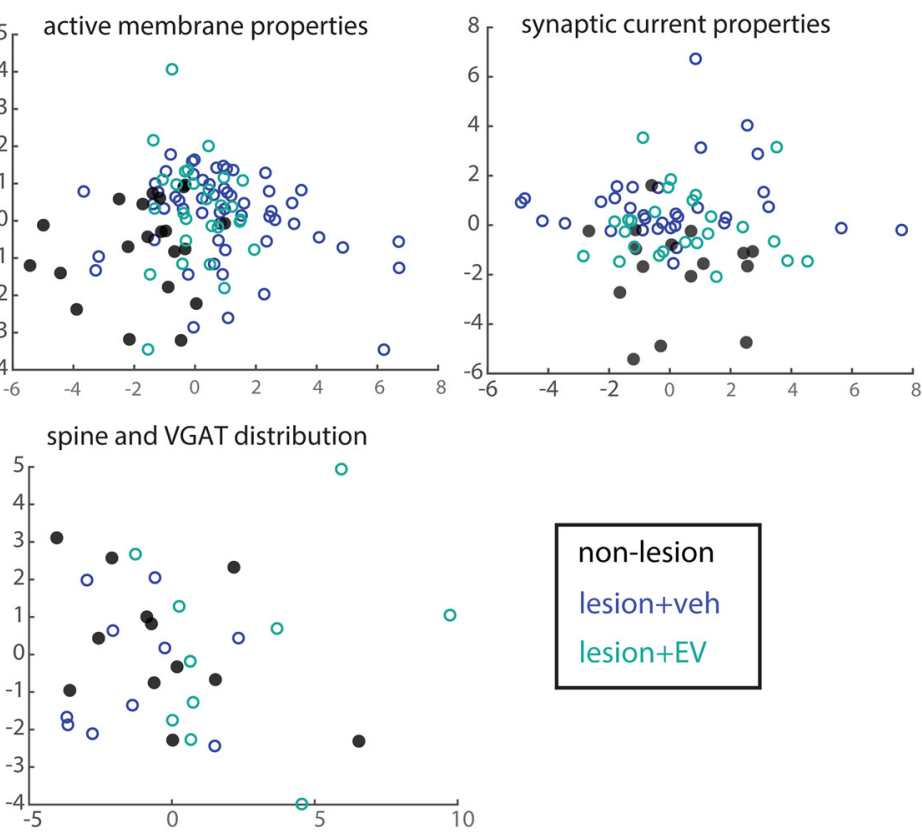

C

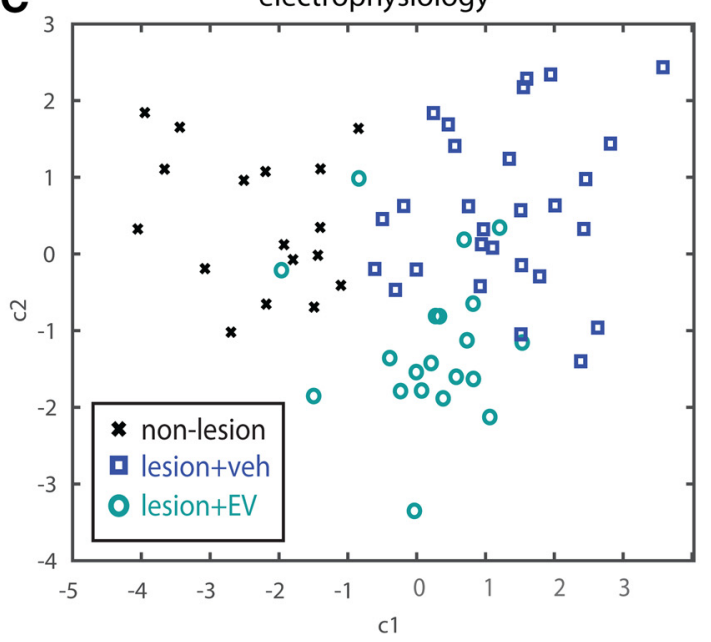

D

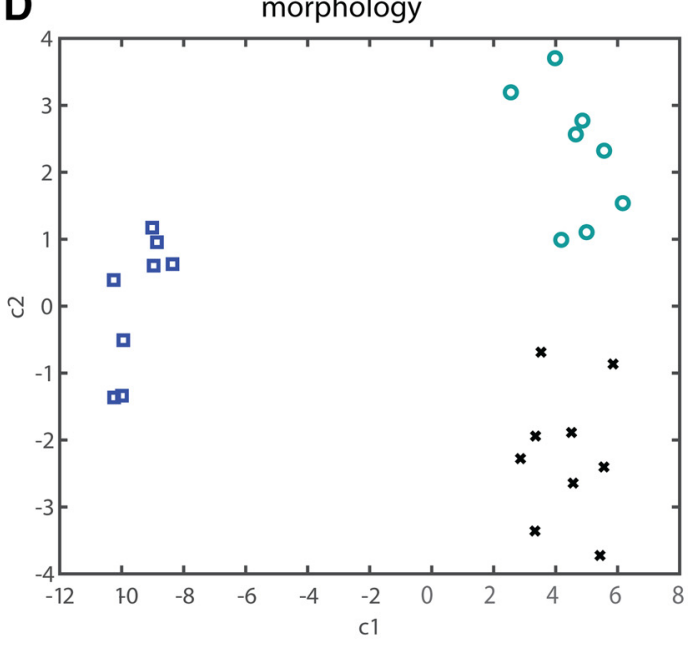

Figure 7. EV treatment after lesion normalizes electrophysiological and morphological properties of VPMC neurons. A, NMDS plots showing clustering on neurons based on multiple passive membrane, active membrane, and synaptic current outcome variables. The proximity of points in each NMDS plots indicate the relative similarity-based pairwise correlation of multiple variables. B, NMDS plots showing clustering on neurons based on multiple dendritic morphologic properties, and spine and VGAT apposition distribution. C, Scatter plot based on MANOVA of active and synaptic current outcome measures that significantly predicted group membership. The MANOVA resulted in two significant canonical variables that separated the population into three distinct groups, based on a linear combination of the outcome measures. The first canonical variable separated the neurons in the nonlesioned control group from the lesioned groups $\left(p=0.0000064\right.$, eigen value $=2.2$ ). The second canonical variable separated neurons based on treatment ( $\mathrm{VPMC}_{\mathrm{veh}} \mathrm{vs}_{\mathrm{VPMC}}$; $p=0.04$, eigen value $=0.67$ ). Among the outcome measures, AP firing frequency and EPSC and IPSC frequencies were the strongest discriminators (i.e., greatest absolute value of the coefficients of the canonical variable) of membership of group membership (see Table 3). D, Scatter plot based on MANOVA of dendritic morphologic, spine, and VGAT apposition distribution properties. The MANOVA resulted in one significant canonical variable $(p=0.01$, eigen value $=49.72)$ that separated the population into two distinct groups separating the $v P M C_{\text {veh }}$ neurons from $\mathrm{VPMC}_{\mathrm{EV}}$ and $\mathrm{VPMC} \mathrm{C}_{\text {nonlesion }}$ group. The second canonical variable clustered $\mathrm{VPMC} \mathrm{EV}_{\mathrm{EV}}$ and $\mathrm{VPMC}$ nonlesion neurons but was not significant $(p=0.52$, eigen value $=3.8)$.

$\mathrm{vPMC}_{\text {nonlesion }}$ neurons, which suggests divergent morphologic changes in neurons from the two treatment groups after lesion.

To examine which outcome measures were most influenced by lesion and treatment, MANOVA was performed on the electrophysiological (active membrane and synaptic) and morphologic (dendritic, spine, and VGAT) outcome measures that significantly differed between the groups (Fig. $7 C, D$ ). The results verified the NMDS results, revealing three distinct clusters of neurons based on active membrane and synaptic properties, with $\mathrm{vPMC}_{\text {nonlesion }}$ neurons clustering closer to $\mathrm{vPMC}_{\mathrm{EV}}$ than to $\mathrm{vPMC}_{\mathrm{veh}}$ neurons (Mahalanobis distance: nonlesion vs veh =
12.8; nonlesion vs EV = 8.8; EV vs veh=4.3). Neurons were separated into three groups based on two significant canonical variables: linear combinations of outcome measures chosen to maximize the separation between groups. The first canonical variable separated nonlesioned from the two lesioned groups $(p=0.0000064$, eigen value $=2.2)$. The second canonical variable separated $\mathrm{vPMC}_{\mathrm{veh}}$ versus $\mathrm{vPMC}_{\mathrm{EV}}(p=0.04$, eigen value $=0.67$; Fig. $7 B$ ). The absolute value of the coefficients of the canonical variables determines the strength of each outcome measure as a predictor of group separation. Among the outcome measures, AP firing frequency and EPSC and IPSC frequencies were the 
Table 3. Coefficients of canonical variables from MANOVA of vPMC layer 3 pyramidal neuron properties

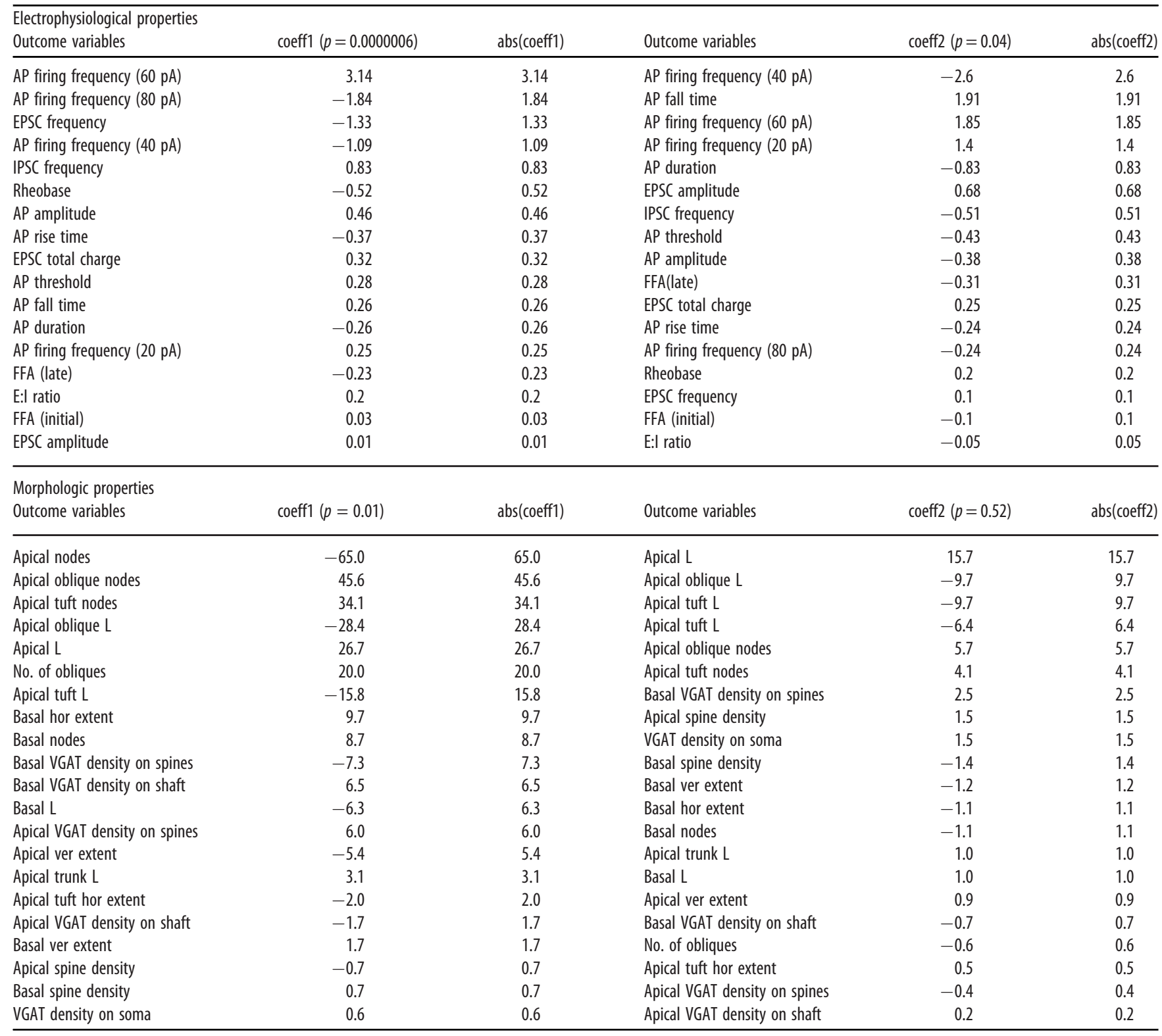

strongest discriminators of lesion versus nonlesion groups (first canonical variable); and AP firing frequency, single AP kinetics, and IPSC frequency were the strongest discriminators of group membership based on treatment (second canonical variable; Table 3). MANOVA of dendritic morphologic, spine, and VGAT apposition distribution properties resulted in the first canonical variable significantly separating the cluster of $\mathrm{vPMC}_{\mathrm{veh}}$ neurons from the cluster of $\mathrm{vPMC}_{\mathrm{EV}}$ and $\mathrm{vPMC}_{\text {nonlesion }}$ groups $(p=0.01$, eigen value $=49.72$; Fig. $7 D)$. Measures of apical dendritic complexity, number of nodes on total apical, apical tuft, and oblique arbors had the highest absolute values of canonical coefficients and were the strongest discriminators of these two clusters (Table 3). The $\mathrm{vPMC}_{\mathrm{EV}}$ and $\mathrm{vPMC}_{\text {nonlesion }}$ neurons each formed distinct clusters that were close in proximity and were not significantly separated from each other $(p=0.52$, eigen value $=3.8)$. These analyses showed that, compared with $\mathrm{vPMC}_{\mathrm{veh}}$ neurons, $\mathrm{vPMC}_{\mathrm{EV}}$ neurons were more similar to nonlesion control neurons. These data suggest that EV treatment appears to shift the population of vPMC neurons from lesioned brains closer to features of nonlesioned control neurons, mainly by altering active membrane, synaptic and dendritic structural properties.

\section{Measures of excitability and E:I balance in vPMC are correlated with recovery}

As reported in our previous study (Moore et al., 2019), EVtreated monkeys took a significantly fewer number of days to recover preoperative grasp patterns and latency to retrieve compared with vehicle-treated monkeys (see also Fig. 1). These EVtreated monkeys also exhibited a greater degree of recovery, with higher grasp pattern ratings and faster mean latency time to retrieve the food reward during the initial 5 and final $5 \mathrm{~d}$ of postoperative testing (Moore et al., 2019). Using the behavioral data from Moore et al. (2019), we used linear regression analyses to determine whether the lesion-related changes in vPMC neuronal properties measured here are related to recovery measures on the HDT (Fig. 8). Among outcome measures of pyramidal neuron excitability, spike frequency adaptation and E:I synaptic balance were significantly correlated with measures of recovery (Fig. 8A,B). Greater adaptation (lower adaptation ratio) at low- 

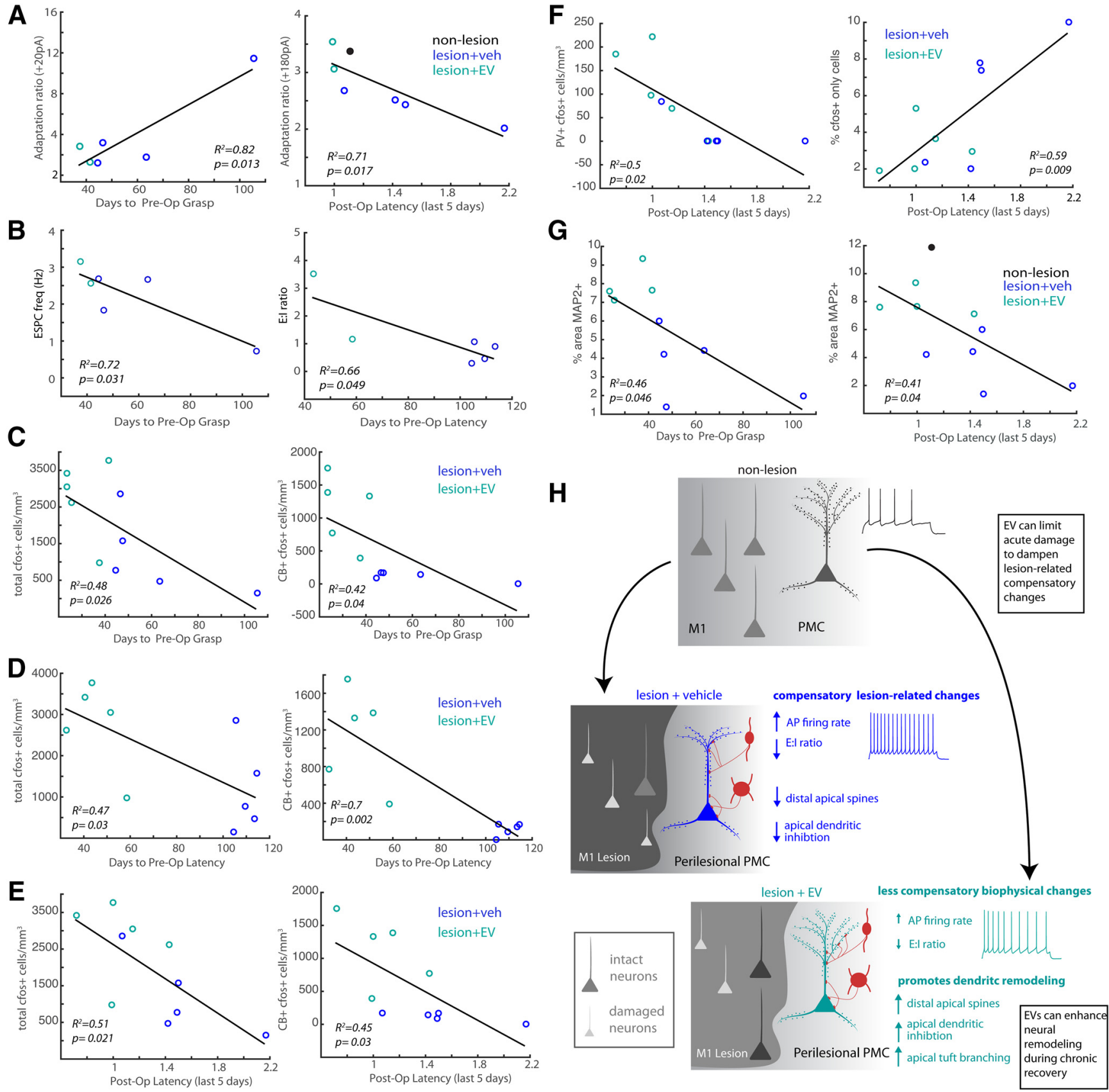

Figure 8. Pyramidal neuron excitability correlates with behavioral measures of recovery of function. $A$, Linear correlations with recovery of function were found for adaptation ratio at lowamplitude (20 pA shown here) and high-amplitude (180 pA) current stimuli, such that greater adaptation (lower ratio) at low-amplitude stimuli is associated with fewer days to recover preoperative grasp but lower adaptation at high-amplitude stimuli is associated with faster latency. $\boldsymbol{B}$, Linear correlations with recovery of function were found for EPSC frequency and E:I ratio, such that the greater excitation relative to inhibition, the greater the recovery. $C-F$, Linear correlations between recovery of function and measures of $c-$ fos ${ }^{+}$activation of neurons during HDT as follows: (C) the total density of $\mathrm{c}-\mathrm{fos}^{+}$cells and the subpopulation of $\mathrm{CB}^{+} / \mathrm{C}-\mathrm{fos}^{+}$cells were significantly correlated with days to return to preoperative grasp level; (D) days to return to preoperative latency; and $(\boldsymbol{E})$ postoperative mean latencies during the final $5 \mathrm{~d}$ of testing.F. The density of $\mathrm{PV}^{+} /\left(-\right.$-fos $^{+}$cells and $\%$ cfos unlabeled with inhibitory neuron markers were significantly correlated with mean latencies during the final $5 \mathrm{~d}$ of testing. $\mathbf{G}$, Linear correlations between MAP2 optical density (\% area labeled) and number of days to recover preoperative grasp level and mean latencies (final $5 \mathrm{~d}$ of testing). $\boldsymbol{H}$, Summary of lesion-associated changes and the effects of MSC-EVs on pyramidal neuron cellular structure and function in perilesional vPMC. Based on our evidence here and from our previous work (Go et al., 2020; Moore et al., 2019), we propose two possible mechanisms of action of EV treatment to either limit initial acute damage and dampen lesion-associated compensatory changes in firing and synaptic current properties, or enhance neurite remodeling during the chronic recovery phase after injury.

amplitude stimuli, near firing threshold, was correlated with fewer days to recover preoperative grasp $\left(R^{2}=0.82, p=0.013\right)$. However, less adaptation at higher-amplitude stimuli was correlated with a more rapid mean latency to retrieve during the final $5 \mathrm{~d}$ of testing $\left(R^{2}=0.71, p=0.017\right.$; Fig. $\left.8 A\right)$. EPSC frequency and E:I ratio were correlated with fewer days to recover preoperative grasp pattern $\left(R^{2}=0.72, p=0.031\right)$ and latency $\left(R^{2}=0.66\right.$, $p=0.049$; Fig. $8 B$ ). Consistent with these relationships, the density of c-fos ${ }^{+}$neurons presumably activated during the performance of HDT was correlated with behavioral recovery (Fig. 8C$F)$. Greater densities of total $\mathrm{c}$-fos ${ }^{+}$neurons and $\mathrm{CB}^{+} / \mathrm{c}-\mathrm{fos}^{+}$ neurons were significantly correlated with fewer days to recover to preoperative grasp pattern (Fig. $8 C$; total $\mathrm{cfos}^{+}, R^{2}=0.48$, $p=0.0026 ; \mathrm{CB}^{+} / \mathrm{cfos}^{+}, R^{2}=0.42, p=0.04$ ) and latency (Fig. $8 D$; 
total $\left.\mathrm{cfos}^{+}, R^{2}=0.47, p=0.03 ; \mathrm{CB}^{+} / \mathrm{cfos}^{+}, R^{2}=0.7, p=0.002\right)$, as well as faster latencies during the last $5 \mathrm{~d}$ of testing (Fig. $8 E$; total $\left.\mathrm{cfos}^{+}, R^{2}=0.51, p=0.021 ; \mathrm{CB}^{+} / \mathrm{cfos}^{+}, R^{2}=0.45, p=0.03\right)$. The greater density of $\mathrm{PV}^{+} / \mathrm{c}$-fos ${ }^{+}$cells was also associated with faster latencies during the last $5 \mathrm{~d}$ of testing (Fig. $8 F ; R^{2}=0.5, p=0.02$ ). Interestingly, a lower proportion of unlabeled $\left(\mathrm{CB}^{-} / \mathrm{PV}^{-} / \mathrm{CR}^{-}\right)$, presumably excitatory, ${\mathrm{C}-\mathrm{fos}^{+}}^{+}$cells in layers $2-3$, was also correlated with faster latencies (Fig. $8 F$, right; $R^{2}=0.59, p=0.009$ ). These data suggest that greater task-related activation of inhibitory neurons but lower task-related excitatory neuron activity in vPMC layers 2-3 both play a role in supporting recovery. Finally, a greater density of intact MAP2 ${ }^{+}$dendrites was correlated with greater measures of recovery: fewer days to recover preoperative grasp patterns $\left(R^{2}=0.46, p=0.046\right)$ and faster latencies $\left(R^{2}=\right.$ $0.41, p=0.04$; Fig. $8 G$ ). Together, these data show that recovery after injury is associated with a restoration of E:I balance, a modulation of excitability, and plasticity and maintenance of dendritic structure in $\mathrm{VPMC}$, which can be facilitated by EV treatment.

\section{Discussion}

This study demonstrates injury-related biophysical and structural changes in perilesional layer $3 \mathrm{vPMC}$ pyramidal neurons in a rhesus monkey model of cortical injury. Systemic administration of bone marrow-derived MSC-EVs after injury can ameliorate lesion-related pathology in these pyramidal neurons by dampening hyperexcitability and restoring E:I balance (Fig. $8 H$ ), providing a neural basis for enhanced recovery of fine motor function.

\section{EV treatment dampens lesion-related pyramidal neuron hyperexcitability through enhancing spike frequency adaptation}

At 14-16 weeks after injury of M1, vPMC neurons exhibited hyperexcitability, consistent with a compensatory mechanism for neuronal damage and deafferentation (for review, see Carmichael, 2012; Kantak et al., 2012). The lesion-related increase in firing frequency, reduction in FFA, and faster AP kinetics, suggest alterations in potassium $(\mathrm{K})$ channel conductances (Sah and Faber, 2002). For instance, the reduction of sAHP and FFA after lesion may implicate decreased expression of Kv2 "delayed rectifier" channels (Liu and Bean, 2014; Honigsperger et al., 2017; Guan et al., 2018) or calcium-dependent SK and BK channels (e.g., Madison and Nicoll, 1984; Ha and Cheong, 2017; Tiwari et al., 2018), which produce persistent K currents to regulate repolarization and dampen repetitive firing. Interestingly, we found that $\mathrm{vPMC}_{\text {nonlesion }}$ neurons with greater sAHPs, also exhibited greater FFA, consistent with previous studies ( $\mathrm{Gu}$ et al., 2007; Pathak et al., 2016).

In rodents, extracellular $\mathrm{K}^{+}$spillover from damaged neurons promotes acute apoptosis and inflammation (for review, see Shah and Aizenman, 2014). Compensatory reduction in $\mathrm{K}^{+}$ channel expression in neurons is thought to limit excessive $\mathrm{K}^{+}$ efflux, which in turn, increases AP firing and stimulates axonal regrowth. However, chronic reduction in neuronal $\mathrm{K}^{+}$channels can lead to excitotoxicity and hinder neurorestoration (for review, see Kaushal and Schlichter, 2008; Carmichael, 2012; Kohman and Rhodes, 2013; Lai et al., 2014; Shah and Aizenman, 2014; Jayaraj et al., 2019). Here we provide evidence that supports the role of MSC-EVs in dampening chronic hyperexcitability after injury, likely via increasing $\mathrm{K}^{+}$channel conductance.

EV treatment after injury normalizes dendritic filtering and synaptic properties to restore E:I balance

Increased inhibitory, coupled with decreased excitatory, synaptic tone after lesion was found in vPMC of both vehicle-treated and
EV-treated monkeys. However, EV treatment restored the dominance of excitation over inhibition, shifting E:I balance to a nonlesioned state. While inhibition is upregulated after injury to likely prevent acute excitotoxicity, restoration of normative E:I balance is needed for recovery (Clarkson et al., 2010; Carmichael, 2012).

At the structural level, $\mathrm{vPMC}_{\mathrm{EV}}$ neurons exhibited significantly greater apical dendrite complexity, MAP2 expression, and densities of spines and inhibitory inputs. Increased dendritic inhibition and greater dendritic complexity allow for greater dendritic filtering in $\mathrm{vPMC}_{\mathrm{EV}}$ neurons (Magee and Johnston, 2005; Capaday and van Vreeswijk, 2006; Muller et al., 2012; Ferrante et al., 2013; Pouille et al., 2013; Jarvis et al., 2018), providing a mechanism to maintain the E:I balance of synaptic events recorded at the soma. Further, EV-treated brains had significantly greater $\mathrm{c}-\mathrm{fos}^{+}$activation of $\mathrm{CB}^{+}$neurons, the major source of inhibitory inputs on distal dendrites and spines in the primate cortex (for review, see DeFelipe, 1997). Interestingly, $\mathrm{CB}$-expressing cells have been found to be more resilient to cell death after hypoxia, compared with other interneurons in the rodent hippocampus (Freund et al., 1990; Diop et al., 1995). Further, increased dendritic inhibition in $\mathrm{vPMC}_{\mathrm{EV}}$ neurons is balanced by increased spines, indicative of enhanced excitatory connectivity. Thus, EV treatment appears to promote dendritic proliferation and synapse growth in the apical dendrites of perilesional vPMC neurons, to fine-tune and restore E:I balance closer to the level of nonlesioned circuits.

\section{Potential mechanisms of EV-mediated modulation of neuronal excitability and structure after injury}

It is established that MSC-EVs contain proteins and miRNAs that stimulate neuronal survival, via regulation of cytokines and trophic factors (for review, see Z. G. Zhang et al., 2019). Previous studies in vitro have shown that bone marrow-derived MSC-EVs stimulate axonal sprouting in cortical neurons directly through increasing miR-17-92 miRNA clusters and activation of the phosphatase and tensin homolog-mechanistic target of rapamycin (PTEN-mTOR) signaling pathway (Y. Zhang et al., 2013, 2017), which is an important regulator of ion channel expression and synaptic transmission (Raab-Graham et al., 2006; Weston et al., 2012; Niere and Raab-Graham, 2017; Nguyen and Anderson, 2018). In rodents, mTOR activation in vivo promotes hyperexcitability, axonal sprouting, and synthesis of MAP2 in dendrites (Gong et al., 2006; Park et al., 2008; Lee et al., 2014), whereas mTOR inhibition can increase dendritic $\mathrm{K}^{+}$and NMDA channel expression (Raab-Graham et al., 2006). While it is likely that the action of EVs is pleiotropic, the PTEN-mTOR pathway is one possible mechanism of the EV-mediated modulation of neuronal excitability, synaptic properties, and dendritic structure observed here.

Other targets of MSC-EVs, such as proinflammatory cytokine TNF- $\alpha$ and BDNF signaling, can also regulate receptor trafficking (Shen et al., 2010; Phinney et al., 2015; Rani et al., 2015; Di Trapani et al., 2016; Xin et al., 2017; Porcher et al., 2018). Glialderived TNF- $\alpha$ can promote $\mathrm{GABA}_{\mathrm{A}}$ receptor endocytosis and AMPA receptor exocytosis (Stellwagen et al., 2005; review Leidenheimer, 2008). BDNF can elicit an acute rapid increase, followed by a decrease, in IPSC amplitude in rodent pyramidal neurons (Mizoguchi et al., 2003; Jovanovic et al., 2004), and modulate $\mathrm{GABA}_{\mathrm{B}}$ metabotropic receptors (Lund et al., 2008; for review, seee Tretter and Moss, 2008; Kuczewski et al., 2011; C. $\mathrm{Wu}$ and Sun, 2015), cAMP expression, and channel excitability (Misgeld et al., 1995; Couve et al., 2000). 
Whether MSC-EVs in the current study act directly on neurons or indirectly via glial or peripheral cells is unknown. While some conflicting evidence exists, it is thought that MSC-EVs can cross the blood-brain barrier (Alvarez-Erviti et al., 2011; OteroOrtega et al., 2017; Yuan et al., 2017). However, neuronal internalization of bone marrow-derived MSC-EVs has only been shown in vitro. Recently, we have shown greater expression of ramified microglia in EV-treated compared with vehicle-treated monkeys (Go et al., 2020). This shift in microglial morphology, thought to promote anti-inflammatory and repair processes (for review, see Y. Wu et al., 2015; Hong et al., 2016; Colonna and Butovsky, 2017; Ruppert et al., 2018), may contribute to dampening injury-related neuropathology shown here. Thus, the question remains as to whether MSC-EVs are acting on glia, which are then leading to downstream changes in neurons, or vice versa, to facilitate restoration of network balance after injury.

\section{Implications on the recovery of cortical motor networks after injury}

The PMC modulates movements primarily driven by M1 corticospinal tracts, especially when greater complexity is introduced and precision is needed in the task (for review, see Dum and Strick, 2002; Rizzolatti et al., 2002; Hoshi and Tanji, 2004; Binkofski and Buccino, 2006; Chouinard and Paus, 2006; Brochier and Umilta, 2007; Olivier et al., 2007; Castiello and Begliomini, 2008; Kraskov et al., 2011; Shenoy et al., 2013). Hyperactivation of the perilesional PMC, such as shown in our data, can compensate for damaged M1 corticospinal tracts after injury, through potentiating outputs of surviving corticospinal projections directly or indirectly via corticocortical PMC and M1 connections (Kraskov et al., 2011; Schulz et al., 2017; for review, see Kantak et al., 2012).

In human stroke patients, PMC hyperactivation is associated with a greater degree of damage and clinical impairment (Chollet et al., 1991; Caramia et al., 1996; Cuadrado et al., 1999; Johansen-Berg et al., 2002; Ward, 2004; Schulz et al., 2017). However, it is the functional coupling between PMC and M1 that is predictive of recovery (Wang et al., 2010; Grefkes and Fink, 2011; Rehme et al., 2011). The amelioration of lesionrelated changes seen here in $\mathrm{vPMC}_{\mathrm{EV}}$ neurons is perhaps indicative of less M1 damage, and hence, less need for compensatory activity, in EV-treated brains. EV-treated monkeys exhibited a more rapid and complete recovery of hand function compared with vehicle-treated monkeys (Moore et al., 2019). In contrast, vehicle-treated monkeys initially demonstrated a compensatory "scooping" grasp, with a subset later recovering noncompensatory grasp, albeit with slower latencies. Compensatory grasp motion is also seen in human stroke patients, and likely involves coactivation of muscle groups that precludes independent control of single digits (Ehrsson et al., 2000; McCrea et al., 2005). The vPMC assessed here included the more caudal subregion (area 6Vb/F4) involved in feeding and arm reaching movements (Rizzolatti et al., 1998; Graziano and Aflalo, 2007; Kaas et al., 2012), as well the more dorsal-rostral "hand" region (area 6Va/ F5) implicated in the recovery of fine motor function after injury in monkeys (Darling et al., 2011). The enhanced dendritic complexity and inhibition specifically in the vPMC hand area in EVtreated monkeys shown here may allow for fine-tuning the signal-to-noise ratio of cortical motor signals (e.g., Wang et al., 2004; Capaday and van Vreeswijk, 2006; Muller et al., 2012; Pouille et al., 2013; Jarvis et al., 2018), thereby enhancing precision grasping.
In conclusion, the functional and structural data presented here add to the body of evidence showing that MSC-EVs can provide some measure of neuroprotection and/or neurorestoration in vivo, which can guide subsequent mechanistic studies. Our findings demonstrate the efficacy of MSC-EVs as a potential therapeutic for reducing injury-related pathology in pyramidal neurons, and shed light on the neuronal circuit mechanisms of recovery of motor function in primates.

\section{References}

Alvarez-Erviti L, Seow Y, Yin H, Betts C, Lakhal S, Wood MJ (2011) Delivery of siRNA to the mouse brain by systemic injection of targeted exosomes. Nat Biotechnol 29:341-345.

Amatrudo JM, Weaver CM, Crimins JL, Hof PR, Rosene DL, Luebke JI (2012) Influence of highly distinctive structural properties on the excitability of pyramidal neurons in monkey visual and prefrontal cortices. J Neurosci 32:13644-13660.

Anrather J, Iadecola C (2016) Inflammation and stroke: an overview. Neurotherapeutics 13:661-670.

Barbas H (2015) General cortical and special prefrontal connections: principles from structure to function. Annu Rev Neurosci 38:269-289.

Barbas H, Pandya DN (1987) Architecture and frontal cortical connections of the premotor cortex (area 6) in the rhesus monkey. J Comp Neurol 256:211-228.

Belmalih A, Borra E, Contini M, Gerbella M, Rozzi S, Luppino G (2007) A multiarchitectonic approach for the definition of functionally distinct areas and domains in the monkey frontal lobe. J Anat 211:199-211.

Benowitz LI, Carmichael ST (2010) Promoting axonal rewiring to improve outcome after stroke. Neurobiol Dis 37:259-266.

Binkofski F, Buccino G (2006) The role of ventral premotor cortex in action execution and action understanding. J Physiol Paris 99:396-405.

Boussaoud D, Tanne-Gariepy J, Wannier T, Rouiller EM (2005) Callosal connections of dorsal versus ventral premotor areas in the macaque monkey: a multiple retrograde tracing study. BMC Neurosci 6:67.

Brochier T, Umilta MA (2007) Cortical control of grasp in non-human primates. Curr Opin Neurobiol 17:637-643.

Brouns R, De Deyn PP (2009) The complexity of neurobiological processes in acute ischemic stroke. Clin Neurol Neurosurg 111:483-495.

Brown CE, Li P, Boyd JD, Delaney KR, Murphy TH (2007) Extensive turnover of dendritic spines and vascular remodeling in cortical tissues recovering from stroke. J Neurosci 27:4101-4109.

Buga AM, Dunoiu C, Balseanu A, Popa-Wagner A (2008) Cellular and molecular mechanisms underlying neurorehabilitation after stroke in aged subjects. Rom J Morphol Embryol 49:279-302.

Caceres A, Banker G, Steward O, Binder L, Payne M (1984) MAP2 is localized to the dendrites of hippocampal neurons which develop in culture. Brain Res 13:314-318.

Callaway EM (2002) Cell type specificity of local cortical connections. J Neurocytol 31:231-237.

Campbell MJ, Morrison JH (1989) Monoclonal antibody to neurofilament protein (SMI-32) labels a subpopulation of pyramidal neurons in the human and monkey neocortex. J Comp Neurol 282:191-205.

Capaday C, van Vreeswijk C (2006) Direct control of firing rate gain by dendritic shunting inhibition. J Integr Neurosci 5:199-222.

Caramia MD, Iani C, Bernardi G (1996) Cerebral plasticity after stroke as revealed by ipsilateral responses to magnetic stimulation. Neuroreport 7:1756-1760.

Carmichael ST (2003) Plasticity of cortical projections after stroke. Neuroscientist 9:64-75.

Carmichael ST (2006) Cellular and molecular mechanisms of neural repair after stroke: making waves. Ann Neurol 59:735-742.

Carmichael ST (2012) Brain excitability in stroke: the yin and yang of stroke progression. Arch Neurol 69:161-167.

Castiello U, Begliomini C (2008) The cortical control of visually guided grasping. Neuroscientist 14:157-170.

Chang YM, Rosene DL, Killiany RJ, Mangiamele LA, Luebke JI (2005) Increased action potential firing rates of layer $2 / 3$ pyramidal cells in the prefrontal cortex are significantly related to cognitive performance in aged monkeys. Cereb Cortex 15:409-418. 
Chavez JC, Hurko O, Barone FC, Feuerstein GZ (2009) Pharmacologic interventions for stroke: looking beyond the thrombolysis time window into the penumbra with biomarkers, not a stopwatch. Stroke 40:e558-e563.

Chivet M, Hemming F, Pernet-Gallay K, Fraboulet S, Sadoul R (2012) Emerging role of neuronal exosomes in the central nervous system. Front Physiol 3:145.

Chollet F, DiPiero V, Wise RJ, Brooks DJ, Dolan RJ, Frackowiak RS (1991) The functional anatomy of motor recovery after stroke in humans: a study with positron emission tomography. Ann Neurol 29:63-71.

Chouinard PA, Paus T (2006) The primary motor and premotor areas of the human cerebral cortex. Neuroscientist 12:143-152.

Clarkson AN, Huang BS, Macisaac SE, Mody I, Carmichael ST (2010) Reducing excessive GABA-mediated tonic inhibition promotes functional recovery after stroke. Nature 468:305-309.

Colonna M, Butovsky O (2017) Microglia function in the central nervous system during health and neurodegeneration. Annu Rev Immunol 35:441468.

Couve A, Moss SJ, Pangalos MN (2000) GABAB receptors: a new paradigm in G protein signaling. Mol Cell Neurosci 16:296-312.

Cuadrado ML, Egido JA, González-Gutiérrez JL, Varela-de-Seijas E (1999) Bihemispheric contribution to motor recovery after stroke: a longitudinal study with transcranial Doppler ultrasonography. Cerebrovasc Dis 9:337-344.

Dancause N, Barbay S, Frost SB, Plautz EJ, Chen D, Zoubina EV, Stowe AM, Nudo RJ (2005) Extensive cortical rewiring after brain injury. J Neurosci 25:10167-10179.

Darling WG, Pizzimenti MA, Morecraft RJ (2011) Functional recovery following motor cortex lesions in non-human primates: experimental implications for human stroke patients. J Integr Neurosci 10:353-384.

Dawson DA, Hallenbeck JM (1996) Acute focal ischemia-induced alterations in MAP2 immunostaining: description of temporal changes and utilization as a marker for volumetric assessment of acute brain injury. J Cereb Blood Flow Metab 16:170-174.

DeFelipe J (1997) Types of neurons, synaptic connections and chemical characteristics of cells immunoreactive for calbindin-D28K, parvalbumin and calretinin in the neocortex. J Chem Neuroanat 14:1-19.

DeLeo AM, Ikezu T (2018) Extracellular vesicle biology in Alzheimer's disease and related tauopathy. J Neuroimmune Pharmacol 13:292-308.

Di Trapani M, Bassi G, Midolo M, Gatti A, Kamga PT, Cassaro A, Carusone R, Adamo A, Krampera M (2016) Differential and transferable modulatory effects of mesenchymal stromal cell-derived extracellular vesicles on T, B and NK cell functions. Sci Rep 6:24120.

Diop AG, Lesort M, Esclaire F, Dumas M, Hugon J (1995) Calbindin D28Kcontaining neurons, and not HSP70-expressing neurons, are more resistant to HIV-1 envelope (gp120) toxicity in cortical cell cultures. J Neurosci Res 42:252-258.

Dragunow M, Faull R (1989) The use of c-fos as a metabolic marker in neuronal pathway tracing. J Neurosci Methods 29:261-265.

Dum RP, Strick PL (2002) Motor areas in the frontal lobe of the primate. Physiol Behav 77:677-682.

Ehrsson HH, Fagergren A, Jonsson T, Westling G, Johansson RS, Forssberg $\mathrm{H}$ (2000) Cortical activity in precision- versus power-grip tasks: an fMRI study. J Neurophysiol 83:528-536.

Estrada LI, Robinson AA, Amaral AC, Giannaris EL, Heyworth NC, Mortazavi F, Ngwenya LB, Roberts DE, Cabral HJ, Killiany RJ, Rosene DL (2017) Evaluation of long-term cryostorage of brain tissue sections for quantitative histochemistry. J Histochem Cytochem 65:153-171.

Ferrante M, Migliore M, Ascoli GA (2013) Functional impact of dendritic branch-point morphology. J Neurosci 33:2156-2165.

Fiala JC, Harris KM (2001) Extending unbiased stereology of brain ultrastructure to three-dimensional volumes. J Am Med Inform Assoc 8:1-16.

Fregni F, Pascual-Leone A (2006) Hand motor recovery after stroke: tuning the orchestra to improve hand motor function. Cogn Behav Neurol 19:21-33.

Freund TF, Buzsáki G, Leon A, Baimbridge KG, Somogyi P (1990) Relationship of neuronal vulnerability and calcium binding protein immunoreactivity in ischemia. Exp Brain Res 83:55-66.

Gabernet L, Meskenaite V, Hepp-Reymond MC (1999) Parcellation of the lateral premotor cortex of the macaque monkey based on staining with the neurofilament antibody SMI-32. Exp Brain Res 128:188-193.
Gao X, Deng P, Xu ZC, Chen J (2011) Moderate traumatic brain injury causes acute dendritic and synaptic degeneration in the hippocampal dentate gyrus. PLoS One 6:e24566.

Garcia-Cabezas MA, Barbas H (2014) Area 4 has layer IV in adult primates. Eur J Neurosci 39:1824-1834

Gilman JP, Medalla M, Luebke JI (2017) Area-specific features of pyramidal neurons: a comparative study in mouse and rhesus monkey. Cereb Cortex 27:2078-2094.

Go V, Bowley BG, Pessina MA, Zhang ZG, Chopp M, Finklestein SP, Rosene DL, Medalla M, Buller B, Moore TL (2020) Extracellular vesicles from mesenchymal stem cells reduce microglial-mediated neuroinflammation after cortical injury in aged Rhesus monkeys. Geroscience 42:1-17.

Gong R, Park CS, Abbassi NR, Tang SJ (2006) Roles of glutamate receptors and the mammalian target of rapamycin (mTOR) signaling pathway in activity-dependent dendritic protein synthesis in hippocampal neurons. J Biol Chem 281:18802-18815.

Graziano MS, Aflalo TN (2007) Mapping behavioral repertoire onto the cortex. Neuron 56:239-251.

Graziano MS, Taylor CS, Moore T (2002) Complex movements evoked by microstimulation of precentral cortex. Neuron 34:841-851.

Grefkes C, Fink GR (2011) Reorganization of cerebral networks after stroke: new insights from neuroimaging with connectivity approaches. Brain 134:1264-1276.

Gu N, Vervaeke K, Storm JF (2007) BK potassium channels facilitate highfrequency firing and cause early spike frequency adaptation in rat CA1 hippocampal pyramidal cells. J Physiol 580:859-882.

Guan D, Pathak D, Foehring RC (2018) Functional roles of Kv1-mediated currents in genetically identified subtypes of pyramidal neurons in layer 5 of mouse somatosensory cortex. J Neurophysiol 120:394-408.

Ha GE, Cheong E (2017) Spike frequency adaptation in neurons of the central nervous system. Exp Neurobiol 26:179-185.

Hilgetag CC, Medalla M, Beul SF, Barbas H (2016) The primate connectome in context: principles of connections of the cortical visual system. Neuroimage 134:685-702.

Hoffman GE, Smith MS, Verbalis JG (1993) c-Fos and related immediate early gene products as markers of activity in neuroendocrine systems. Front Neuroendocrinol 14:173-213.

Hong S, Dissing-Olesen L, Stevens B (2016) New insights on the role of microglia in synaptic pruning in health and disease. Curr Opin Neurobiol 36:128-134.

Honigsperger C, Nigro MJ, Storm JF (2017) Physiological roles of Kv2 channels in entorhinal cortex layer II stellate cells revealed by Guangxitoxin1E. J Physiol 595:739-757.

Hoshi E, Tanji J (2004) Functional specialization in dorsal and ventral premotor areas. Prog Brain Res 143:507-511.

Jang SH, Kim YH, Cho SH, Chang Y, Lee ZI, Ha JS (2003) Cortical reorganization associated with motor recovery in hemiparetic stroke patients. Neuroreport 14:1305-1310.

Jarvis S, Nikolic K, Schultz SR (2018) Neuronal gain modulability is determined by dendritic morphology: a computational optogenetic study. PLoS Comput Biol 14:e1006027.

Jayaraj RL, Azimullah S, Beiram R, Jalal FY, Rosenberg GA (2019) Neuroinflammation: friend and foe for ischemic stroke. J Neuroinflammation 16:142.

Johansen-Berg H, Rushworth MF, Bogdanovic MD, Kischka U, Wimalaratna S, Matthews PM (2002) The role of ipsilateral premotor cortex in hand movement after stroke. Proc Natl Acad Sci USA 99:14518-14523.

Jones TA, Schallert T (1992) Overgrowth and pruning of dendrites in adult rats recovering from neocortical damage. Brain Res 581:156-160.

Jovanovic JN, Thomas P, Kittler JT, Smart TG, Moss SJ (2004) Brain-derived neurotrophic factor modulates fast synaptic inhibition by regulating GABA(A) receptor phosphorylation, activity, and cell-surface stability. J Neurosci 24:522-530.

Kaas JH, Stepniewska I, Gharbawie O (2012) Cortical networks subserving upper limb movements in primates. Eur J Phys Rehabil Med 48:299-306.

Kantak SS, Stinear JW, Buch ER, Cohen LG (2012) Rewiring the brain: potential role of the premotor cortex in motor control, learning, and recovery of function following brain injury. Neurorehabil Neural Repair 26:282-292.

Kaushal V, Schlichter LC (2008) Mechanisms of microglia-mediated neurotoxicity in a new model of the stroke penumbra. J Neurosci 28:22212230 . 
Kim BG, Dai HN, McAtee M, Bregman BS (2008) Modulation of dendritic spine remodeling in the motor cortex following spinal cord injury: effects of environmental enrichment and combinatorial treatment with transplants and neurotrophin-3. J Comp Neurol 508:473-486.

Kohman RA, Rhodes JS (2013) Neurogenesis, inflammation and behavior. Brain Behav Immun 27:22-32.

Kovacs KJ (2008) Measurement of immediate-early gene activation: c-fos and beyond. J Neuroendocrinol 20:665-672.

Kraskov A, Prabhu G, Quallo MM, Lemon RN, Brochier T (2011) Ventral premotor-motor cortex interactions in the macaque monkey during grasp: response of single neurons to intracortical microstimulation. J Neurosci 31:8812-8821.

Kuczewski N, Fuchs C, Ferrand N, Jovanovic JN, Gaiarsa JL, Porcher C (2011) Mechanism of GABAB receptor-induced BDNF secretion and promotion of GABAA receptor membrane expression. J Neurochem 118:533-545.

Lai TW, Zhang S, Wang YT (2014) Excitotoxicity and stroke: identifying novel targets for neuroprotection. Prog Neurobiol 115:157-188.

Lakhan SE, Kirchgessner A, Hofer M (2009) Inflammatory mechanisms in ischemic stroke: therapeutic approaches. J Transl Med 7:97.

Lambertsen KL, Finsen B, Clausen BH (2019) Post-stroke inflammation-target or tool for therapy? Acta Neuropathol 137:693-714.

Lannes N, Eppler E, Etemad S, Yotovski P, Filgueira L (2017) Microglia at center stage: a comprehensive review about the versatile and unique residential macrophages of the central nervous system. Oncotarget 8: 114393-114413.

Lee DH, Luo X, Yungher BJ, Bray E, Lee JK, Park KK (2014) Mammalian target of rapamycin's distinct roles and effectiveness in promoting compensatory axonal sprouting in the injured CNS. J Neurosci 34:15347-15355.

Leidenheimer NJ (2008) Regulation of excitation by GABA(A) receptor internalization. Results Probl Cell Differ 44:1-28.

Li GL, Farooque M, Lewen A, Lennmyr F, Holtz A, Olsson Y (2000) MAP2 and neurogranin as markers for dendritic lesions in CNS injury: an immunohistochemical study in the rat. APMIS 108:98-106.

Li S, Carmichael ST (2006) Growth-associated gene and protein expression in the region of axonal sprouting in the aged brain after stroke. Neurobiol Dis 23:362-373.

Li Y, Jiang N, Powers C, Chopp M (1998) Neuronal damage and plasticity identified by microtubule-associated protein 2 , growth-associated protein 43 , and cyclin D1 immunoreactivity after focal cerebral ischemia in rats. Stroke 29:1972-1980.

Liu J, Morel A, Wannier T, Rouiller EM (2002) Origins of callosal projections to the supplementary motor area (SMA): a direct comparison between pre-SMA and SMA-proper in macaque monkeys. J Comp Neurol 443:71-85.

Liu PW, Bean BP (2014) Kv2 channel regulation of action potential repolarization and firing patterns in superior cervical ganglion neurons and hippocampal CA1 pyramidal neurons. J Neurosci 34:4991-5002.

Lund IV, Hu Y, Raol YH, Benham RS, Faris R, Russek SJ, Brooks-Kayal AR (2008) BDNF selectively regulates GABAA receptor transcription by activation of the JAK/STAT pathway. Sci Signal 1:ra9.

Madison DV, Nicoll RA (1984) Control of the repetitive discharge of rat CA 1 pyramidal neurones in vitro. J Physiol 354:319-331.

Magee JC, Johnston D (2005) Plasticity of dendritic function. Curr Opin Neurobiol 15:334-342.

Matelli M, Luppino G (1996) Thalamic input to mesial and superior area 6 in the macaque monkey. J Comp Neurol 372:59-87.

McCrea PH, Eng JJ, Hodgson AJ (2005) Saturated muscle activation contributes to compensatory reaching strategies after stroke. J Neurophysiol 94:2999-3008

Medalla M, Luebke JI (2015) Diversity of glutamatergic synaptic strength in lateral prefrontal versus primary visual cortices in the rhesus monkey. J Neurosci 35:112-127.

Medalla M, Gilman JP, Wang JY, Luebke JI (2017) Strength and diversity of inhibitory signaling differentiates primate anterior cingulate from lateral prefrontal cortex. J Neurosci 37:4717-4734.

Misgeld U, Bijak M, Jarolimek W (1995) A physiological role for GABAB receptors and the effects of baclofen in the mammalian central nervous system. Prog Neurobiol 46:423-462.

Miyai I, Yagura H, Oda I, Konishi I, Eda H, Suzuki T, Kubota K (2002) Premotor cortex is involved in restoration of gait in stroke. Ann Neurol 52:188-194.
Mizoguchi Y, Kanematsu T, Hirata M, Nabekura J (2003) A rapid increase in the total number of cell surface functional GABAA receptors induced by brain-derived neurotrophic factor in rat visual cortex. J Biol Chem 278:44097-44102.

Moore TL, Pessina MA, Bowley BG, Calderazzo SM, Medalla M, Go V, Zhang ZG, Chopp M, Finklestein S, Harbaugh AG, Rosene DL, Buller B (2019) Mesenchymal derived exosomes enhance recovery of motor function in a monkey model of cortical injury. Restor Neurol Neurosci 37:347-362

Morecraft RJ, Cipolloni PB, Stilwell-Morecraft KS, Gedney MT, Pandya DN (2004) Cytoarchitecture and cortical connections of the posterior cingulate and adjacent somatosensory fields in the rhesus monkey. J Comp Neurol 469:37-69.

Morecraft RJ, Ge J, Stilwell-Morecraft KS, Rotella DL, Pizzimenti MA, Darling WG (2019) Terminal organization of the corticospinal projection from the lateral premotor cortex to the cervical enlargement (C5-T1) in rhesus monkey. J Comp Neurol 527:2761-2789.

Muller C, Beck H, Coulter D, Remy S (2012) Inhibitory control of linear and supralinear dendritic excitation in CA1 pyramidal neurons. Neuron 75:851-864

Munir H, Ward LS, McGettrick HM (2018) Mesenchymal stem cells as endogenous regulators of inflammation. Adv Exp Med Biol 1060:73-98.

Nguyen LH, Anderson AE (2018) mTOR-dependent alterations of Kv1.1 subunit expression in the neuronal subset-specific Pten knockout mouse model of cortical dysplasia with epilepsy. Sci Rep 8:3568.

Niere F, Raab-Graham KF (2017) mTORC1 is a local, postsynaptic voltage sensor regulated by positive and negative feedback pathways. Front Cell Neurosci 11:152.

Nishimura Y, Isa T (2012) Cortical and subcortical compensatory mechanisms after spinal cord injury in monkeys. Exp Neurol 235:152-161.

Olivier E, Davare M, Andres M, Fadiga L (2007) Precision grasping in humans: from motor control to cognition. Curr Opin Neurobiol 17:644648.

Orczykowski ME, Arndt KR, Palitz LE, Kramer BC, Pessina MA, Oblak AL, Finklestein SP, Mortazavi F, Rosene DL, Moore TL (2018) Cell based therapy enhances activation of ventral premotor cortex to improve recovery following primary motor cortex injury. Exp Neurol 305:13-25.

Otero-Ortega L, Laso-García F, Gómez-de Frutos MD, Rodríguez-Frutos B, Pascual-Guerra J, Fuentes B, Díez-Tejedor E, Gutiérrez-Fernández M (2017) White matter repair after extracellular vesicles administration in an experimental animal model of subcortical stroke. Sci Rep 7:44433.

Park KK, Liu K, Hu Y, Smith PD, Wang C, Cai B, Xu B, Connolly L, Kramvis I, Sahin M, He Z (2008) Promoting axon regeneration in the adult CNS by modulation of the PTEN/mTOR pathway. Science 322:963-966.

Pathak D, Guan D, Foehring RC (2016) Roles of specific Kv channel types in repolarization of the action potential in genetically identified subclasses of pyramidal neurons in mouse neocortex. J Neurophysiol 115:23172329.

Peters A, Sethares C (1991) Organization of pyramidal neurons in area 17 of monkey visual cortex. J Comp Neurol 306:1-23.

Phinney DG, Di Giuseppe M, Njah J, Sala E, Shiva S, St Croix CM, Stolz DB, Watkins SC, Di YP, Leikauf GD, Kolls J, Riches DW, Deiuliis G, Kaminski N, Boregowda SV, McKenna DH, Ortiz LA (2015) Mesenchymal stem cells use extracellular vesicles to outsource mitophagy and shuttle microRNAs. Nat Commun 6:8472

Porcher C, Medina I, Gaiarsa JL (2018) Mechanism of BDNF modulation in GABAergic synaptic transmission in healthy and disease brains. Front Cell Neurosci 12:273

Pouille F, Watkinson O, Scanziani M, Trevelyan AJ (2013) The contribution of synaptic location to inhibitory gain control in pyramidal cells. Physiol Rep 1:e00067.

Preuss TM, Stepniewska I, Jain N, Kaas JH (1997) Multiple divisions of macaque precentral motor cortex identified with neurofilament antibody SMI-32. Brain Res 767:148-153.

Raab-Graham KF, Haddick PC, Jan YN, Jan LY (2006) Activity- and mTORdependent suppression of Kv1.1 channel mRNA translation in dendrites. Science 314:144-148.

Rani S, Ryan AE, Griffin MD, Ritter T (2015) Mesenchymal stem cell-derived extracellular vesicles: toward cell-free therapeutic applications. Mol Ther 23:812-823. 
Rehme AK, Eickhoff SB, Wang LE, Fink GR, Grefkes C (2011) Dynamic causal modeling of cortical activity from the acute to the chronic stage after stroke. Neuroimage 55:1147-1158.

Reza-Zaldivar EE, Hernandez-Sapiens MA, Minjarez B, Gutierrez-Mercado YK, Marquez-Aguirre AL, Canales-Aguirre AA (2018) Potential effects of MSC-derived exosomes in neuroplasticity in Alzheimer's disease. Front Cell Neurosci 12:317.

Rizzolatti G, Luppino G, Matelli M (1998) The organization of the cortical motor system: new concepts. Electroencephalogr Clin Neurophysiol 106:283-296.

Rizzolatti G, Fogassi L, Gallese V (2002) Motor and cognitive functions of the ventral premotor cortex. Curr Opin Neurobiol 12:149-154.

Rodriguez A, Ehlenberger DB, Hof PR, Wearne SL (2006) Rayburst sampling, an algorithm for automated three-dimensional shape analysis from laser scanning microscopy images. Nat Protoc 1:2152-2161.

Rosene DL, Roy NJ, Davis BJ (1986) A cryoprotection method that facilitates cutting frozen sections of whole monkey brains for histological and histochemical processing without freezing artifact. J Histochem Cytochem 34:1301-1315.

Rosene DL, Lister JP, Schwagerl AL, Tonkiss J, McCormick CM, Galler JR (2004) Prenatal protein malnutrition in rats alters the c-Fos response of neurons in the anterior cingulate and medial prefrontal region to behavioral stress. Nutr Neurosci 7:281-289.

Ruppert KA, Nguyen TT, Prabhakara KS, Toledano Furman NE, Srivastava AK, Harting MT, Cox CS Jr, Olson SD (2018) Human mesenchymal stromal cell-derived extracellular vesicles modify microglial response and improve clinical outcomes in experimental spinal cord injury. Sci Rep 8:480.

Saeedi S, Israel S, Nagy C, Turecki G (2019) The emerging role of exosomes in mental disorders. Transl Psychiatry 9:122.

Sah P, Faber ES (2002) Channels underlying neuronal calcium-activated potassium currents. Prog Neurobiol 66:345-353.

Schindelin J, Arganda-Carreras I, Frise E, Kaynig V, Longair M, Pietzsch T, Preibisch S, Rueden C, Saalfeld S, Schmid B, Tinevez JY, White DJ, Hartenstein V, Eliceiri K, Tomancak P, Cardona A (2012) Fiji: an opensource platform for biological-image analysis. Nat Methods 9:676-682.

Schulz R, Park E, Lee J, Chang WH, Lee A, Kim YH, Hummel FC (2017) Interactions between the corticospinal tract and premotor-motor pathways for residual motor output after stroke. Stroke 48:2805-2811.

Shah NH, Aizenman E (2014) Voltage-gated potassium channels at the crossroads of neuronal function, ischemic tolerance, and neurodegeneration. Transl Stroke Res 5:38-58.

Shanmuganathan M, Vughs J, Noseda M, Emanueli C (2018) Exosomes: basic biology and technological advancements suggesting their potential as ischemic heart disease therapeutics. Front Physiol 9:1159.

Shen LH, Li Y, Chopp M (2010) Astrocytic endogenous glial cell derived neurotrophic factor production is enhanced by bone marrow stromal cell transplantation in the ischemic boundary zone after stroke in adult rats. Glia 58:1074-1081.

Shenoy KV, Sahani M, Churchland MM (2013) Cortical control of arm movements: a dynamical systems perspective. Annu Rev Neurosci 36:337-359.

Sholl DA (1953) Dendritic organization in the neurons of the visual and motor cortices of the cat. J Anat 87:387-406.

Spruston N (2008) Pyramidal neurons: dendritic structure and synaptic integration. Nat Rev Neurosci 9:206-221.

Stellwagen D, Beattie EC, Seo JY, Malenka RC (2005) Differential regulation of AMPA receptor and GABA receptor trafficking by tumor necrosis factor-alpha. J Neurosci 25:3219-3228.

Stroemer RP, Kent TA, Hulsebosch CE (1998) Enhanced neocortical neural sprouting, synaptogenesis, and behavioral recovery with $\mathrm{D}$-amphetamine therapy after neocortical infarction in rats. Stroke 29:2381-2393; discussion 2393-2385.

Szepesi Z, Manouchehrian O, Bachiller S, Deierborg T (2018) Bidirectional microglia-neuron communication in health and disease. Front Cell Neurosci 12:323.

Thurgur H, Pinteaux E (2019) Microglia in the neurovascular unit: bloodbrain barrier-microglia interactions after central nervous system disorders. Neuroscience 405:55-67.
Tigges J, Gordon T, McClure H, Hall E, Peters A (1988) Survival rate and lifespan of the rhesus monkeys at the Yerkes regional primate research center. Am J Primatol 15:263-273.

Tiwari MN, Mohan S, Biala Y, Yaari Y (2018) Differential contributions of $\mathrm{Ca}(2+)$-activated $\mathrm{K}(+)$ channels and $\mathrm{Na}(+) / \mathrm{K}(+)$-ATPases to the generation of the slow afterhyperpolarization in CA1 pyramidal cells. Hippocampus 28:338-357.

Tretter V, Moss SJ (2008) GABA(A) receptor dynamics and constructing GABAergic synapses. Front Mol Neurosci 1:7.

Ueno Y, Chopp M, Zhang L, Buller B, Liu Z, Lehman NL, Liu XS, Zhang Y, Roberts C, Zhang ZG (2012) Axonal outgrowth and dendritic plasticity in the cortical peri-infarct area after experimental stroke. Stroke 43:22212228.

van Niel G, D’Angelo G, Raposo G (2018) Shedding light on the cell biology of extracellular vesicles. Nat Rev Mol Cell Biol 19:213-228.

Veiga-Fernandes H, Artis D (2018) Neuronal-immune system cross-talk in homeostasis. Science 359:1465-1466.

Wang L, Yu C, Chen H, Qin W, He Y, Fan F, Zhang Y, Wang M, Li K, Zang Y, Woodward TS, Zhu C (2010) Dynamic functional reorganization of the motor execution network after stroke. Brain 133:1224-1238.

Wang Q, Tang XN, Yenari MA (2007) The inflammatory response in stroke. J Neuroimmunol 184:53-68.

Wang XJ, Tegnér J, Constantinidis C, Goldman-Rakic PS (2004) Division of labor among distinct subtypes of inhibitory neurons in a cortical microcircuit of working memory. Proc Natl Acad Sci USA 101:1368-1373.

Ward NS (2004) Functional reorganization of the cerebral motor system after stroke. Curr Opin Neurol 17:725-730.

Weston MC, Chen H, Swann JW (2012) Multiple roles for mammalian target of rapamycin signaling in both glutamatergic and GABAergic synaptic transmission. J Neurosci 32:11441-11452.

Wilson JJ, Foyle KL, Foeng J, Norton T, McKenzie DR, Payne N, Bernard CC, McColl SR, Comerford I (2018) Redirecting adult mesenchymal stromal cells to the brain: a new approach for treating CNS autoimmunity and neuroinflammation? Immunol Cell Biol 96:347-357.

Wu C, Sun D (2015) GABA receptors in brain development, function, and injury. Metab Brain Dis 30:367-379.

Wu Y, Dissing-Olesen L, MacVicar BA, Stevens B (2015) Microglia: dynamic mediators of synapse development and plasticity. Trends Immunol 36:605-613.

Xin H, Li Y, Cui Y, Yang JJ, Zhang ZG, Chopp M (2013) Systemic administration of exosomes released from mesenchymal stromal cells promote functional recovery and neurovascular plasticity after stroke in rats. J Cereb Blood Flow Metab 33:1711-1715.

Xin H, Wang F, Li Y, Lu QE, Cheung WL, Zhang Y, Zhang ZG, Chopp M (2017) Secondary release of exosomes from astrocytes contributes to the increase in neural plasticity and improvement of functional recovery after stroke in rats treated with exosomes harvested from microRNA 133boverexpressing multipotent mesenchymal stromal cells. Cell Transplant 26:243-257.

Xiong Y, Mahmood A, Chopp M (2019) Remodeling dendritic spines for treatment of traumatic brain injury. Neural Regen Res 14:1477-1480.

Yshii L, Gebauer C, Bernard-Valnet R, Liblau R (2015) Neurons and T cells: understanding this interaction for inflammatory neurological diseases. Eur J Immunol 45:2712-2720.

Yuan Z, Kolluri KK, Gowers KH, Janes SM (2017) TRAIL delivery by MSCderived extracellular vesicles is an effective anticancer therapy. J Extracell Vesicles 6:1265291.

Zaitsev AV, Povysheva NV, Gonzalez-Burgos G, Lewis DA (2012) Electrophysiological classes of layer $2 / 3$ pyramidal cells in monkey prefrontal cortex. J Neurophysiol 108:595-609.

Zhang Y, Ueno Y, Liu XS, Buller B, Wang X, Chopp M, Zhang ZG (2013) The microRNA-17-92 cluster enhances axonal outgrowth in embryonic cortical neurons. J Neurosci 33:6885-6894.

Zhang Y, Chopp M, Liu XS, Katakowski M, Wang X, Tian X, Wu D, Zhang ZG (2017) Exosomes derived from mesenchymal stromal cells promote axonal growth of cortical neurons. Mol Neurobiol 54:2659-2673.

Zhang ZG, Chopp M (2016) Exosomes in stroke pathogenesis and therapy. J Clin Invest 126:1190-1197.

Zhang ZG, Buller B, Chopp M (2019) Exosomes: beyond stem cells for restorative therapy in stroke and neurological injury. Nat Rev Neurol 15:193-203. 